\title{
Media responses to new medical treatments: A study of multiple sclerosis and the liberation procedure
}

\author{
By \\ Catherine Campbell \\ A thesis submitted to \\ the Faculty of Graduate Studies and Research \\ in partial fulfillment of \\ the requirements for the degree of \\ Master of Journalism \\ School of Journalism and Communication
}

Carleton University

Ottawa, Ontario

December 16, 2011

C 2011, Catherine E. Campbell 
Library and Archives

Canada

Published Heritage

Branch

395 Wellington Street

Ottawa ON K1A ON4

Canada
Bibliothèque et

Archives Canada

Direction du

Patrimoine de l'édition

395 , rue Wellington

Ottawa ON K1A ON4

Canada
Your file Votre référence

ISBN: 978-0-494-87839-2

Our file Notre référence

ISBN: $978-0-494-87839-2$

\section{NOTICE:}

The author has granted a nonexclusive license allowing Library and Archives Canada to reproduce, publish, archive, preserve, conserve, communicate to the public by telecommunication or on the Internet, loan, distrbute and sell theses worldwide, for commercial or noncommercial purposes, in microform, paper, electronic and/or any other formats.

The author retains copyright ownership and moral rights in this thesis. Neither the thesis nor substantial extracts from it may be printed or otherwise reproduced without the author's permission.
AVIS:

L'auteur a accordé une licence non exclusive permettant à la Bibliothèque et Archives Canada de reproduire, publier, archiver, sauvegarder, conserver, transmettre au public par télécommunication ou par l'Internet, prêter, distribuer et vendre des thèses partout dans le monde, à des fins commerciales ou autres, sur support microforme, papier, électronique et/ou autres formats.

L'auteur conserve la propriété du droit d'auteur et des droits moraux qui protege cette thèse. $\mathrm{Ni}$ la thèse ni des extraits substantiels de celle-ci ne doivent être imprimés ou autrement reproduits sans son autorisation.
In compliance with the Canadian Privacy Act some supporting forms may have been removed from this thesis.

While these forms may be included in the document page count, their removal does not represent any loss of content from the thesis.
Conformément à la loi canadienne sur la protection de la vie privée, quelques formulaires secondaires ont été enlevés de cette thèse.

Bien que ces formulaires aient inclus dans la pagination, il n'y aura aucun contenu manquant. 


\section{Abstract}

This study probes media coverage of new and unproven medical therapies by examining Canadian newspaper and television reporting on a novel hypothesis and experimental treatment for multiple sclerosis (MS), developed by Italian vascular surgeon Dr. Paolo Zamboni. The study found that initial media coverage was exaggerated and unbalanced; social media played a significant role in driving the issue; and media coverage influenced personal decision-making and organizational responses. Research involved a literature review; a media scan; interviews with medical specialists, journalists and people living with MS; an analysis of the response of funding agencies; and a scan of social media sites. Further research is needed to explain how journalists can mitigate or manage the magnifying effect of social media. Awareness and increased accountability are required by news editors and producers to improve the framing of health stories. Journalists need to exercise caution in the selection of research from academic journals. 


\section{Acknowledgements}

I would like to extend my sincere appreciation to the people living with multiple sclerosis who shared their stories with me: Evan, Andrew, Margo, Rebecca and Jennifer. Without their help, this research project would not have been possible. I would like to thank the physicians and researchers who made time to speak with me between patients or after long shifts at the hospital or on a Sunday morning. I am grateful to the five health reporters - André, Kelly, Joanna, Tom and Crystal - whose thoughtful insights and articulate reflections proved so valuable.

I extend gratitude to my thesis adviser, Kathryn O'Hara, who provided ideas and encouragement during all stages of the research and writing - and who showed me where to get the best coffee and biscotti in Ottawa.

To my "work family" - Katie, Tony and others - thank you for providing me with the support and the flexibility to balance my day job and my Carleton deadlines. Finally, I would like to thank Todd and our three daughters - Marina, Lara and Christy - for their love and encouragement.

I dedicate this thesis to my parents, Gordon and Betty Campbell, for teaching me the value of education and the opportunity it presents at any age. 


\section{Table of Contents:}

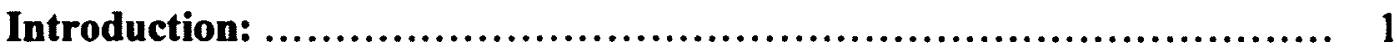

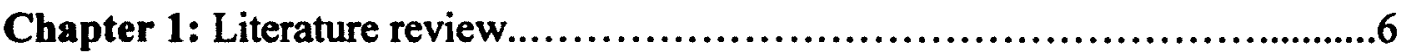

Chapter 2: MS: potential causes and proposed treatments.................. 20

Chapter 3: Media scan: November 2009-December 2010 ................... 35

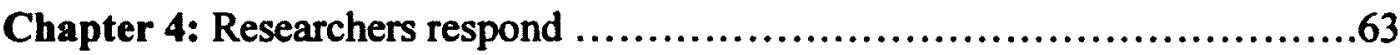

Chapter 5: The journalists' perspective.....................................76

Chapter 6: Personal stories................................................96

Chapter 7: Research funding agencies respond...........................117

Chapter 8: The power of social media....................................133

Chapter 9: Conclusion.................................................... 144

References:......................................................... 155 


\section{Introduction:}

Twenty-five years ago, I was assigned to cover the health beat at The Ottawa Citizen. I was a Carleton University journalism graduate with a few years of work experience but no qualifications for this specialized reporting. I'd never taken a course in science journalism. I had limited understanding of anatomy, physiology and pharmacology. I didn't know anything about the politics or policymaking behind healthcare funding or the role of industry and professional associations in shaping decisions. But in the mid-'80s, I was pretty typical of people assigned to cover health news.

For me, the beat held enormous potential because health stories often wound up on the front page. Back then, health news dealt with the most talked-about issues of the day - from the misunderstood AIDS virus to emerging technologies like artificial hearts to the apparent dangers of second-hand smoke. It provided opportunities for good storytelling: life-and-death struggles, unpredictability, interesting characters, hope and heroism. The appeal of the beat remains.

Looking back, I realize that I made all of the mistakes health journalism scholars describe today. I relied on public relations people for news tips. I scoured medical journals for off-beat research and I depended on go-to sources (readily available experts who provided good quotes) for insight on controversial topics. I wrote about far too many breakthroughs and potential cures. I didn't have the background, training or wherewithal to do more than skim the surface of most subject matters. Health news receives far better coverage today and reporters, for the most part, are better trained. 
There is no question that the job of a health reporter in 2011 is challenging. I have enormous respect for people who take on this task. Not only do reporters have to file faster to more forums using multiple technologies, the media landscape has become incredibly complex. There are more medical journals issuing more media releases and health-research organizations have increasingly sophisticated PR departments. On top of that, the push-and-pull of daily journalism is fed by cash-strapped governments, hospitals and funding agencies, which often measure research success in news hits.

At the same time, the era of participatory journalism means that social media adds to the noise of news. News production has become decentralized, delivered by anyone with a camera, cell phone and computer. Mainstream media stories move from local to national to international news items when shared in a matter of Tweets. Words are amplified through Facebook, blogs and websites.

The focus of this research study is to probe the role of news media in promoting novel medical therapies. I approach this with the shortcomings and perspective of someone who once covered health news, later worked on a news desk and now tries to advance health research as a communications professional. Of particular interest to me is the interplay between patients, researchers, reporters, health charities and funders.

The case study for my research is coverage of a proposed therapy for multiple sclerosis (MS), which has garnered widespread attention from Canadian news media, the public and policymakers. In November 2009, CTV News and The Globe and Mail newspaper, two respected national news organizations, reported a stunning new hypothesis that questioned prevailing belief about the cause of MS, widely thought to be an immune system disorder. They described the work of an Italian vascular surgeon, 
Paolo Zamboni, who had treated a small group of MS patients by unblocking neck veins to improve blood flow from the brain. The result, they said, was a halt in progression of the disease and, in some cases, the reversal of symptoms. Dr. Zamboni theorized that MS was easily fixed with a simple treatment he called the "liberation procedure". His treatment involved deploying a thin catheter and balloon to open veins, using the same technique routinely performed to open clogged arteries in the heart.

Stories about Dr. Zamboni's success reverberated across Canada. Through social media, people with MS spread the news. Websites and blogs were created. Conspiracy theories were advanced, including a widely held belief that drug companies - "big pharma" - were putting the kibosh on the treatment because they feared a cure would result in lost revenue from lucrative MS drug sales. News stories described skepticism in the medical community. The MS Society of Canada, a health charity that represents individuals with the condition, urged caution. But the story grew and grew. Canadians with MS called on governments to fund the procedure. Those who couldn't wait for action travelled abroad, usually at great expense, to seek treatment in places like Poland, Israel, Mexico, Costa Rica and elsewhere. Journalists sometimes journeyed alongside the patients, recording their experiences. Other times, individuals blogged their personal details, even posting videos of their surgical procedures on YouTube.

Many Canadian neurologists - the health specialists who treat MS patients experienced a backlash from the public for failing to support this new hypothesis. Neurologists warned patients to be wary of the placebo effect and to fear snake-oil treatments, describing the myriad cures for MS that have come before - from bee pollen to hyperbaric oxygen therapy to removal of mercury amalgam dental fillings. Meanwhile, 
federal and provincial governments were the focus of lobbying efforts from proponents of the therapy as late-night news reports featured rallies and protests. While patient groups expressed anger and frustration with the MS Society for its failure to be an aggressive advocate for the therapy, provincial health ministers weighed in and some announced funding for preliminary trials. Finally, the Canadian Institutes of Health Research - the federal granting council that oversees dispersal of health research dollars - convened an expert panel to consider how or if this new procedure fit into the country's research agenda. The panel's report made headlines when experts dismissed the science behind the blocked-vein hypothesis and advised it would be premature to fund clinical trials.

Almost to the year after the first news stories, CBC television reported that an Ontario man had died after having the procedure in Costa Rica. Some news reports blamed Canadian doctors for failing to provide adequate follow-up care, forcing the patient to return to Costa Rica for further treatment. Physicians, meanwhile, expressed concern for patient safety.

The story of the MS "liberation procedure" continues to evolve and the outcry and interest in the story remains focused in Canada. In the course of preparing this study interviews were conducted between January and July 2011 - there were more twists and turns:

- The federal government established a registry to track people with MS who had sought medical care out of the country;

- More patients reported complications from the therapy;

- Patients continued to protest inaction and more people travelled abroad for treatment; 
- The federal health minister changed course and announced funding for clinical trials based on an analysis of the research literature and preliminary findings from investigative research;

- Another death was reported - this time a 57-year-old Alberta woman who sought treatment in California; and.

- There were further reports of complications, including stroke.

What this points out is that, less than two years after initial news reports on the new hypothesis, perspective has yet to be gained. Many lessons will not be apparent for years - when research and clinical trials are complete and the long-term impact can be measured. However, given pressure on health-care expenditures, the pace of medical journalism and the powerful role of social media, there is value in examining emerging issues and concerns.

This study will begin with a literature review on medical reporting and media theory before looking at research into MS, including Dr. Zamboni's publications. A scan of news coverage by six media outlets, including three newspapers and three television networks will examine reporting on the issue. MS medical specialists, five people living with MS and five journalists who covered the story will be interviewed for their perspective. The reaction of research funding agencies will be probed. And, finally, the role of social media will be examined.

This research will guide discussion and provide perspective on the impact of news coverage of unproven medical therapies on individuals, the medical community, politicians and research funders. 


\section{Chapter 1: Literature Review}

This chapter reviews the literature on reporting of health news. It highlights the appeal and popularity of health stories in Canadian media; examines the role of news media in agenda setting and framing of health stories; and probes some of the issues related to coverage of health. These issues include the influence of medical journals on the production of daily news and the role of social media in magnifying the work of the mainstream press. Academic perspective gained from this review will provide a framework for the focus of this study: an analysis of media impact on new and unproven medical therapies.

There is no question that the members of the public rely heavily on the media for daily doses of health news, including 'groundbreaking' research developments, 'breakthrough' therapies, and 'miracle' drugs. Despite evidence that some news stories should come with warning labels, research shows that media reports shape public opinion and influence decisions Canadians make about their health [1,2]. "Many people hear about medical discoveries for the first time through popular media. Newspapers, magazines, television and the Internet play an increasingly crucial role in communicating information about health issues and informing the public about research findings and new treatments," University of Victoria researcher Alan Cassels writes in a 2007 publication in Open Medicine. [3]

British sociologist and media theorist Clive Seale argues that health stories have particularly strong appeal because of their folktale quality and the use of standard story templates to describe the struggle between life and death; the vulnerability of victims; and the search for heroes in everyday life. [4, p. 33] 
"Emotional engagement of audiences is the key task for news ... An atmosphere of fear, danger and excitement followed by secure resolutions creates a roller-coaster effect that keeps the customers signing up for more. Health media stories can quite easily lock into this ride, as dangers to bodily integrity and their potential resolution by powerful hero-helpers (including the heroic sufferer himself or herself) can quite readily be told." $[4$, p. 40$]$

A number of theoretical components underpin the study of health reporting in Canadian media, including agenda setting, priming and framing. University of Calgary communications professor Edna Einsiedel, who has done extensive research into media coverage of health and science news, says that media influence can be described on two levels: "What issues or topics are elevated or downplayed, affecting public perceptions of issue salience? How are these topics or issues framed?" [5, p. 90]

\section{Agenda setting}

Selection of news stories for publication and the importance placed on certain stories is called agenda setting. [6] The way media highlight or ignore issues has an influence on what people think about $[7$, p. 265] and "more recently, there is also growing consensus that in influencing what people think about, the media also shape how they think." $[5$, p. 90$]$ By focusing public attention on certain issues and not others, news media sway the policy agenda and create boundaries for public debate. [8]

"The media help set the discussion agenda for society ... The media tend to reinforce conventional definitions of health problems and hence determine, to a large extent, the legitimacy of various solutions ... (the media) selects, combines, and presents events in the real world and it therefore constructs versions of reality that can shape our understandings of health and illness." $[9$, p. 558]

\section{Framing the news}

Framing, closely linked to agenda-setting, describes how journalists evaluate and 
contextualize issues. Scholars of media framing examine the way in which journalists consciously or unconsciously select and highlight certain aspects of a story in order to have an impact on audience perception and understanding. [6] Framing also relates to how the news is presented, the way sources are chosen, the way stories are edited, and the news structure. The news frame defines the story for the audience and can "exert an important impact on the cultivation of more enduring images, attitudes and expectations." $[5$, p. 90] An important rhetorical device is the framing of stories as a "confrontation of opposing forces." [4, p. 32]

"Based on the notion of 'framing', it stands to reason that the overall impact of a news report on an individual's perception may vary according to whether only problems, disadvantages, weaknesses, or failures are described; or successes or beneficial aspects are presented; or when both pluses and minuses are presented. Some research suggests that the way a problem is formulated - whether it is presented as a loss (risk) or gain (benefit) - is an important frame that influences perceptions of outcomes. [5, p. 91]

\section{Priming}

A third component of media theory, also seen as an extension of agenda-setting, is priming. Priming refers to the way news media shape the public's perceptions and judgments about issues. [6] Priming research considers the role of news media in determining how people think about and evaluate issues and how news media help their audiences form opinions. Discourse theorists, who probe the question "what does the story actually say?"'[10], also describe how journalists produce narratives with structure, order, viewpoints and values that shape the way people think.

Health journalism research shows that, in framing a compelling story and priming the audience, media tend to dramatize the effects of a therapy, so that treatments are either described as good or bad. [11] Risks are often downplayed or omitted altogether. 
[12] For example, a comprehensive content analysis of Canadian newspaper reports on five drugs, published in 2003, found that 68 per cent of stories "did not mention a single potential harmful effect, and benefits were mentioned nearly five times as often." [13, p.1136] At the same time, journalists seek out stories with heroes. "These often contain a significant anti-medical component in which orthodox medicine is cast as unhelpful or flawed." [11, p. 11]

The media play an important role in the education of the public, "particularly when the topic is about new medical applications and prior knowledge is low ... Therefore, journalists have a crucial role in presenting comprehensive stories so as not to misinform readers or foster false conclusions." $[14$, p. 312)

\section{Medical journals}

An issue of particular concern in health journalism literature is the reliance of reporters on published reports from scientific journals to generate news. A number of studies describe how "scientific journals and scientific experts constitute, by and large, the main source of information for health and science journalists." [2]

Among these studies is the Canadian Health and Media Project (CHAMP), a research effort funded by the Social Sciences and Humanities Research Council. Canadian health reporters surveyed as part of the CHAMP initiative said that journal articles often form the basis of news. [9] CHAMP researchers criticized health reporters for attributing too much certainty to research findings, for premature representation of 'breakthroughs' and for being alarmist, incomplete or inaccurate. Other research shows that media often give too much weight to maverick ideas [2] and that reporters often fail to contextualize the scope, depth and size of medical studies. [15] 
There is danger in putting too much emphasis on medical journals because many contain shoddy science. Former British Medical Journal editor Richard Smith describes how medical journals, which are the link between science and practice, often contain weak research with no controls, conclusions unsupported by methods and data, and deficient peer review. [16] When faulty science is exposed, the editors of scientific journals are reluctant to print retractions, according to the Retraction Watch blog, established about a year ago by two American science journalists. [17]

Consider the 1998 research article in the prestigious medical journal The Lancet, in which Dr. Andrew Wakefield et al [18] linked the measles, mumps and rubella (MMR) vaccine to autism in a small study of 12 children in the U.K. In the 12 years it took the journal to retract the study, tens of thousands of parents did not vaccinate their children. The result was a 2008-09 measles outbreak in the U.K and smaller outbreaks in Canada and the U.S. At the same time, millions of dollars were spent on follow-up studies to validate or disqualify Wakefield's research. Even today, Wakefield's supporters argue that vaccine makers discredited his research in an effort to protect financial interests of the pharmaceutical industry. [19]

\section{Newswork practices}

Reliance on medical journals and over-simplification of complex issues is, in part, a result of the organizational structure of journalism today. Writing in the New England Journal of Medicine, health journalist Susan Dentzer blames the era of 24/7 news for the frequent failure by reporters to contextualize their reports. Instead, they engage in what she calls "hit and run" journalism. "This leads them to frame a story as new or different 
- depicting study results as counterintuitive or a break from the past - if they want it to be featured prominently or even accepted by an editor at all." [20, p. 2]

A number of interesting books and websites on this topic have been produced in recent years. Among them is the popular book Bad Science, which has an accompanying website, www.badscience.uk. Dr. Ben Goldacre, a columnist for the U.K.'s Guardian newspaper, wrote Bad Science to draw attention to what he sees as the media's inability to evaluate evidence and to interpret scientific data. "Science stories generally fall into one of three categories: the wacky stories, the 'breakthrough' stories, and the 'scare' stories. Each undermines and distorts science in its own idiosyncratic way." [21, p. 225] He says this parody is endangering public health.

Goldacre says journalists don't understand the subtle difference between a research hypothesis and the research evidence. "How do the media work around their inability to deliver scientific evidence? Often they use authority figures," he says, elevating scientists to special status. "Andrew Wakefield and the rest can all get a whole lot further in an environment where their authority is taken as read, because their reasoning and evidence are rarely publicly examined." [21, p. 240]

In Flat Earth News, British journalist Nick Davies describes how journalists reinforce conventional thinking, regurgitate spoon-fed news releases, and fall into the trap of "churnalism." "This is the heart of modern journalism, the rapid repackaging of largely unchecked second-hand material, much of it designed to service the political or commercial interests of those who provide it." $[22$, p. 60] 


\section{Public relations push}

Reliance by journalists on unchecked news from academic journals is exacerbated by the push from a growing public relations sector, including media specialists who are employed by scholarly journals to promote researchers, institutions and funded projects. Many universities and government agencies measure their researchers contribution by the number of "media hits" they get about their work. "Investigators see attention in the media as a valuable professional opportunity, as do their academic institutions, their funding sources (both public and private), and even their specialty societies, not to mention the pharmaceutical and medical-device industries." [23] A number of studies have found that research articles covered in the popular press have more credibility and more citations than those that do not receive media attention, further encouraging scientists to flog their findings. [8, p. 128]

Scientists increasingly belong to organizations that may employ public relations consultants to hype scientific results inordinately to the press. Scientists themselves, in comments to journalists, may succumb to the temptation of exaggerating the significance of their studies. $[4$, p. 53]

Media scholar Lester Friedman chronicles the story of an unknown researcher who describes how his career took off after the press office at his university highlighted a relatively obscure publication in a low-impact journal. In his book on medical culture and the media, Friedman quotes health journalist Chris Woolston, who writes the Healthy Skeptic column in the Los Angeles Times, as saying that "media coverage can raise the profile of scientists, boost their grant support and even speed the pace of scientific discovery ... In fact, a television spot or newspaper story can build scientific partnerships ... (and) also help you rack up citations." [24, p. 3] In other words, 
research funding is a political process and those who want support and advancement need to talk about their work.

"The intricate web spun jointly by medicine and the media results from a collaborative process that resembles a mating ritual as much as a professional relationship. The media do not simply cannibalize the medical world for news stories and fictional plotlines. Health care institutions, medical researchers and academic physicians all endeavor to manipulate the media spotlight for their own agendas, to accentuate their bright spots and deflect its harsh glare from less savoury specters crouching in the shadows ... In this way, millions of people who would never read these journals or possess the sophisticated knowledge necessary to understand their studies watch researchers discuss their studies in prepublication interviews with national news outlets." $[24$, p. 2]

\section{Sources}

According to Paul Manning in News and News Sources, public relations people are often former journalists who invest "a great deal of time in maintaining links with former colleagues" and are very accommodating to the media. [25] The relationship between reporters and sources is not unique to health reporting, but, perhaps, more symbiotic than on other beats. That's because reporters covering health generally do not have a background in science or medicine and need to rely heavily on access to expert opinion to validate stories. Newswork practices occur when journalists pick and choose their sources based on who is available and who is most likely to simplify an issue. [26] Concern about over-reliance on published studies, medical experts and lack of specialized knowledge in the field of medical reporting are major themes in health journalism research. Most Canadian reporters who cover health news have university degrees in journalism or English and very limited science education, making it "easier for journalists without some background in the sciences to surrender to scientific expertise." $[5$, p. 99) And yet, "simplifying the information to the point where the science behind it is obscure or nonexistent deprives people of information needed for public discussion." [27, p. 112] 
However, the level of scientific expertise among health reporters may be improving. A 2008 online survey by the Canadian Science Writers Association of its approximately 500 members found that 56 per cent of the 109 respondents had a science degree. About half of the respondents said they worked in the news media. [34]

\section{Social media}

Relatively new to the sphere of news production is the influence of social media on mainstream health news coverage. (Social media includes all online technology tools that allow people to communicate easily, including blogs, Facebook, Twitter and chat rooms.) Society has entered the era of "participatory journalism" where power is shifting to a formerly passive audience and changing the nature of journalism. [28] What was once linear communication - media outlets covered events and supplied information to their audiences - has evolved into a two-way conversation. [29] Social media enables journalists to listen to the public and to monitor conversations and, at the same time, for the public to instantly react and respond to news coverage and to share and distribute media stories well beyond the intended audience.

In Journalism Practice, Indiana University professor Mark Deuze says that "the people formerly known as the audience" have become 'produsers' of news. Social media amplifies the conversation society has with itself, alters the "traditional separation of journalists, their sources and the public" and clashes with "entrenched notions of professionalism, objectivity, and carefully cultivated arrogance regarding the competences (or talent) of the audience to know what is good for them." [30, p. 334] As mainstream reporters and editors select and frame medical news, social media creates a 
new layer of analysis and interpretation as well as a powerful distribution network for their stories. The work of news reporters in the mainstream media is amplified and magnified like never before, making it especially important to ensure they do their jobs well.

\section{Reportine guidelines}

Health journalist and scholar Gary Schwitzer, whose popular U.S. website Health News Review casts a critical eye on medical reporting, suggests that, for every new medical procedure or drug, reporters should consider how often benefits and harms occur, the strength of the evidence, whether there are alternate options, who is promoting the therapy, whether there is a conflict of interest, and whether what is described is really a new approach.

Journalists face unique challenges in covering health news. Some specialized skills, knowledge, and judgment are helpful. For example, some information based on poorly designed or poorly powered studies should not be reported unless the flaws are emphasized. Editors, reporters, and writers need to scrutinize the terminology used in health news. Vague, sensational terms (such as "cure," "miracle," and "breakthrough") may harm news consumers by misleading and misinforming. At the core of journalism's values, such terms should not be used because they are meaningless. It is not the role of journalists to become advocates for causes. $[31$, p. 576]

Almost 20 years ago, in an article in the Journal of the American Medical Association, Schwitzer called for special certification for medical reporters, who he described as puppets of self-promoting physicians, the pharmaceutical industry and public relations people. [32] Other scholars agree. "For those working in health journalism in particular, remedies such as research appraisal training for journalists have been suggested to improve the accuracy and completeness of research coverage." $[8, p$. 
Many of those working within medical and science journalism are aware of these concerns. André Picard, public health reporter at The Globe and Mail, has written about the need for reporters to exercise more skepticism, seek evidence to support health claims and use multiple sources in reporting on issues. [33] Other health reporters have expressed similar opinions. Susan Dentzer writes:

In my view, we in the news media have a responsibility to hold ourselves to higher standards if there is any chance that doctors and patients will act on the basis of our reporting. We are not clinicians, but we must be more than carnival barkers; we must be credible health communicators more interested in conveying clear, actionable health information to the public than carrying out our other agendas. There is strong evidence that many journalists agree - and in particular, consider themselves poorly trained to understand medical studies and statistics. But not only should our profession demand better training of health journalists, it should also require that health stories, rather than being rendered in black and white, use all the grays on the palette to paint a comprehensive picture of inevitably complex realities. Journalists could start by imposing on their work a "prudent reader or viewer" test: On the basis of my news account, what would a prudent person do or assume about a given medical intervention?" [20, p. 3]

In addition to sober second thought by health reporters, scholars say that scientific researchers have a role to play. "To truly assist journalists, researchers must not only be available but also able to explain complex ideas ... to make the salient points clear, like a bell ringing." $[8$, p. 133]

\section{Conclusion:}

There is a large body of scholarly research into the reporting of health news, and much of it focuses on a core set of themes: concern over how media select and frame stories and how they prime audiences to develop certain beliefs; over-reliance by health journalists on articles that appear in medical journals - especially those that are accompanied by a press release; the negative impact of the 24-hour news cycle on the quality, depth and balance of reporting; the dependence of reporters on PR people and 
medical experts; the influence of social media in driving the news agenda; the need for more training of health reporters to assess the validity and importance of research findings; and the hyping of health news to the detriment of public health.

This body of literature will be applied to a case study of media coverage of a new therapy for the treatment of multiple sclerosis (MS), a chronic and potentially debilitating disease that affects more than 55,000 Canadians. The treatment, based on a hypothesis that the disease is caused by restricted blood flow to the brain, gained widespread media attention in Canada beginning in late 2009 with the publication of a study in the Journal of Neurology Neurosurgery and Psychiatry.

\section{References:}

1. Roy, S.C, Faulkner, G., \& Finlay, S. (2007). Fit to print: A natural history of obesity research in the Canadian news media. Canadian Journal of Communication, 32, 575-594.

2. Hivon, M., Lehoux, P., Denis, J.-L. \& Rock. M. (2010). Marginal voices in the media coverage of controversial health interventions: how do they contribute to the public understanding of science? Public Understanding of Science, 19(1), 34-51.

3. Cassels, A. (2007). The media-medicine mix: quality concerns in medical reporting. Open Medicine. 1(1). Retrieved from: http://www.openmedicine.ca/article/view/54/4

4. Seale, C. (2002). Media and Health, London: Sage Publications Ltd.

5. Einsiedel, E.F. (1992). Framing science and technology in the Canadian press. Public Understanding of Science 1(89), 89-101.

6. Scheufele, D.A. \& Tewksbury, D. (2007). Framing, agenda-setting, and priming: The evolution of three media effects models. Journal of Communication, 57, 9-20.

7. Soroka, S. (2002). Issue attributes and agenda-setting by media, the public and policymakers in Canada. International Journal of Public Opinion Research, 14(3), 264- 
518.

8. Waddell, C., Lomas, J., Lavis, J.N., Abelson, J., Shephard, C.A. and Bird-Gayson, T. (2005). Joining the conversation: newspaper journalists' view on working with researchers, Healthcare Policy, 1 (1), 123-139.

9. Gasher, M., Hayes, M., Hackett, R., Gutstein, D., Ross, I. \& Dunn, J. (2007). Spreading the news: social determinants of health reportage in Canadian daily newspapers. Canadian Journal of Communication, 32, 557-574.

10. Bell, A. (1998). The discourse structure of news stories. (Chapter 3) In Bell, A. and Garrett, P. (1998) (Eds.) Approaches to Media Discourse. Blackwell Publishers, UK.

11. Seale, C., Ed. (2004). Health and the Media. Oxford, U.K: Blackwell Publishing.

12. Bubela, T.M. and Caulfield, T.A. (2004). Do print media 'hype' genetic research? A comparison of newspaper stories and peer-reviewed research papers. Canadian Medical Association Journal, 170(9), 1399-407

13. Cassels, A., Merrilee, A., Cole, C., Mintzes, B. Lexchin, J. and McCormack, J.P. (2003). Drugs in the news: an analysis of Canadian newspaper coverage of new prescription drugs. Canadian Medical Association Journal, 168(9), 1133-1137.

14. Kelly, B.J., Leader, A.E., Mittermaier, D.J., Hornik, R.C., Cappella, J.N. (2009).

The HPV vaccine and the media: how has the topic been covered and what are the effects on knowledge about the virus and cervical cancer? Patient Education and Counselling, 77, 308-313.

15. Nelkin, D. (1987) Selling Science: How Press Covers Science and Technology. New York: W.H. Freeman and Company.

16. Smith, R. (2006) The trouble with medical journals. Journal of the Royal Society of Medicine, 99, 115-119.

17. Adam, M. \& Oransky, I. Retraction Watch: Tracking retractions as a window into the scientific process. Retrieved from: http://retractionwatch.wordpress.com/

18. Wakefield, A.J., Murch, S.H., Anthony, A., Linnell, J., Casson, D.M., Malik, M., Berelowitz, M., Dhillon, A.P., Thomson, M.A., Harvey, P., Valentine, A., Davies, S.E., Walker-Smith, J.A. Ileal-lymphoid-nodular hyperplasia, non-specific colitis, and pervasive developmental disorder in children. The Lancet, 351, 637-41.

19. Eggertson, L. Lancet retracts 12-year-old article linking autism to MMR vaccines. Canadian Medical Association Journal, 182(4), 199-200.

20. Dentzer, S. (2009). Communicating medical news - Pitfalls of health care journalism. 
New England Journal of Medicine, 360, 1-3.

21. Goldacre, B. (2009). Bad Science. London: Random House.

22. Davies, N. (2008). Flat Earth News. London: Random House.

23. Campion, E.D., (2004). Medical research and the news media. New England Journal of Medicine, 351(23), 2436-2437.

24. Friedman, L.D. (2004). Through the looking glass: medical culture and the media. In Friedman, L.D. (Ed.) Cultural Sutures: Medicine and media. Duke University Press.

25. Manning, P. (2001). New media politics and the politically marginal. News and News Sources: A Critical Introduction. London: Sage.

26. Emke, I. (2000). Agents and structures: journalists and constraints on AIDS coverage. Canadian Journal of Communication. 25(3).

27. Hinnant, A. \& Len-Rios, M.E. (2009). The tacit understandings of health literacy: interview and survey research with health journalists. Science Communication, 31(1), 84115.

28. Gillmor, D. (2006) We the media. Sebastopol, CA: O'Reilly Media Inc.

29. Sifry, M.L. (2009). A see-through society. Columbia Journalism Review. Retrieved from: www.cjr.org/feature/a seethrough_society.php

30. Deuze, M., Bruns, A. \& Neuberger, C. (2007). Preparing for an age of participatory news. Journalism Practice, 1(3), 322-335

31. Schwitzer G., Mudur G., Henry D., Wilson A., Goozner M., et al. (2005). What are the roles and responsibilities of the media in disseminating health information? PLoS Med 2(7), 576-582.

32. Schwitzer, G. (1992) The magical medical tour. Journal of the American Medical Association, 267(14).

33. Picard, A. (2005). How can we improve medical reporting? Let me count the ways. International Journal of Health Services, 35(3).

34. Hoag, Hannah. (2008) Membership survey, Canadian Science Writers Association. [unpublished and using the online tool SurveyMonkey.com] 


\section{Chapter 2: Multiple sclerosis: the disease, potential causes and proposed treatments}

This chapter will provide a description of multiple sclerosis as well as a brief explanation of conventional treatments and experimental approaches. It will examine publication of Dr. Paolo Zamboni's hypothesis and present the perspective of medical leaders in the MS community. A complete description of mainstream news media coverage and the social media response will follow in subsequent chapters.

Physicians and researchers characterize MS as a complex and unpredictable disease, usually striking between adolescence and age 40 and generally thought to have no cure. Multiple sclerosis affects women more often than men. Most scientific research describes MS as an autoimmune disease triggered by gene-environment interaction. In other words, people may be born with a genetic predisposition to develop MS, but require an environmental trigger to activate the disease. Possible environmental triggers include vitamin $D$ deficiency and exposure to a virus. $[1,2,3,4]$ An estimated 55,000 to 75,000 Canadians have MS. Poor epidemiology in some provinces and territories accounts for the broad statistical range. [5]

MS attacks the protective covering, or myelin, around the nerves. This may lead to cognitive changes, vision and hearing loss, as well as balance and mobility issues. [6] It is impossible to predict the course of the disease and it can take months or years to determine a diagnosis for MS in individual patients because symptoms may come and go. Magnetic resonance imaging (MRI) is normally used to identify damaged myelin and to diagnose the disease. 
According to the MS Society of Canada, there are four different and distinct types of MS. [7]

- Relapsing Remitting MS (RRMS), which affects about 80-85 per cent of MS patients. It has unpredictable and clearly defined flare-ups that last anywhere from 48 hours to a few months. People generally recover between the attacks;

- Primary Progressive MS (PPMS), which affects about 10 per cent of people with MS. PPMS, tends to be diagnosed after age 40 and is a more progressive form of the disease, characterized by a slow deterioration over time. Unlike RRMS, this form of the disease affects both genders equally;

- Secondary Progressive MS (SPMS) follows the course of RRMS but relapses and remissions lessen and the disease becomes worse over time. About half of RRMS patients develop SPMS within 10 years of diagnosis; and,

- Progressive Relapsing MS (PRMS) affects about five per cent of patients and is the most severe form of the disease. People experience rapid decline with clear attacks and limited remission.

"They are kind of pigeonholed disease courses but, quite honestly, they are variable with each patient," says neurologist Dr. Mark Freedman, director of the MS clinic at the Ottawa Hospital, which has about 4,000 registered patients from all parts of Ontario. "I think each patient is unique in the way they move but, in general, patients will present with a history of relapses and remissions in well over 70 per cent of the cases 
and it is a matter of time before they evolve into a secondary progressive course ... Once the patients enter a progressive phase it doesn't almost matter whether they started with it or they evolved to it from a relapsing phase, the rate of progression seems quite similar."

Some news reports have said that Canada has the world's highest incidence of MS, but Dr. Freedman contends this information is misleading. "There's probably a high incidence in Russia but we don't have good epidemiology from Russia. Where there are countries with good epidemiology - Northern Europe, Scandinavia - the incidence is very high. It could be even higher than Canada. Scotland has a high incidence." Evidence seems to demonstrate that the farther you get away from the Equator in either direction, the higher the incidence of MS. "Could vitamin D be protective? Is there something about sunlight and UV radiation where it tends to be highest at the Equator and MS rates are the lowest?" Dr. Freedman asked. "With the latitude also comes the change of the microbiology flora and with viruses. If it's a virus, there are some viruses that seek out temperate climates."

Traditional treatment for the disease includes a variety of drug therapies that can be divided into two categories. The first category is the use of drugs and rehabilitation to manage the symptoms of MS, including pain, incontinence and numbness. The second course of treatment involves drugs to slow or stop the progression of the disease.

\section{A new theory}

In 2009, an Italian vascular specialist published a small study [8] in the Journal of Neurology, Neurosurgery and Psychiatry (JNNP), a medical journal of moderate scientific impact, challenging conventional thinking about MS. The Institute for 
Scientific Information, which maintains citation databases for academic journals, has assigned JNNP an impact factor (IP) of 4.87. The top five per cent of journals in the field have an IP of 5.5 or higher. Impact factor measures the average number of citations for articles published in academic journals over a certain period and is used to describe the relative importance of journals.

The study by Dr. Paolo Zamboni, who treated and reportedly cured his wife of MS, captured the imagination of patients and their families around the world when it posited that MS is actually a vascular disease and not an immune-system disorder. This was not the first time the venous blood-flow hypothesis had been described [9], but it was the first time the research had been widely disseminated.

"He had some other papers going back a couple of years prior about his theory," Dr. Freedman said. "You know, when you're a hammer, the whole world looks like a nail. ... His expertise is looking at veins and he starts to study veins of patients and comes up with this notion that there are blockages in veins in patients that are not seen in controls. He goes to the extent of saying ' 100 per cent of patients have it; 0 per cent of non-MS patients have it.' And usually that's when the red flag starts going up because we all know in medicine nothing is 100 per cent."

Dr. Zamboni's team investigated 65 patients, of whom 35 had been diagnosed with RRMS, 20 with SPMS and 10 with PPMS. The research team determined MS patients had an abnormal backup of blood into the brain, which Dr. Zamboni called chronic cerebrospinal venous insufficiency (CCSVI.) This drainage problem caused iron to build up in the brain, and the Italian team speculated that this iron buildup precipitated MS. Dr. Zamboni hypothesized that clearing out the blockages in the neck and chest 
would improve symptoms in people with the disease and he gave the treatment the sensational name "liberation procedure". His treatment involved deploying a thin catheter and balloon and using the same technique routinely performed to open clogged arteries in the heart. In almost half of patients the opened veins became blocked again and required further treatment. Although Dr. Zamboni did not use stents (supports placed inside blood vessels to keep them open), his finding led other physicians to employ this procedure to maintain blood flow.

From the start, Ottawa's Dr. Freedman thought the hypothesis was weak. "Well, the veins in your head drain your head, not just your brain. Your sinus, your nose, your eyes, your mouth, your ears, your skin. You know, if we had chronic drainage problems, the skin changes. It turns brown from the iron deposition in the skin because you've got nowhere for this blood to go. So how come people with MS don't have red, iron-clad faces? If you're blocking veins, you're blocking all the drainage. What, the face has separate drainage from the brain? ... . There are hundreds of reasons here why this theory falls to pieces." Dr. Freedman said the hypothesis also doesn't account for the higher female preponderance of MS and the increased incidence of MS related to latitude. "How can this possibly explain that? And all the years of epidemiology."

Stem cell scientist Dr. Harry Atkins at the University of Ottawa, whose successful trials of stem cell therapy to treat MS have been widely reported, also had questions. [10] "You know, sometimes you have to have new ideas that break the mold. But, often times, even those ideas are built on a solid foundation - other researchers that have kind of skimmed around the idea but just haven't put it together," Dr. Atkins said. "This one kind 
of seemed like it came out of right field. And so I am skeptical that there is anything there."

At the University of Calgary, vascular neurologist Dr. Michael Hill, associate dean of clinical research, also expressed skepticism. [11] "First of all, there's no evidence that venous abnormalities are a cause of MS and, second, there's no evidence whatsoever that trying to angioplasty or stent (veins) will improve the situation. So, it's pretty remarkable."

Subsequent testing of Dr. Zamboni's hypothesis by independent research groups in The Netherlands [12] Lebanon [13] the U.S. [14] and elsewhere have found no link or limited evidence connecting MS and CCSVI. Even the Buffalo, N.Y. team led by Dr. Robert Zivadinov, an early collaborator and supporter of the Zamboni hypothesis, found no significant difference in the extracranial venous systems between MS patients and healthy controls. [15] Canadian researchers are also testing Dr. Zamboni's hypothesis. [16]

But not everyone was quick to dismiss Dr. Zamboni's research. Vascular specialist Dr. Sandy McDonald of Barrie, Ontario, and McMaster University imaging specialist Mark Haacke, $\mathrm{PhD}$, were early and vocal supporters of the Italian scientist's work, believing his hypothesis had merit. [17]. Others suggested it may be unwise to rush to judgment. In an editorial in the Canadian Medical Association Journal, editors argued that "good health policy decisions should not be based on hope and desperation ... On the other hand, scientists and skeptics should avoid dismissing novel ideas prematurely. It is precisely the unexpected scientific discovery that often leads to major advances in care." They described how the Nobel Prize-winning discovery that bacterial infection 
causes peptic ulcer disease was initially met with "widespread skepticism that delayed its translation to further research and practice." [18]

\section{Other approaches}

This was not the first time a new treatment for MS had come out of what seemed to be thin air. Clinicians who work in the field describe a number of sham cures. "There have been numerous false claims over the years from poisonous snake venom to hyperbaric oxygen," said Dr. Barry Arnason of the University of Chicago, a leading MS researcher. [19] Dr. Freedman adds a few more to the list: a Frenchman who claimed that MS was related to Rocky Mountain Spotted Fever and mixed up an antidote; the healingpower of goat serum, which gained attention and a large following in England; and reports that people stung by certain bees in Vermont were cured of their MS symptoms. [20] "People rallied around this guy so that they actually had to do a study. And what they showed is that people who got stung had more allergic reactions. Their MS didn't get better," Dr. Freedman said. In 1990, the U.S. current affairs program 60 Minutes described what was believed to be a link between MS and mercury amalgam dental fillings. The theory was that mercury was slowing leeching out of dental fillings, causing MS. Dentists were over-run with people who wanted their fillings removed. [21]

Compounding the problem is the large placebo effect with multiple sclerosis, a disease that waxes and wanes naturally. There is extensive literature on the power of placebo to actually perform better than proven drugs in clinical trials, a phenomenon that requires further study. [22] 


\section{Stem cell therapy}

Although a lot of unconventional treatments have been hypothesized for MS over the years, an aggressive and invasive clinical trial involving stem cell therapy has shown some early promise. (This is described in further detail and from a personal perspective by patient Jennifer Molson in Chapter 6.) Dr. Atkins and Dr. Freedman were able to reverse the symptoms of MS in some people with a very progressive form of the disease.

The conceptual basis for this approach was developed in the mid-'90s when physicians noticed that patients experienced improvements in their autoimmune diseases after receiving stem cell therapy - in this case, bone marrow transplants - for leukemia. From there, animal studies were conducted to determine if the theory was plausible. When the animal studies proved successful, physicians and researchers met to determine if there was a safe way to test the treatment in humans. "So at that time, I had just come on staff here (at the Ottawa Hospital Research Institute) and there was some interest in using transplants in this way," Dr. Atkins said. He met with Dr. Freedman and the pair developed a hypothesis: "It was that the immune system was the root of the disease in multiple sclerosis. If our trial was positive, we would know that the immune system really was the cause of multiple sclerosis and it would fit in with a huge amount of other research that has shown that autoimmunity is the real reason for multiple sclerosis.... While we thought it would work, we weren't certain." Dr. Atkins said. [10]

It was a complicated trial. Treatment involved chemotherapy to wipe out the patient's immune system and establish a new one. Drs Atkins and Freedman sent their proposal to the MS Society of Canada to seek funding for the work. The MS Society was "very cautious about it and (the proposal) was very thoroughly reviewed by a lot of 
people and then we had to address all the concerns," Dr. Atkins said. "This went on for maybe two or three years from when we thought of the trial to when we actually had approval to go ahead."

There was concern because stem-cell therapy was a completely unconventional treatment for MS, and the society wanted to ensure the trial was well organized, safe and that patients were protected, Dr. Atkins said. The first of 24 patients was treated in 2001 and the last one was treated in 2009. The doctors have been following up with the patients ever since and have not published their findings. "It's the long-term follow-up that we are very interested in because of the natural history of multiple sclerosis ... It's really changing the long-term outcomes that we are interested in," Dr. Atkins said.

So far, their data show that most patients have not had progression in their disabilities. In a subset of patients, disabilities lessened or disappeared. Improvement didn't happen right away, but symptoms slowly improved over the course of a couple of years. "That is something that we didn't expect but we feel is very important." Dr. Atkins is now trying to understand why people can have disabilities reversed.

Despite national news coverage of the successful stem cell research, the response from patients has been tentative and measured, partly because the treatment is grueling and it was made clear that only individuals with a rapidly progressing form of the disease could potentially benefit. "We are really looking for those people who have a two- or three- or four-year history between being normal and starting to get visibly disabled from their multiple sclerosis because there are risks to our procedure and we always make sure that people understand what those risks are, including the risk of dying," Dr. Atkins said. Because of that, patients have been reluctant to take part and MS medical specialists "are 
worried about the side effects that we see and still are worried about doing harm to their patients."

The Ottawa results, which physicians say seem to confirm that MS is an autoimmune disease, received media attention from some of the same reporters who later covered the Zamboni hypothesis. According to Dr. Atkins, reporters did not attempt to contact him for his perspective on the validity of the vascular approach proposed by Dr. Zamboni.

\section{Medical complications}

The University of Toronto's Dr. Andreas Laupacis and Dr. Arthur Slutsky wrote in Open Medicine "although Zamboni found no serious complications in 65 MS patients undergoing angioplasty of the jugular veins, no large-scale study of complications has been reported." [23] This is likely why the procedure continued to receive strong support among media and patient groups throughout 2010. Although complications weren't reported (likely because they happened in other countries and over great distances), some medical specialists were aware that they did exist.

Dr. Barry Rubin, head of vascular surgery at Toronto General Hospital, described a number of reported complications for MS patients gleaned from medical reports in 2009 and 2010 when he delivered the Peter Munk Cardiovascular Symposium in Toronto in January 2011. [24] Complications include a brain hemorrhage and death in the U.S. in 2009 and a dislodged stent that ended up in the heart, requiring emergency heart surgery also in the U.S. in 2009. In 2010, there was a brain hemorrhage in Mexico; blocked stents in patients treated in the U.S.; neck pain and swallowing problems from the placement of 
oversized stents in India; a dislodged stent in Bulgaria that migrated to the renal vein; surgery in Mexico to remove a balloon lodged in the femoral vein that caused abdominal pain and a compressed bladder, resulting in a transfusion; infection in India; a bleeding death in Costa Rica following treatment for a clotted stent; pulmonary embolism and deep vein thrombosis in Mexico. It is unclear how many of these medical complications involved Canadians.

\section{News media put spotlight on Zamboni}

While the medical establishment repudiated Dr. Zamboni's findings, the news media embraced this radical new approach to the disease, beginning in the fall of 2009 with a "relatively uncritical article" in The Globe and Mail and a laudatory report on CTV's current affairs show W5. "Both portrayed Dr. Zamboni as a pioneer whose theories were discounted by conventional medicine and focused relatively little on the criticisms of his studies." [23]

On Nov. 21, 2009, a special report on Dr. Zamboni's research appeared on CTV's W5 current affairs program, characterizing the vascular hypothesis and venoplasty procedure as a potential cure for MS. Reporter Avis Favaro and producer Elizabeth St. Phillip travelled to Italy to interview Dr. Zamboni, speak with his patients - including his wife - and described what seemed to be spectacular results. The television network framed the report as "a world-first exclusive" and described the research as "a revolution in the battle against MS." [24] "The doctors called it the liberation procedure, the Italian word for freedom, as the operation restored normal blood flow from the brain. For the patients, however, this liberation had an even more profound meaning," said Favaro in 
her report. To coincide with the W5 report, Favaro and Globe and Mail health reporter André Picard co-authored a story on the Zamboni treatment. The newspaper article, which filled most of the front page and included a headline that indicated there was a cure in sight for MS, ignited interest in the procedure and spurred further media coverage in Canada. "The experimental surgery he performed on his wife offers hope that MS, which afflicts 2.5 million people worldwide, can be cured and even largely prevented," The Globe and Mail story read. [25]

A complete media analysis of television and print coverage by six news outlets from Nov. 20, 2009 to Dec. 31, 2010 will be the focus of Chapter 3. However, it is important to state here that it was the Nov. 21, 2009 reporting by CTV and The Globe and Mail that pushed the Zamboni hypothesis from an article in a modest medical journal - and the accompanying online chatter it created - to a major national news story. Those working in the MS field had serious concerns about how reporters framed the story. Their concerns will be described in Chapter 4 , following the media scan of news coverage on the topic.

\section{Conclusion:}

There is no question that multiple sclerosis is a complex disease that affects many Canadians who desperately want an effective treatment or cure. It has a long history of false promises and sham treatments, including oxygen therapy, bee pollen, snake venom and the removal of dental fillings. The disease naturally waxes and wanes and, as a result, it is susceptible to the placebo effect. Canada has a high rate of MS - but likely not the highest in the world as has been stated in some reports. 
For their part, physicians who treat MS have seen many sham treatments come and go and many patients left disillusioned. There is widespread skepticism in the medical community towards any treatment that is not grounded in established research and does not employ solid scientific methods.

As described, a recent clinical trial of stem-cell therapy to treat MS reveals that the testing of new therapies normally involves lengthy and rigorous approval processes in order to address concerns about patient safety. In the case of the Ottawa MS-stem cell trial, approvals took several years.

The Zamboni approach was based on a small study that did not follow a conventional scientific approach. The Italian vascular specialist challenged established scientific thinking by hypothesizing that the underlying cause of MS is related to vascular abnormalities. MS is generally thought to be an autoimmune disease triggered by a geneenvironment interaction. Although Dr. Zamboni described his procedure as simple, liberating and highly successful, the therapy was not without risk - a fact not communicated to the general public at the time.

\section{References:}

1. Ramagopalan, S.,V. \& Sadovnick, A. D. (2011). Epidemiology of multiple sclerosis. Neurologic Clinics, 29(2), 207-217.

2. Dyment, D. A.; Ebers, G. C \& Sadovnick, A. D. (2004). Genetics of multiple sclerosis, Lancet Neurology, 3(2), 104-110.

3. Sawcer, S. (2008). The complex genetics of multiple sclerosis: pitfalls and prospects. Brain, 131(12), 3118-3131

4. Orton, S.M, Ramagopalan, S.V., Brocklebank, D., Herrera, B.M., Dyment, D.A., Yee, I.M., Sadovnick, A.D. \& Ebers, G.C. (2010). Effect of immigration on multiple sclerosis 
sex ratio in Canada: the Canadian collaborative study. Journal of Neurology Neurosurgery \& Psychiatry, 81, 31-37.

5. Freedman, M. Personal interview, January 31, 2011.

6. Noseworthy, J.H., Lucchinetti, C., Rodriguez, M. \& Weinshenker, B.G. (2000). Medical progress: multiple sclerosis. New England Journal of Medicine, 343, 938-952.

7. MS Society of Canada. Retrieved from: http://www.mssociety.ca

8. Zamboni, P., Galeotti, R., Menegatti, E., Malagoni, AM, Tacconi, G., Dall'Ara, S., Bartolomei, I., Salvi, F. (2009) Chronic cerebrospinal venous insufficiency in patients with multiple sclerosis. Journal of Neurology Neurosurgery \& Psychiatry, 80(4), 392 399.

9. Zamboni, P. (2006). Iron-dependent inflammation in venous disease and proposed parallels in multiple sclerosis. Journal of the Royal Society of Medicine, 99, 589-93.

10. Atkins, H. Personal interview, March 2, 2011.

11. Hill, M. Personal interview, February 13, 2011.

12. Wattjes, M., van Oosten, BW, de Graaf, W. L, Seewan, A., Bot, JC, van den Berg, R., Uitdehaag, B.M., Polman, C.H., Barkhof, F. (2010). No association of abnormal cranial venous drainage with multiple sclerosis: a magnetic resonance venography and flowquantification study. Journal of Neurology Neurosurgery \& Psychiatry. Doi: 10.1136/jnnp.2010.223479

13. Yamout, B., Herlopian, A., Issa, Z., Habib, R.H., Fawaz, A., Salame, J., Wadih, A., Awdeh. H., Muallem, N., Raad, R., Al-Kutoubi, A. (2010). Extracranial venous stenosis is an unlikely cause of multiple sclerosis. Multiple Sclerosis, 16(11), 1341-1348.

14. Dorne, H., Zaidat, O.O, Fiorella, D., Hirsch, J., Prestigiacomo, C., Albuquerque, F., Tarr, R.W. (2010). Chronic cerebrospinal venous insufficiency and the doubtful promise of an endovascular treatment for multiple sclerosis. J Neurolntervent Surg, 2, 309-311, doi:10.1136/jnis.2010.003947

15. Zivadinov, R.; Lopez-Soriano, A.; Weinstock-Guttman, B.; Schirda, C.V; Magnano, C. R; Dolic, K.; Kennedy, C. L; Brooks, C. L; Reuther, J. A; Hunt, K.; Andrews, M.; Dwyer, M. G; Hojnacki, D. W. (2011). Use of MR venography for characterization of the extracranial venous system in patients with multiple sclerosis and health control subjects. Radiology, 258(2), 562-570.

16. Rynor, B., (2010). Canadian trials to examine "liberation procedure" for multiple sclerosis. Canadian Medical Association Journal, 182(9), E403. 
17. Haacke E. M., Garbern J., Miao Y., Habib C., Liu M. (2010). Iron stores and cerebral veins in MS studied by susceptibility weighted imaging. International Angiology, 29(2), 149-157.

18. Stanbrook, M. B., Hebert, P. C. (2010). Access to treatment for multiple sclerosis must be based on science, not hope. Canadian Medical Association Journal, 182(11) 1151 .

19. Arnason, B. G. Personal communication, 27 June, 2011.

20. Castro HJ, Mendez-Inocencio JI, Omidvar B. (2005). A phase I study of the safety of honeybee venom extract as a possible treatment for patients with progressive forms of multiple sclerosis. Allergy and Asthma Proceedings, 26(6), 470-476

21. 60 Minutes. (1990) Excerpts of broadcast about dental fillings posted on YouTube: http://www.youtube.com/watch? $v=\operatorname{trWTCEIPdfY}$

22. Brooks, M. (2008) The power of the placebo effect. New Scientist, 2670, 36-39.

23. Laupacis, A. \& Slutsky, A. (2010) Endovascular treatment for multiple sclerosis: The intersection of science, policy and the public. Open Medicine, 4(4). Retrieved from: http://www.openmedicine.ca/article/view/443

22. Rubin, B. University Health Network Peter Munk Cardiac Centre, Public Lecture on CCSVI and MS. 28 January 2011. Retrieved from:

www.uhn.ca/Focus_of_Care/Munk_Cardiac/whats_new/PMCC_Conference/publiclectureMS/index.asp

23. Favaro, A. \& Laflamme, L. (2009, November 20). MS Treatment. [Broadcast transcript]. CTV NEWS. Retrieved from: http://www.fpinfomart.ca/.

24. Favaro, A. (2009, November 21). The Liberation Treatment. [Broadcast transcript]. CTV NEWS W5. Retrieved from: http://www.fpinfomart.ca/.

25. Picard, A. and Favaro, A. Weekend Special: (2009, November 21). A cure in sight. The Globe and Mail, pp. A1. 


\section{Chapter 3: Media scan of news reports on MS therapy}

A media scan of reporting on Dr. Zamboni's MS therapy in a selected sample of English-language news media in Canada will be the focus of this chapter. The time period under review is Nov. 20, 2009 (when the story first broke in Canada) to Dec. 31, 2010 (shortly after the first highly-publicized death of a Canadian who had gone abroad for treatment).

It is interesting to note that a May 2011 commentary in the journal Nature described how the Zamboni story received far more media coverage in Canada than elsewhere. A search of what are described as "two leading newspapers" in each of seven countries between November 2009 and January 2011 found 83 articles on Zamboni and CCSVI in Canadian papers, 16 in Italian papers and a total of six articles in newspapers in the other five countries. [1] (The newspapers are not identified in the commentary.)

While news reporting on Dr. Zamboni's new therapeutic approach to MS has been extensive in Canada, analysis using the FP Infomart media monitoring tool focused on 143 items from the following sources:

- Canada's two national English-language newspapers, The Globe and Mail, owned by The Globe and Mail Inc., and The National Post, owned by Postmedia. The Globe and Mail has a circulation of 1.9 million copies per week. The National Post has a circulation of 940,000 copies per week, according to the 2009 Circulation Data Report of the Canadian Newspaper Association [2];

- Canada's highest-circulation English-language daily, the Toronto Star, owned by Torstar Corporation. Circulation of the Toronto Star is 2.2 million copies per week; 
- Television transcripts from CBC TV News and Current Affairs; CBC TV News and Current Affairs; and Global News and Current Affairs, representing news coverage by the three major television networks in Canada. CTV News has an audience of about 1.2 million viewers and Global News has an audience of about a million viewers, [3] while the nightly audience for $\mathrm{CBC}$ 's The National was about 900,000 .

English-language media sources were selected for the scan because the story broke in the English-language media - the largest English-Canadian national newspaper and television network. As well, by focusing on a single language it was easier to search news items for keywords.

Broad search terms - "MS" and "multiple sclerosis" - were used to capture all possible stories and each item was reviewed to determine the focus was indeed on Zamboni and CCSVI. The search tool found:

- 31 items among the CTV News and Current Affairs transcripts, including two documentaries on W5, 12 interviews on Canada AM and 17 news stories. Medical specialist Avis Favaro was responsible for the W5 features and 15 of the 17 news stories;

- 18 news reports on CBC's The National. Health reporter Kelly Crowe did 12 of the 18 stories.

- Eight news reports on Global National. Reporter Crystal Goomansingh was responsible for four of the reports. 
- 41 items in The Globe and Mail newspaper, including 10 editorials and columns. Reporters André Picard, Carly Weeks, Gloria Galloway and Caroline Alphonso shared the bulk of coverage.

- 30 items in the National Post, including six columns and editorials. Of the 24 news stories, health reporter Tom Blackwell wrote the most at seven.

- 26 items in the Toronto Star, including five editorials and commentaries. Health reporter Joanna Smith wrote 10 of the 21 news stories.

The columns and commentaries picked up in the FPInformart search were reviewed but not considered in a media scan for keywords. Canada AM transcripts were referenced only when used as promotional pieces for the network's national news reports. Headlines as well as print and television lead-ins and intros were evaluated because they frame and contextualize the news reports. Also examined was the banter between television reporters and anchors immediately after news reports as audiences look at this as part of the story package.

Articles and transcripts were scanned for nine keywords, seven of which are from a list of "seven words to never use in medical reporting" prepared by U.S. media scholar and journalism professor Gary Schwitzer. [4] Search terms included: miracle, cure, breakthrough, promising, dramatic, hope and victim. According to Schwitzer these words are "misleading and dangerous", loaded, ill-defined and "carry different meanings for different audiences". Added to Schwitzer's list in this media scan was the word 'groundbreaking', a popular variation of 'breakthrough', which appeared frequently in initial news reports on this story. As well, articles were scanned for 'liberation', a word Dr. Zamboni himself assigned to his new therapy for MS. 
News coverage was divided into four distinct periods. The bulk of analysis for the media scan surrounds early coverage because these stories primed the audience, framed the issue and set the agenda for public reaction and political discussion.

The breaking story: November 2009 to February 2010

- Nov. 20-21, 2009: The story about Dr. Zamboni's theory 'breaks' on CTV News on Nov. 20 and a day later in The Globe and Mail newspaper. The two organizations shared the same owners at the time. Other media outlets follow the story.

- February 2010: Patient groups begin a push to gain access to the therapy, urging the government and MS Society to fund clinical trials. Individuals with MS look to participate in a study in Buffalo probing the prevalence of narrowed veins in people with MS. Thousands apply but few can participate in the research project.

- February 2010 - Research reports indicate Dr. Zamboni's early claim that 100 per cent of people with MS have blocked veins was overstated. The number appears to be closer to 55 per cent.

Public reaction: March to June 2010

- April - June 2010: Pressure continues to mount on the Multiple Sclerosis Society of Canada to fund more research into the therapy, while there are a growing number of media reports on patients travelling abroad for treatment.

Political response: June to September 2010

- June 2010: The Multiple Sclerosis Society of Canada announces funding for seven new research projects investigating the link between blocked veins and MS. 
- June 2010: Dr. Zamboni appears before a House of Commons committee urging funding for clinical trials into his novel therapy for MS.

- July-August 2010: Saskatchewan, Newfoundland and Labrador and Manitoba indicate they will provide funding for clinical trials to test the Zamboni theory.

- September 2010: Federal Health Minister Leona Aglukkaq accepts the advice of a CIHR review panel and declares the federal government will not proceed with clinical trials into CCSVI due to lack of evidence.

Negative outcomes: October to December 2010

- Nov. 18, 2010: CBC News reports a St. Catharines, Ontario man, Mahir Mostic, died in October after travelling to Costa Rica for the liberation procedure. His death was linked to complications related to a clotted stent placed in his jugular vein.

\section{The breaking story:}

Promotion of the CTV story about Dr. Paolo Zamboni's liberation therapy began about 36 hours in advance of a Nov. 21, 2009 special report on the current affairs program W5. Canada AM host Beverly Thomson interviewed CTV medical specialist Avis Favaro, who had travelled to Italy with producer Elizabeth St. Philip to meet Dr. Zamboni and his patients and to witness the procedure. [5]

The early-morning teaser and interview included six of the keywords used in the media scan, including 1 reference to groundbreaking, 2 breakthroughs, and 3 uses of liberation or liberating. The reporter indicated "we were the first crew in the world to film the new treatment" and that "only MS patients have this narrowing (in their neck veins) 
... Not in normal people, just in MS patients." She said she met more than a dozen patients "that he is liberating" and Dr. Zamboni's research suggests the novel treatment “stops MS whenever they're treated." The Canada AM host replied: "Stops MS? That's unbelievable. It just gives me chills to think about it."

The W5 feature was profiled again on the late-night CTV National News, topping the newscast with the following introduction by anchor Lisa Laflamme.

LISA LAFLAMME: Good evening. It's not every night we begin with good news, but when something has the potential to dramatically improve the lives of a quarter million Canadians, it's worthy of top billing. It's a medical breakthrough in the treatment of multiple sclerosis and a discovery that challenges everything the medical community has ever known about the debilitating disease. An investigation by CTV's W5 reveals a new treatment, pioneered by a doctor in Italy, that appears to stop the disease. CTV's medical specialist Avis Favaro has this exclusive first look at the procedure and its remarkable results. [6]

It was never made clear how the treatment could "dramatically improve the lives of a quarter million Canadians" when an estimated 55,000 to 75,000 Canadians are thought to have the disease. The statistic used by Laflamme in her lead-in to the news report may include immediate family members or caregivers of people with MS, however that is not indicated.

Following her report, Favaro engaged in an on-air discussion with Laflamme. She said Dr. Zamboni's research was "the number one subject on the Internet chat sites among MS patients, which is one reason we went to Italy." This seems to indicate that social media triggered news coverage of the therapy. (Chapter 8 will provide a broader discussion of the role of social media in promoting the story and reacting to new developments.) 
The Toronto Star ran a 349-word story on page A26 on Nov. 20, previewing the W5 report and its findings. Keywords were found twice (once in the headline:

"Researcher says surgery has cured MS patients; His belief that twisted veins trigger the disease met with skepticism"; and once in the story: according to the W5 investigation, the researcher had discovered a "potentially promising" treatment.) [7]

The next morning, Saturday, Nov. 21, 2009, about two-thirds of the front page of The Globe and Mail newspaper was devoted to the Zamboni research. [8] The article was co-authored by Globe and Mail public health reporter André Picard and CTV's Favaro. The newspaper and television network collaborated on stories as the two organizations shared ownership under CTVglobemedia Inc. The overline on the article read: Weekend Special: A cure in sight. A large headline, written in alternating blue and grey typeface, was wrapped around a photo of Dr. Zamboni. The lead-in to the article indicated that Canada has "the world's highest incidence of MS" and a doctor in Italy had made "an astounding discovery, one that suggests MS can be cured or even prevented." The article and headline contained the following keywords: 2 cure, 1 breakthrough, 2 dramatic, 2 hope and 2 liberation/liberating for a total of 9.

In the article, Dr. Zamboni is quoted as saying he is "confident that this could be a revolution for the research and diagnosis of multiple sclerosis." His results are described in the news text as stunning with research showing 90 per cent of people with MS have blocked or malformed veins, compared to no one without MS. One Italian patient who had undergone the treatment was described as "reborn". "I don't remember what it's like to have MS," the patient said. "It gave me a second life." 
No one from the MS Society of Canada was quoted directly in the story, but the MS societies in Canada and the United States were described as reacting cautiously to the research, indicating questions remained about the theory. There were no Canadian neurologists (the medical specialists who treat MS) quoted in the story. However, a Canadian imaging specialist - Mark Haacke, $\mathrm{PhD}$, an adjunct professor at McMaster University - urged Canadians to send him their scans to verify the hypothesis.

On Nov. 21, 2009, hundreds of thousands of Canadians watched the muchanticipated W5 report. [9] The report included eight of the keywords in the media scan, including 1 breakthrough, 1 promising, 2 hope, 2 cure and 2 dramatic. The special report was framed by host Lloyd Robertson, one of Canada's most respected news personalities, as "stunning" and "revolutionary" and "a radical approach" that could "free" people from suffering.

The 21-minute W5 documentary, which can be accessed on the CTV website (www.ctv.ca/CTVNews/WFive/20091120/W5_liberation_091121), provided a compelling description of Dr. Zamboni's treatment, based on research to find a cure for his wife. Again, there were no Canadian MS experts quoted in the report and no one from the MS Society was interviewed on camera.

Hours after the W5 report, the story was again highlighted on CTV's 11 p.m. national newscast. Anchor Sandie Rinaldo said the "exclusive report featured a radical discovery" that "could be a game changer in the fight against MS." Reporter Avis Favaro told Rinaldo:

FAVARO: Well, Sandie, I can tell you that for many months now Dr. Zamboni's work has been one of the hottest things on the chat sites among the MS community, and it's very interesting to watch them all talk around the world as they watch the "W-5" item, because it's the first time that Dr. Zamboni and his team have actually talked through the 
media to patients. So there's a lot of interest. There's a sense of hope because most of the research in MS has been on different drugs to control the immune reactions. There's also been stem cell work at the University of Ottawa where they're trying to deal with chemotherapy and that sort of thing. But this is a whole different approach, so there's a sense of hope out there. [10]

It is interesting to note that Favaro alluded to her earlier story on stem cells as a potential therapy for MS, but did not seek comment from stem cell researchers about this alternative approach or describe how the two therapies - based on completely different underlying theoretical approaches - could co-exist.

Also on November 21 - the day the W5 report aired - CBC's The National invited MS expert Dr. Paul O'Connor, scientific adviser to the Multiple Sclerosis Society of Canada, to comment on the reports. Dr. O'Connor indicated the research was fascinating but very preliminary and required further investigation, including larger and more complex trials. "The history of treatments in MS is that very often treatments that initially were felt to be effective turned out not to be with further study." [11] While the keyword "cure" was found twice in the transcript, it was used in reference to the fact that there is no cure for MS.

In the first few days following the W5 report, Favaro's investigative story was highlighted on Canada AM and featured in a follow-up report on CTV National News on Monday, Nov. 23, 2009. Once again, CTV anchor Lloyd Robertson provided a powerful introduction to the story.

LLOYD ROBERTSON: Now to a potential medical breakhrough that has captured the imagination of people all over the world. The story was brought forward on the weekend by CTV's "W5" and holds out hope for sufferers of multiple sclerosis. There are 75,000 of them in Canada. The cause and potential cure for MS was developed by Italian doctor Paolo Zamboni. CTV medical specialist Avis Favaro, who broke the story, has the latest developments. [12]

Favaro's report focused on Dr. Zamboni's publication in the December issue of 
the Journal of Vascular Surgery, indicating his research group found negligible complications among $65 \mathrm{MS}$ patients treated with liberation procedure and 50 per cent of patients with the most common form of MS were relapse free for at least 18 months. The CTV report featured a female Italian patient who said: "I walk now. Yesterday I don't walk. I jump. Yesterday I don't jump. Very miracle."

Favaro cautioned there was concern in the medical community that some people were considering discontinuing their medications. "To people with MS, we say don't abandon the course of treatment that you've started. Those treatments have been proven in large trials to be effective," said MS Society of Canada CEO Yves Savoie, who was quoted in Favaro's report. The following transcript accessed through FPInfomart provides some interesting insight into the early priming, framing and agenda-setting by CTV.

ROBERTSON: So, Avis, how might this major discovery benefit MS patients in the shortterm?

FAVARO: Well, what it's going to do, Lloyd, is open up the doors. We've spoken to a couple of researchers who are very excited with what's going on and hope to begin studies in Canada. We also spoke to Dr. Zamboni who has had a hard time getting funding for his research, and he jokingly said he may apply for Canadian research money as well.

ROBERTSON: That would be fun. Now I know that you've been fielding e-mails and phone calls from this all weekend. How do you account for this overwhelming positive response?

FAVARO: It's really astounding, Lloyd. You have to understand that for months patients around the world have been hearing about Dr. Zamboni and his team's work. This has been the first time that they've actually heard from the man and the scientist at the centre of this. We heard even from people in the UK, and in New Zealand where a couple drove 50 kilometres to watch the item because there is so much interest in this, and, Lloyd, there's a lot of demand among patients to find treatments that don't just involve medications. 
ROBERTSON: Well, congratulations to you, Avis, on a great story. Thank you.

FAVARO: We were honoured to do the story, Lloyd.

Including the intro, the news story included six of the keywords: 1 cure, 1 miracle, 2 breakthrough, 1 hope, 1 liberation. By Dec. 16, 2009, the University of British Columbia announced plans to begin patient trials to test the "potentially groundbreaking" procedure, according to a Globe and Mail report. [13] The story included two references to hope and one to breakthrough but they were used in the context of people wanting a breakthrough and being filled with hope and anxiety.

Just over a month after the broadcast of the W5, the "liberation" therapy was named one of the "top medical breakthroughs" of 2009 by CTV Canada AM medical contributor Dr. Barry Dworkin. (3 keywords: breakthrough, promising and liberation.) $[14]$

It is interesting to examine how other media outlets approached the story. After CTV and the Globe broke the story, CBC's The National did two early news reports. The National Post and Global News did not cover the story until early 2010. The first CBC news report was on Nov. 27, 2009 by journalist Darrow MacIntyre. [15] It included the keywords 'breakthrough' and 'hope' in the intro. ("Word of a possible breakthrough in the treatment of multiple sclerosis is attracting a lot of attention this week and raising a lot of hopes.") MS Society CEO Yves Savoie is quoted in the story as saying it's too early to say this is a cure.

Less than three weeks later, $\mathrm{CBC}$ health reporter Kelly Crowe provided what was described as "a reality check" on the new therapy in a feature report on The National. [16] She described how the therapy had been sold as a cure ( 4 mentions of misplaced cure), but that this characterization was far from the truth. She indicated that researchers 
were stunned by the public response to early media reports and the new therapy's promise had been overplayed. "With words like 'cure' popping up, MS patients became desperate to learn more," Crowe reported. In the days after the first media reports, more than 8,000 people, mostly Canadians, contacted a Buffalo, N.Y. clinic investigating the procedure. CBC framed the story with skepticism, as this transcript obtained through FPInformart reveals:

KELLY CROWE (REPORTER): But the patients are looking for something that doesn't exist. There is no established treatment. It's just research, early research. Dr. Robert Zivadinov, one of the lead investigators, says he doesn't believe this will explain the entire cause of $M S$ and it's not likely to be the cure.

DR. ROBERT ZIVADINOV (BUFFALO NEUROIMAGING ANALYSIS CENTER): I fully understand on the other side MS patients who heard on the news that there is now a cure for MS, but that's not true.

While CBC questioned early coverage by CTV and The Globe and Mail, it took The National Post two months to tackle the issue. Health reporter Tom Blackwell wrote a 2,622-word feature article, which began on page 1 on Jan. 23, 2010, focusing on media coverage of the Zamboni procedure. [17] "Indeed, glowingly positive Canadian media accounts of work by Italy's Dr. Paolo Zamboni ... (have) raised questions about how journalists and scientists portray medical research to the public," Blackwell wrote.

Blackwell interviewed six MS specialists and a bioethicist who were angry with what they saw as a media-driven frenzy, blaming CTV and The Globe and Mail for "onesided depictions of preliminary, unproven research, including the treatment Dr. Zamboni evocatively terms the 'Liberation' procedure."

Yves Savoie, CEO of the MS Society, said in the article that a speedy decision by his organization to announce grants of up to $\$ 200,000$ to fund investigative research in the field was unpredecented. "You have a researcher who hypothesizes something and 
dares call it the Liberation procedure," Mr. Savoie noted. "It was already branded as something that sounded like a cure." Blackwell also interviewed University of Calgary bio-ethicist Dr. Ian Mitchell, who provided an interesting perspective on the early news stories.

The affair underlines generally the perils of journalists failing to carefully scrutinize the claims of medical science, especially in an era when researchers compete aggressively for funding and bragging rights, said Dr. Ian Mitchell, a bio-ethicist at the University of Calgary.... "You'd never be allowed to have a drug called Liberationex, it's such an emotive title. Usually, flags would go up," said Dr. Mitchell, who is also a pediatrician. But "[the research] was portrayed uncritically as a modern miracle."

Blackwell's feature story included 22 references to the keywords ( 2 miracle, 6 cure, 3 breakthrough, 1 promising, 4 hope, 6 liberation) but the words were generally used to question other claims and for raising false hope.

In February, initial hype around the therapy seemed to be tempered when Dr. Zamboni attended a medical conference in Canada and indicated more research was required. A Feb. 8, 2010 CTV news report by Favaro contained none of the keywords [18], and her report two days later described how Buffalo researchers found that 55 per cent of people with MS had blocked or abnormal veins in their necks and chests, compared to 22 per cent of controls. [19] However, the story did not correct initial reports indicating 100 per cent of people with MS had abnormalities, compared to no one in the normal population.

The Globe and Mail also covered the conference $[20,21]$ and The National Post's Blackwell filed twice from the meeting $[22,23]$. He interviewed a number of neurologists who criticized the studies and pointed out some of the researchers involved - including physicians in Buffalo - were making a lot of money from scanning neck veins. Other media reports did not examine the money-making angle. Blackwell's stories on Feb. 9 
and 11,2010 , both of which received front-page play, included two references to the word hope but in the context of raising false hope and pitting hope against skepticism.

By February, language in news reports began to change. Instead of branding the treatment a breakthrough, news reports described it as a controversial new theory or experimental procedure. Between November 2009 and March 2010, the FP Infomart search found 26 news hits from media organizations studied. Of those, 12 were CTV News and Current Affairs transcripts, which included Canada AM. Keywords, especially breakthrough, hope and liberation, were found 44 times.

\section{Public reaction}

By early spring 2010, news reports focused on personal profiles of people living with MS, the frustration of people wanting treatment in Canada, as well as stories of recovery in people who travelled abroad for treatment. There was also growing skepticism from the medical community about the benefits of the therapy. On March 18, 2010, CBC's The National featured two Canadian brothers - Evan and Duncan Thornton - who travelled to Poland for treatment and reported immediate benefits. [24] In a March 29, 2010 article in The Globe and Mail, journalist Carly Weeks reported "signs are emerging that it may not be as revolutionary as hoped, and could also present significant dangers to patients." [25] On April 12, 2010, CBC health reporter Kelly Crowe accompanied a popular MS blogger, Ginger McQueen, to Poland to watch her undergo the procedure. She reported that physicians there perform five operations a day for $\$ 10,000$ each. [26] This was the first time a journalist quantified profits from the therapy. Crowe's report was called "Ginger's Last Hope" and made 13 references to hope. On 
April 14 in The Globe and Mail, journalist Caroline Alphonso described the remarkable recovery of a patient who had received treatment. [27] And the following day, Weeks of the Globe and Blackwell of the National Post reported how physicians urged caution at a major neurology meeting, calling on patients to wait until the procedure was properly tested. [28, 29] "The work by Dr. Paolo Zamboni, spurred on by sometimes-glowing media coverage, has triggered a sensation in the MS world, with Canadian patients bombarding their doctors for a chance at the operation or more information about it," Blackwell wrote. As these examples indicate, there were a lot of mixed messages being sent to Canadian newspaper readers and television audiences about the potential benefits and drawbacks of the procedure.

By mid-spring 2010, CTV began to temper language around the treatment. An April 14, 2010 report by Favaro used none of the keywords and described skepticism emerging in "this controversial new field." [30] On April 29, 2010, The Globe and Mail reported that some U.S. hospitals were banning doctors from performing the procedure until there was further research. [31] On June 5, 2010, The Globe and Mail described dissention in the MS Society of Canada while other media outlets reported on internal power struggles. [32]

Through April, May and June, the six media organizations carried 24 stories about people with MS demanding treatment, pushing for political action and organizing rallies to make their voices heard. Global News finally weighed in with coverage of May 5 rallies in Nova Scotia and across the country at which thousands of people demanded access to treatment in Canada. Reporter Ross Lord used keywords seven times, including 1 promising, 3 victim and 3 liberation. [33] 


\section{Political reaction}

Politicians were not immune to the pleas of people with MS seeking to gain access to the treatment. In the summer and fall, the focus of media reports shifted to political reaction towards public interest in this research. From July to October, 2010, there were 69 items (18 Globe and Mail, 17 Toronto Star, 14 National Post, 8 CTV, 7 CBC, 5 Global TV), including a few columns and editorials, in the six media outlets surveyed. Most of the stories focused on government response to the issue.

In The Globe and Mail, there were six A1 stories from July to October. Of the 18 Globe news stories running during this time period, the word "liberation" was used 45 times. These included articles on Saskatchewan premier Brad Wall's decision to fund clinical trials, a call from Manitoba health minister Theresa Oswald for national clinical trials and support from Nova Scotia politicians for trials. In late July, there was also a provocative piece by Globe columnist Margaret Wente, [34] arguing that medical research funding is too important to be driven by popular demand instead of facts and, on August 4, the Globe [35] reported on two new studies casting doubt on Zamboni's theory.

Likewise, over the summer and early fall Toronto Star news reports focused on the Ontario government's decision to hold off on funding for the therapy as well as the reaction of other provincial leaders and the federal government response. The word 'liberation' was used 24 times in Toronto Star stories and headlines from July to October - about half as often as in The Globe and Mail.

The National Post also turned its attention to funding decisions from July to October with news reports on discussions in Saskatchewan, British Columbia, Quebec, Nova Scotia as well as at the health ministers' meeting in Newfoundland and Labrador in 
late August. Of the 14 National Post items, there were two columns, an editorial, two news briefs and four stories picked up from other Postmedia papers. The word liberation was used 18 times and the only other keyword found was dramatic, which appeared once.

The FPInfomart search found eight CTV News and Current Affairs transcripts from July to October, including five news items and three Canada AM interviews. Of the five news items, three were scripts read by the news anchor. Keywords found included 11 references to liberation, 1 dramatic and 1 hope. Language became toned down.

Six stories appeared on CBC's The National. The keyword 'liberation' was found once. During the same period, Global National did five stories on the topic, two of which were scripts read by the anchor. Like other news outlets, the focus was on whether trials should receive funding. The word liberation was found six times in the news scan. No other keywords were used.

As the summer ended, the Canadian Institutes of Health Research held a closeddoor forum of research experts to discuss whether the federal government should direct health-care dollars towards clinical trials. Results of the meeting created a great deal of media attention. Health Minister Leona Aglukkaq announced she would follow expert advice indicating there was not enough research evidence to proceed. (A full discussion of the CIHR meeting can be found in Chapter 7.) This prompted an editorial in The Globe and Mail on September 3, calling for Canada to be bold and to fund medical trials of this "revolutionary" treatment of MS. [36] The Toronto Star, in an editorial, congratulated the health minister on her prudent and responsible response. [37] The National Post's Blackwell reported that there was an overwhelming lack of evidence to fund clinical trials. [38] On CTV National News, the news anchor described the "strong and negative 
reaction today from MS patients in Canada frustrated over a decision by Canadian health officials not to fund clinical studies here into liberation treatment." [39].

On Sept. 16, 2010, health reporter Picard, who co-authored the original news story in the Globe, said in his opinion column that the health minister was correct in accepting the decision of a CIHR expert panel and that scientists, not politicians, should evaluate the merit of research efforts. "Federal Health Minister Leona Aglukkaq has taken a lot of flak, but, on this issue, she has acted properly. Pressured to fund a clinical trial, she confided the issue to a panel of experts and then accepted their recommendation. (The CIHR panel said there was an "overwhelming lack of evidence on the safety and efficacy" of liberation therapy, so it was premature to conduct clinical trials)," Picard wrote. [40]

While the Toronto Star's Joanna Smith focused on the political decision-making around clinical trials through the late summer and early fall, on Sept. 25 she co-authored an Al feature with reporter Meagan Ogilvie examining the vitriol directed at physicians who spoke out against the therapy and their newfound reluctance to stand up for their scientific and medical beliefs.

Mark Freedman was unprepared for the onslaught of hate. There were the angry letters and phone calls. There were patients who told him he was fired, and others who accused him of conspiring with drug companies to keep them ill in the name of profit. There was the vitriol being poured into online forums, where he was called a pompous windbag with the bedside manner of Adolf Hitler, a pill pusher and, even, the "King of all Turds". He had spent a quarter century searching for a cure for multiple sclerosis, spurred on by being a daily witness to the fear and pain of his patients, but when Freedman urged caution over a proposed new theory of the debilitating disease - something he says he did in the best interest of patients - he was labelled a villain. [41]

Smith described unprecedented patient mobilization and hostility towards physicians disappointed to see "their healthy skepticism has been so wrongly interpreted as conspiracy and stubborn arrogance." 
Quoted in the story was neurologist Dr. Alexandre Prat, who heads the Neuroimmunology Laboratory at the University of Montreal Hospital Centre. “(The) media have actually showed some interest and some compassion for a number of patients that claim they were doing better on the therapy. I think that is fair. The problem is that there are a number of scientific truths that have been presented and that do not support the claims of these Italian scientists and (these have) not been very well presented by the media."

Coverage continued to focus on rallies and public anger at government inaction. On Sept. 21, The Toronto Star reported on another angry protest on Parliament Hill. "We are going to be coming to those voting polls," Sandra Delaunais from the Ottawa area shouted into the microphone to loud applause as the rally (on Parliament Hill) wrapped up. 'Bring it on, government. We're going to take you on.' " [42]

\section{Negative outcomes}

Almost a year to the day after the W5-Globe and Mail special report on Dr. Zamboni's vascular theory for MS, CBC reported that a Canadian man had died in Costa Rica from complications related to the procedure. In a CBC "exclusive" report, Kelly Crowe chronicled the death of a St. Catharines man with MS, who received the veinopening procedure in Costa Rica and later died there after returning to the country to unblock the stents placed in the veins in his neck. In her CBC report, Crowe said: KELLY CROWE (HEALTH REPORTER): Five months ago Mahir Mostic went to Costa Rica in search of a miracle. Suffering from multiple sclerosis, he was no longer able to walk. His friends raised thousands of dollars to send him to this private hospital for an experimental procedure to open up the veins in his neck. Dr. Marcial Fallas did the surgery. He said he was forced to use a stent to keep the vein open, a stent that is not intended for use in veins. Dr. Fallas warned Mahir Mostic that with a stent there was a higher risk of complications. [43] 
Although Mostic felt some improvement in his symptoms after the procedure and he returned home, his condition soon deteriorated. Crowe reported that he returned to Costa Rica because he couldn't get a specialist in Canada to see him. Costa Rican doctors' efforts to dissolve a blood clot led him to bleed to death. A Canadian physician interviewed as part of the story indicated that it is more dangerous to treat a blocked vein than to leave it alone. "We generally don't try and dissolve clots because of the danger of that treatment and the fact that the natural history of a clot in veins is usually benign," said Dr. Barry Rubin, head of vascular surgery, University Health Network.

Crowe said Dr. Rubin knew of other cases of serious complications faced by MS patients who have sought treatment in foreign clinics. [44] She did not use the word 'liberation' to describe the procedure or any of the other keywords. On Nov. 19, CTV also reported on the Mostic death and pinned the tragedy on the lack of follow-up care by Canadian physicians for patients who travel abroad. [45] Reporter Favaro interviewed Dr. Zamboni, who said stents were never part of his procedure and he had concerns about patient safety. The word liberation was used once in the story.

Global National's Goomansingh reported the Mostic death "is only widening the divide between patients who want the treatment, and doctors who warn it may not be safe." [46] The word liberation was used in the introduction to her story.

As for print coverage of the Mostic death, the Toronto Star's Kate Allen described the controversy behind the procedure, which cost at least $\$ 11,000$ in Costa Rica. [47] She quoted Ottawa MS specialist Mark Freedman as saying: "This is guaranteed not the first death." She said Dr. Freedman was frustrated patients were 
ignoring medical advice in search of "the magic cure. They want relief of their symptoms badly enough that they're willing to take the risks. And the risks, we've been saying, are significant," Freedman said. "How many places are willing to take Canadians' money because they can?' The word liberation was used four times in the story.

Following the death, the National Post led with a plea from the health minister for Canadians with MS to put their passports away and wait for research to support the controversial procedure. The word liberation was used three times in the story. [48] And, finally, The Globe and Mail described how the death had "deepened the chasm between doctors and patients: Physicians are urging more caution than ever, and people with MS are demanding with increased fervour that doctors set aside their reservations and perform the operation in Canada." The word liberation was not used to describe the procedure. [49]

After a year of hope-filled reports on the benefits of "liberation procedure", on Nov. 21, the Toronto Star then told the story of 26-year-old Albertan Jamie McGowan whose painful experience left him fearful one of the four stents in his neck would dislodge and kill him. The Star described him as "one of apparently few patients" to suffer complications.

His $\$ 30,000,10$-day medical journey to India was financed by a generous aunt and uncle. On Sept. 25, McGowan found himself lying in an operating room at a Bangalore hospital with a tube in his groin and an angioplasty balloon being threaded through his blood vessels to be inflated in his neck. "I must have been ballooned 50 or 60 times," he recalls, "and every time I' $\mathrm{m}$ being ballooned, something else is snapping in my neck and there was this horrible cracking." The noise was "like somebody taking a dying tree branch, a really thick one, and just snapping it. ... It was a horrible sensation. And it was painful." [50]

Subsequent coverage in The Star quotes Dr. Zamboni telling people not to rely on 
patient blogs, which he blamed for fuelling medical problems:

Liberation therapy has been hailed as a multiple sclerosis miracle cure. But the recent death of Ontario resident Mahir Mostic, who died from complications after undergoing the procedure in Costa Rica, has revealed a sobering truth: that liberation therapy's hype has gone far beyond what its creator, Dr. Paolo Zamboni, originally claimed. "Please," Zamboni said at a web forum in April. "Refer just to what was published - not the blogs of patients." What the Italian vascular disease researcher published in 2009 was a small, uncontrolled study that indicated one specific vein-widening procedure can alleviate symptoms for one specific type of MS sufferer. [51]

The Globe and Mail reported on Nov. 24, 2010, that Dr. Zamboni felt things had spiraled out of control. He urged the Canadian government to step in to fund trials in order to prevent people from travelling abroad and having stents placed in their veins, a procedure he never advocated.

... Paolo Zamboni said he has been inundated with urgent pleas for help from MS sufferers around the world and seen his name attached to dangerous practices that have led to accidental deaths and dashed hopes. His theory - which suggests that MS might be caused by blocked veins and could be cured with a simple procedure known as an angioplasty - has spawned an industry beyond his control, he said, and led him to conclude that governments must take responsibility to prevent unsafe treatments abroad by offering MS patients a safe procedure at home... And he agrees that there is not enough evidence to suggest that angioplasty offers any actual benefit when it comes to MS. But he also knows that people will not stop seeking out the treatment, even if he tells them to. [52.]

Interestingly, what neurologists Dr. Paul O’Connor, scientific adviser to the MS Society of Canada, and Dr. Michael Hill of the University of Calgary later recalled most about media coverage in interviews for this study was a column by Picard in The Globe and Mail two days after Mostic's death was reported by CBC. They recounted how he wrote mea maxima culpa - Through my great fault. They felt Picard seemed to be acknowledging a role in the spread of misinformation. Picard wrote in his column:

So where does that leave people with MS? It leaves them exactly where they were one year ago - when intriguing research by Dr. Paolo Zamboni exploded into the headlines - 
notably on CTV National News and in a companion piece in The Globe and Mail. (Mea maxima culpa.) The media, of course, are being blamed for fuelling the hype. In response to Mr. Mostic's death, some have already said there is blood on our hands. [53]

However, Picard argued in his column that initial coverage was more balanced than given credit for and it was the blogosphere that fuelled the hype. "The story of "liberation" is a brutal reminder that any intervention - drugs, surgery, etc. - that has a potential benefit has an equal or greater potential for harm. In medicine, there are no free passes. The saga is also a sobering reminder that, as much as we yearn for simple solutions, they rarely exist. ... MS remains a bedeviling autoimmune disease - not one that can be miraculously cured with a little plumbing of the neck."

At year end, CBC National News and Global National described MS liberation procedure as the top health news story of 2010 , ending with a tragic death. [54] "Well, this has all been about hope," said CBC's Crowe in a year-end report.

\section{Conclusion:}

The media scan reveals that early coverage - most notably the breaking stories on television and in print - was unbalanced and failed to include the perspective of MS specialists. Reporters also failed to explain how the proposed theory could co-exist alongside earlier reports on stem cells as a treatment for MS. Stem cells researchers were not contacted for comment.

The new medical therapy for MS was framed as a cure for the disease. Language used to describe the treatment often included the "seven words to never use in medical reporting" as well as the term "liberation", which Dr. Zamboni assigned to his work. Reporters became more cautious as the year unfolded and the groundbreaking procedure was rebranded as a controversial therapy. 
Initial CTV reports primed the audience to believe that Dr. Zamboni had made a major discovery and urged them to contact the MS Society if they wanted action, setting the agenda for research funding decisions. At the same time, CTV editors and producers pushed the "world exclusive" and created hype around the research with intros and promos over-selling the theory. With its reach and credibility as Canada's 'national newspaper', The Globe and Mail initially played the story as if MS was about to be cured.

Reluctance by the MS Society and medical specialists to embrace the vascular theory created tension among physicians, patients, the MS Society and journalists. Controversy and tension fed the story as a struggle between opposing forces. Meanwhile, as described in the literature review, there was a classic folktale quality to the story, with Dr. Zamboni portrayed as a hero-helper who had uncovered a simple, relatively non-invasive therapy for a complex disease.

Within weeks of initial news reports, journalists began to self-police, criticizing each other for their handling of the topic and rallying to the defence of the medical community. Media interest also focused on the intense human-interest angle to the story life and death struggles of individuals, remarkable hope and favourable outcomes. There was little mention of the role of the placebo effect. Attention focused on rallies and fundraisers and pressure on politicians to embrace a potentially lifesaving therapy.

A year after the promise of "a cure in sight", an Ontario man had died and an Alberta man described the pain and fear he experienced while undergoing the procedure. Meanwhile, the scientist behind the research felt that initial reports had spiraled out of control, due largely to social media. 


\section{References:}

1. Chafe, R.; Born, Karen, B.; Slutsky, Arthur, S.; Laupaucis, A. (2011). The rise of people power. Nature, 472, 410-411.

2. Canadian Newspaper Association. Circulation Data Report 2009. Retrieved from: http://www.newspaperscanada.ca/sites/default/files/2009CirculationDataReport_3.pdf

3. Bureau of Broadcast Measurement. Retrieved from: http://www.bbm.ca

4. Schwitzer, G. (2000). Seven words you shouldn't use in medical news. Retrieved from: http://www.healthnewsreview.org/article2_7_words_not to_use.php

5. Favaro, A.; Thomson, B (2009, November 20). W5 to examine possible breakthrough MS treatment. [Broadcast transcript]. CTV NEWS W5. Retrieved from:

http://www.fpinfomart.ca/.

6. Favaro, A.; Laflamme, L. (2009, November 20). MS Treatment. [Broadcast transcript]. CTV NEWS. Retrieved from: http://www.fpinfomart.cal.

7. van Rijn, N. (2009, November 21). Researcher says surgery has cured MS patients. The Toronto Star, p. A26.

8. Picard, A.; Favaro, A. (2009, November 21). Weekend Special: A cure in sight. The Globe and Mail, p. A1.

9. Favaro, A.; Robertson, L.; (2009, November 21). The Liberation Treatment. [Broadcast transcript]. CTV NEWS W5. Retrieved from: http://www. fpinfomart.ca/.

10. Favaro, A.; Rinaldo, S.;. (2009, November 21). MS. [Broadcast transcript]. CTV NEWS W5. Retrieved from: http://www.fpinfomart.ca/.

11. Swain, D. Transcript. (2009, November 21). [Broadcast transcript]. CBC NEWS The National. Retrieved from: http:/www.fpinfomart.cal.

12. Favaro, A.; Robertson, L. (2009, November 23). MS Breakthrough. [Broadcast transcript]. CTV NEWS. Retrieved from: http://www.fpinfomart.cal.

13. Armstrong, J. (2009, December 16) UBC targets new way of looking at MS; University plans patient trials in hopes of building on potentially groundbreaking studies of Italian researcher Paolo Zamboni, The Globe and Mail. p A13

14. Ien, M.; Dworkin, B. (2009, December 29) 2009: Top Five Medical Breakthroughs. [Broadcast transcript]. CTV NEWS - Canada AM. Retrieved from: http://www.fpinfomart.ca/. 
15. MacIntrye, D., Swain, D; (2009, November 27). [Broadcast transcript]. CBC NEWS

- The National. Retrieved from: http://www.fpinfomart.ca/.

16. Crowe, K.; Mansbridge, P. (2009, December 15). [Broadcast transcript]. CBC NEWS - The National. Retrieved from: http://www.fpinfomart.ca/.

17. Blackwell, T. (2010, January 23). Cure vs. hype; Is new MS research the real thing, or a media-driven frenzy? National Post, p. Al.

18. Clark, T; Favaro, A. (2010, February 8). MS. [Broadcast transcript]. CTV NEWS. Retrieved from: http://www.fpinfomart.ca/.

19. Clark, T.; Favaro, A. (2010, February 10). MS. [Broadcast transcript]. CTV NEWS. Retrieved from: http://www.fpinfomart.ca/.

20. Alphonso, C. (2010, February 9). Hamilton researchers to test Italian scientist's MS theory; Idea that MS is a treatable vascular disease has been controversial. The Globe and Mail, p. A4.

21. Alphonso, C. (2010, February 11). Second MS study finds high rate of blocked veins; Buffalo scientists call work promising. The Globe and Mail, p. A6.

22. Blackwell, T. (2010, February 9). Test theory, but treat MS patients, doctor says. National Post, p. Al.

23. Blackwell, T. (2010, February 11). Research casts doubt on new MS theory. National Post, p. Al.

24. Duncombe, L.; Lang, A. (2010, March 18). [Broadcast transcript]. CBC NEWS The National. Retrieved from: http://www.fpinfomart.cal.

25. Weeks, C. (2010, March 29). Study may have treatment implications. The Globe and Mail, p. L1.

26. Crowe, K.; Mansbridge, P. (2010, April 12). Ginger's last hope. [Broadcast transcript]. CBC NEWS - The National. Retrieved from: http://www. fpinfomart.ca/.

27. Alphonso, C. (2010, April 14). MS patient has 'energy to burn' after Zamboni treatment. The Globe and Mail, p. A10.

28. Weeks, C. (2010, April 15). Doctors behind new MS theory urge more testing. The Globe and Mail, p. A7.

29. Blackwell, T. (2010, April 15). MDs warn against MS treatment; Blocked vein theory. National Post, p. A4. 
30. Favaro, A.; Clark, T. (2010, April 14). MS. [Broadcast transcript]. CTV NEWS. Retrieved from: http://www.fpinfomart.ca/.

31. Agrell, S. (2010, April 29). Legal fears thwart doctor's bid for 'liberation' from MS pain. The Globe and Mail, p. A1.

32. Boesveld, S. (2010, June 5). Controversial theory creating bitter MS Society elections. The Globe and Mail, p. A8.

33. Lord, R.; Gill, R. (2010, May 5). Surgical Roadblock. [Broadcast transcript]. Globe National. Retrieved from: http://www.fpinfomart.ca/.

34. Wente, M. (2010, July 29). Explosive politics of MS. The Globe and Mail, p. A13.

35. Alphonso, C. (2010, August 4). Studies cast doubt on hotly debated MS treatment. The Globe and Mail, p. A1

36. Editorial. (2010, September 3). Don't put this idea on ice. The Globe and Mail, p. A14.

37. Editorial. (2010 September 2). Prudent steps on MS surgery. Toronto Star, p. A22.

38. Blackwell, T. (2010, September 1). Little proof to back MS procedure, agency says; Call for more study leaves critics 'dumbfounded'. National Post, p. A4.

39. Laflamme, L. (2010, September 1). MS. [Broadcast transcript]. CTV NEWS. Retrieved from: http://www.fpinfomart.ca/.

40. Picard, A. (2010, September 16). Note to health minsters: Stop micromanaging. The Globe and Mail, p. L1.

41. Smith, J.; Ogilvie, M. (2010, September 25). MS doctors attacked for their skepticism; Neurologists stunned by backlash from patients furious with them for advising caution on new therapy. Toronto Star, p. A1.

42. Smith, J. (2010, September 21). MS patients take the fight to Ottawa. Toronto Star, p. A4.

43. Crowe, K. (2010, November 18). Seeking a Miracle. [Broadcast transcript]. CBC NEWS - The National. Retrieved from: http:/www.fpinfomart.ca/.

44. Crowe, K.; Swain, D.; (2010, November 18). Ontario man dies after MS vein opening procedure. [Broadcast transcript]. CBC NEWS - The National. Retrieved from:

http://www.fpinfomart.ca/. 
45. Favaro, A.; Laflamme, L.; (2010, November 19). MS Treatment. [Broadcast transcript]. CTV NEWS. Retrieved from: http://www.fpinfomart.ca/.

46. Goomansingh, C.; Jarvis, C. (2010, November 19). [Broadcast transcript]. Globe National. Retrieved from: http://www. fpinfomart.ca/.

47. Allen, K. (2010, November 19) MS patient dies in quest for 'magic cure'; Niagara Falls man had controversial vein surgery in Costa Rica. Toronto Star, p. A1.

48. Fitzpatrick, M. Postmedia News. ( 2010, November 20). Don't fall for overseas MS cure: Minister. National Post, p. A11.

49. Alphonso, C. (2010, November 20). Death of MS patient fuels debate over new treatment. The Globe and Mail, p. A4.

50. Takacs, M. (2010, November 21). Man regrets having MS therapy: I felt like I was dying, really. Toronto Star, p. A8.

51. Allen, K. (2010, November 22). Hype around cure for MS proves deadly; Liberation therapy creator says treatment 'a work in progress'. Toronto Star, p. A13.

52. Agrell, S. (2010, November 24). Father of 'liberation' treatment calls on Ottawa to step in and help MS sufferers. The Globe and Mail, p. A1.

53. Picard, A. (2010, November 20). Tragic case proves medical truth: There are no free passes. (Column) The Globe and Mail, p. A4.

54. Crowe, K.; Lang, A. (2010, December 29). Top health story of 2010: the controversial MS 'liberation therapy'. [Broadcast transcript]. CBC NEWS - The National. Retrieved from: http://www.fpinfomart.ca/. 


\section{Chapter 4: Researchers respond to Zamboni therapy and media interest}

The response of MS research leaders to media coverage of Dr. Zamboni's CCSVI hypothesis will be the focus of this chapter. In general, there was widespread skepticism in the medical and scientific community and concern about how the media reported on Dr. Zamboni's work. Medical leaders believe news coverage had a substantial impact on patients, families and the physicians who treat people with MS. Upcoming chapters will provide the perspective of journalists who covered the story and people living with MS.

Months before the initial CTV report, MS specialist Dr. Mark Freedman said he was contacted by a reporter from CTV's W5 and asked for his opinion on Dr. Zamboni's research. He indicated that he felt the Italian physician did not have a solid hypothesis. [1] Dr. Paul O'Connor, Director of the Multiple Sclerosis Clinic and MS Research at St. Michael's Hospital in Toronto and National Scientific and Clinical Adviser to MS Society of Canada, said he too warned the reporter about the pitfalls of Dr. Zamboni's work, but his concerns were disregarded. [2] (In Chapter 5, Globe and Mail journalist André Picard discusses how CTV did, in fact, interview some MS experts but chose not to use their comments because they added nothing.)

\section{Alerted by the media}

Before the story about the CCSVI theory made headlines, both MS specialists said they received a heads-up from the CTV reporter, indicating a major feature on Dr. Zamboni was going to air on W5. Both said they were not asked for an interview. At the time of the W5 broadcast, Dr. Freedman was at a medical conference in Portugal, where 
Zamboni was a presenter. "And I am getting email messages from (the reporter) telling me that, by the way, we're going to be doing a whole W5 on this and it is appearing on Saturday with a companion story in the Globe," Dr. Freedman said. "And I said (to the reporter), I've seen the guy here. I've seen his data. He can't answer my questions. This is very premature to release the story in this way. And she said 'well I'm doing it anyway."”

Months before the story broke, Dr. O'Connor said he was contacted by the same CTV reporter to convey that she was investigating the Zamboni research. "I said 'be careful this stuff is very unproven' and then she went over to Italy with her camera crew, she did a story and she did not contact me after that. But she did say to me in an email at one point that she was going to be doing the story." Dr. O'Connor said at no time did CTV ask for him to comment, despite the fact the reporter "has on many occasions in the past, when a new MS treatment would come along, would get the input of Canadian MS experts and they would be interviewed on camera to present some context and balance for the news. But this time she did not ask for any Canadian expert input into her W5 story. So it was all about how wonderful this is."

In Calgary, vascular neurologist Dr. Michael Hill was surprised by the first CTV news reports on Dr. Zamboni's work. [3] "You had very low-quality research from this guy in Italy. Methodologically, very low quality. It was even amazing that it was published in JNNP (Journal of Neurology Neurosurgery and Psychiatry) where it was. Coming out saying that he had found a cure." Dr. Hill also indicated that none of his colleagues were invited to comment on TV. And, as indicated earlier, stem cell researcher Dr. Harry Atkins, who had been interviewed extensively about his research into MS as an 
autoimmune disorder, was not asked to comment on how the disease could have a vascular origin when earlier news reports had described a different hypothesis for the cause of the disease. [4]

The intensive coverage of Dr. Zamboni's research by CTV's W5 resulted in the issue receiving much more attention in Canada than in other countries, said health policy research expert Dr. Andreas Laupacis of the University of Toronto, who has done extensive research on this topic. [5]

\section{Concern about the approach}

The five physicians interviewed for this study expressed concerns about agendasetting, priming and framing of the initial news stories, as well as the explosive amplifying impact of social media on the story. A full discussion of the role of social media will be the focus of Chapter 8 .

From the perspective of Drs Freedman and O'Connor, agenda-setting by the media - what they saw as the selection and positioning of a research story with limited credibility - was irresponsible. In the lead-up to the initial CTV report, the audience was primed to believe that a revolutionary discovery was to be announced. The story was framed as a major breakthrough, a stunning discovery that could change the lives of thousands of Canadians. People were encouraged to learn more. MS specialists said this positioning made it especially exciting for people living with a very difficult illness.

"It was promoted in a way that this is the cure and there are no downsides. If I heard that, as someone not involved in medicine, I would wonder why are we hesitating if there is no downside. It might make me better," Dr. Atkins, the stem cell researcher, 
said. "Why shouldn't we go ahead with it? But you know, . . . anybody in medicine knows that there are no benign interventions. They always have a risk. And the benefits were probably overstated." What initially struck him was lack of balance in news reports.

Dr. O'Connor said he thought the Nov. 21, 2009 W5 television report was completely one-sided and that "The Globe and Mail article was a disgrace for a newspaper which considers itself the newspaper of record in this country to write such a biased and cheerleading piece on an unproven treatment for MS."

"It's a free country. A joumalist can do any story they want - no problem, do whatever story you like - but just try to have some balance. That's all," Dr. O'Connor said in an interview. He believes coverage of the issue was better in the National Post and Toronto Star.

Dr. Hill agreed "the story (in The Globe and Mail) was incredibly poorly written, very biased, uncritical so the quality of the reporting is very poor ... but my view is that if the quality of reporting in general is anything as bad as medical reporting then you shouldn't even bother reading the newspaper."

\section{Missine voices}

The major problem with initial news stories was the missing voices of Canadian MS specialists and the MS Society of Canada, Dr. Andreas Laupacis said in an interview. He called the original television feature on the therapy "an embarrassment."

"I think they really should have done a better job - particularly the W5 story - of getting some real live docs who look after patients with MS to actually on camera indicate their concerns so that it came across that these docs aren't hard-feeling sons of 
bitches, that they're actually people who genuinely care for their patients and they're genuinely worried that the science isn't there yet," Dr. Laupacis said. "You know, you might disagree with them but just to give it more balance."

Dr. Laupacis has analyzed the reaction to publicity around Dr. Zamboni's research hypothesis and feels initial framing of the story was "phenomenally biased in favour of this being something innovative." It is unclear why no one from the MS Society appeared on camera in the television documentary. The W5 report simply described the society's position. (It questioned the quality of the science and raised the need for further evaluation.) Dr. Laupacis said this made the MS Society seem unfeeling and bureaucratic. "So I thought the W5 program was awful journalism." While he doesn't rule out the fact that Dr. Zamboni's research might be found to have some merit, Dr. Laupacis said "I do think the claims and the hype about it have gone way out of proportionality to what reality is likely to be."

The whole story provides an interesting case study of what happens when science and emotions run amok, Dr. Atkins argued. "Part of the problem is that there has been no balance in presenting the dissenting view. And what is really interesting is that while there are these groups saying the doctors are self-interested, pharmaceutical companies are self-interested, in the meantime there are all these physician groups in different parts of the world that are now in business doing this stuff and are very willing to take people."

He believes that the issue has evolved into a religion where people are either for or against CCSVI and 'there is this divide opening up and it's hard to change ideas or talk rationally about ideas when there is an emotional overlay involved in it." Asked if any of his patients regretted their involvement in his arduous stem-cell trial when a 
simpler, less invasive treatment was described as a potential cure for MS, Dr. Atkins said no. "In fact, most of the patients in our trial are somewhat upset because they see that they have really benefited from the stem cell transplant and it is not being seen in the same way as the CCSVI," he said. "And they have been a little in your face about wanting to get the news out there about the stem cell trial. To me, it's not a competition. To me, it's about applying the appropriate treatment to the right patient so I know that not every MS patient would benefit from a transplant."

In an editorial in the Canadian Medical Association Journal [6], Dr. Paul Hebert and Dr. Matthew Stanbrook also argued the situation had become overheated. "Do we want hopeful media reports, special interest groups and political opportunism to decide which treatments we should study, provide and insure? . . . Good health policy decisions should not be based on hope and desperation."

\section{Impact on physicians}

The impact of media coverage on physicians who treat MS has been profound and MS specialists interviewed said they consider the patient response to media reports directly attributable to early framing of the issue and priming of patients to view the therapy as a breakthrough.

"There was a tidal wave of phone calls and emails the following week from patients begging, imploring, demanding - whatever word you want to use, depending on the patient - to be allowed access to vein assessment and vein treatment," Dr. O'Connor said. "Huge, huge interest. Understandably, right? The cure for MS is finally here. So it was a very difficult week for anyone who takes care of MS patients because you had a 
huge surge of messages ... and on the other hand you had to play the role of spoiler, pouring cold water on these reborn hopes of patients. It was very, very difficult. And ever since then, not a day has gone by when I have seen patients that I haven't spent a good part of the day talking about CCSVI." He said none of his U.S. colleagues, where Dr. Zamboni has received limited attention, saw anything like it. (The first story on the topic in a major U.S. newspaper was in the New York Times on June 29, 2010. Coverage has been scant since. The article by science reporter Denise Grady described how the jury was still out on the treatment.) [7]

Dr. Freedman had a similar experience to that of Dr. O'Connor after news spread about Dr. Zamboni's research. "Everyone went crazy. There were people stopping their drugs. They wanted to know where they could get this done." When he saw the initial news reports, "I said it was over. I kept all the emails back and forth with (the reporter). And there's even one email I flagged from her and I said 'when all this blows over and it turns out to be bunk, are you going to stand up to Canadians and tell them that you made a mistake?' And she said yes."

\section{Follow the money}

While they were being vilified by patients for dismissing the therapy and accused of being in the pocket of the pharmaceutical industry, MS physicians say reporters failed to ask who was really profiting from promotion of the CCSVI procedure. Dr. Zamboni holds a patent on the diagnostic ultrasound Doppler microphone and stood to cash in, Dr. O'Connor said. (The 2008 patent application is available for online viewing at http://www.freepatentsonline.com/y201 1/0009749.html.) 
Physicians in other countries began offering the treatment, even to people with an unconfirmed diagnosis of MS, and making massive amounts of money. There was virtually no media coverage of this fact. "Nobody asks for medical records. Nobody asks for referrals from their neurologists. They don't even care if you have MS. All they care is whether your VISA card can carry the cost of the procedures," Dr. Freedman said.

The Ottawa MS specialist said vascular surgeons in Poland barely earned $\$ 100,000$ a year before the Zamboni procedure, and now they're laughing all the way to the bank. "They're charging $\$ 10,000$ a pop and doing six a day, five days a week," Dr. Freedman said. "They're making $\$ 300,000$ a week. A million bucks a month. If this goes on for a year or two, they retire." He points to the fact that many websites about MS feature medical tourism packages offering the procedure, an angle that hasn't been covered by news media.

Dr. Hill agrees that physicians in other countries are definitely cashing in. He says he has a patient who went abroad to have her veins opened before even being diagnosed with MS. "I mean, that tells you a couple of things. That tells you the kind of impact that some of the testimonial type of evidence has had on some people and their decisionmaking. It also tells you how poor the physicians are and how ridiculous they are in terms of doing this procedure. They're not even trying to confirm a diagnosis of MS. They don't even care. For 20,000 bucks if you want to have your veins angioplastied, bring it on, I'll do it for you. So, it's one of those amazing, amazing things."

As of February 2011, Dr. O'Connor had treated about 40 patients who had the procedure outside of Canada "although many patients say they feel better - they have less 
fatigue for example - it's also clear whatever disability they had before they went paralysis, loss of balance - hasn't changed much, if at all, despite the procedure."

A number of Dr. Freedman's patients have travelled abroad for treatment and he feels the results have been unremarkable. "I say, take your $\$ 10,000$ and go to one of these spas where they can give you therapy for two weeks and work on you and you will get more from that in those two weeks that will sustain you than having your veins unplugged."

Physicians are concerned about the toll that false hope has on MS patients. "A lot of these people can ill afford to spend $\$ 20,000$ of their savings to have something done which could potentially kill them," said Dr. Hill. Medical specialists are also concerned because the patients who travel abroad receive virtually no follow-up care from the physician who performed the procedure. People are treated and put on a plane to return home, which is why complication rates appear low in foreign clinics. The complications don't happen until people return to Canada - and Canadian physicians are left to deal with the fallout.

\section{Accountability needed}

Dr. Freedman wants people who have suffered as a result of CCSVI treatments, who have mortgaged their homes for procedures, who've stopped their drugs and had setbacks and who have developed complications from travelling abroad, to launch a massive lawsuit against the media for its coverage of the therapy.

Even when it was reported that Mahir Mostic of Ontario died after receiving CCSVI treatment in Costa Rica, some reporters spun the story to make it look like 
Canadian physicians were to blame for failing to provide follow-up care, Dr. Freedman said. In reality, Canadian physicians didn't want to touch Mr. Mostic's blocked vein because it would put him at greater risk, he said. "Veins have a way of getting around obstructions. Leave it alone." The patient did not listen to his doctors, returned to Costa Rica with the goal of getting his vein unplugged, and bled to death. "Why didn't (reporters) tell us that? Instead, (it was reported that) he couldn't get care here. Doctors denied him. Bad doctors."

Dr. O'Connor agrees that journalists were "trying to make the doctors look bad, talking about the denial of treatment of patients, and that is actually nonsense. As I say, I've seen over 40 patients who've had that procedure done and I tell all of my patients, as I am sure other neurologists do, if you get that procedure done, it's up to you, but keep in touch I want to see you for follow-up. And they come." Neurologists are more than willing to treat their patients and don't want to punish them for getting the procedure, he said.

\section{Inaccessibility}

Part of what may have been driving outrage towards physicians is the fact that Canadians were completely blocked from getting the procedure in their own country, Dr. Laupacis said. In the U.S., for example, although private insurance companies were unlikely to cover it, people had the option of going to a clinic and paying for treatment. "Here, though, you have to leave the country, it costs a lot of money - and I think more and more people are just going across the border to Buffalo and Albany - but, early on, people were travelling to Poland and Romania and India and Mexico and it's just a much, 
much bigger deal because there's not the option if you wanted to pay for it to get it done here."

\section{Assigning blame}

While physicians are quick to point fingers at early glowing media coverage of the therapy, they said all blame cannot be laid on just a couple of media outlets. "I mean you had hoped that a sensible, careful media coverage of the subsequent stories would have started to ask the kinds of questions that should have been asked," Dr. Laupacis said. "So to blame W5 and (The Globe and Mail) for relatively uncritical coverage for six months, I think it is not just their fault it is probably the rest of the media's as well."

\section{Conclusion}

Although this chapter provides a small sample of a select group of MS specialists, including at least one of the most vocal opponents of the therapy and surrounding media coverage, it serves to highlight some of the issues expressed by the neurologists and the Canadian MS research community about Dr. Zamboni's hypothesis. While neurologists are generally skeptical about the research, some Canadian physicians, including Barrie, Ontario, vascular specialist Dr. Sandy McDonald, support further investigation of Dr. Zamboni's work. [8] Biomedical imaging expert Mark Haacke, PhD, of McMaster University, was also an early advocate for more research into the vascular link to MS. [9] Vocal supporters of federal funding for research include Liberal members of Parliament Dr. Carolyn Bennett, a family physician, and Kirsty Duncan, who has her $\mathrm{PhD}$ in medical geography. [10] 
As this chapter describes, physicians who treat MS felt early stories did not provide balance. In particular, the first reports on CTV's W5 and in The Globe and Mail did not include comments or on-camera interviews from MS neurologists, even though two of the individuals interviewed for this chapter indicated they told the CTV reporter that Dr. Zamboni's science was questionable. The first report on W5 also failed to include an on-camera interview with someone from the MS Society, although CBC's The National contacted Dr. O'Connor, scientific adviser to the MS Society, to provide expert comment when the story broke. News stories got more balanced over time.

Media coverage created a great deal of excitement and anxiety in people with MS, according to their physicians. When MS specialists expressed skepticism over the news reports, they experienced a backlash from patients, who had not heard their side of the story on W5 or in The Globe and Mail report. Physicians have been upset to see their patients spending money and travelling far from home to receive a largely untested and unproven treatment.

From the physicians' perspective, they felt news media failed to ask the tough questions around the Zamboni treatment: Was the procedure properly tested using scientific methods? How does this hypothesis make sense in the context of other research about MS? Who in the medical community was hyping the story and why? Who is profiting from medical tourism and how much are they making? Are foreign physicians properly screening patients for MS? Are they treating some people without a diagnosis of MS? What kinds of complications have arisen and how many?

Instead, messages of hope, promise and cure permeated the news of Dr. Zamboni's CCSVI hypothesis and left MS specialists facing major challenges. 


\section{References}

1. Freedman, M. Personal interview. January 31, 2011

2. O'Connor, P. Personal interview. February 11, 2011.

3. Hill, M. Personal interview. February 13, 2011.

4. Atkins, H. Personal interview. March 2, 2011.

5. Laupacis, A. Personal interview. June 29, 2011.

6. Stanbrook, M.B., Hebert, P.C. (2010) Access to treatment for multiple sclerosis must be based on science, not hope. Canadian Medical Association Journal, 182(11), 1151.

7. Grady, D. (2010, June 29). From M.S. Patients, Outcry for Surgery. The New York Times, Science Section, p. 1.

8. McDonald, S. (2010, May 11). Address to the Subcommittee on Neurological Disease of the Standing Committee on Health. Retrieved from:

http://www.parl.gc.ca/HousePublications/Publication. aspx?DocId=4519570\&Language= E\&Mode $=1 \&$ Parl $=40 \&$ Ses $=3$.

9. Haacke, M. ( 2010, Oct. 4). Google TechTalk. [YouTube video]. Breakthroughs in Imaging Neurovascular Diseases." Retrieved from: http://www.youtube.com/watch?v=lqDrvNC7Oi8

10, Bennett, C.; Duncan, K. (2010, May 6). Letter to Minister of Health Leona Aglukkaq. Retrieved from: http://carolynbennett.liberal.ca/blog/letter-to-the-minister-of-healthregarding-ms-and-ccsvi/ 


\section{Chapter 5: The journalists' perspective}

Health reporters who played the largest role in news coverage for each organization were contacted to provide their perspective. Six journalists were sent the interview questions in advance and informed that they could decline to answer any of the questions, stop the interview at any time or request anonymity. Reporters were informed that if they chose to participate in this research study, telephone interviews would be recorded and transcribed. Of the six journalists identified and contacted to participate, five agreed. The sixth was not permitted to take part due to employers' concerns. "I must have their clearance... I have many insights but I guess they will be on hold until the scientific debate is settled." [1]

Reporters who participated in this research include André Picard [2] of The Globe and Mail, who has worked on the paper's health beat for 24 years; Tom Blackwell [3] of the National Post, who has been the Post's health reporter for six years; Joanna Smith [4] of the Toronto Star, who has been on the health beat for two years; Kelly Crowe [5] of CBC television news, who has covered science and health for about a decade but officially worked the CBC health beat for two years; and Crystal Goomansingh [6] of Global TV News, a general assignment reporter who has covered two maternity leave replacements for the health reporter at Global News during recent years.

Each reporter was asked the following questions:

- Do you usually cover health or science stories? If so, how long have you been covering medical news? If not, how much reporting have you done on medical issues? Do you have any specialized training in science, medicine or health? Have you taken any journalism courses on health or science reporting?

- What are the most likely sources for your stories? Tips? Press releases? Medical journals? Social media? Other? 
- If you find stories in medical journals, do you select story ideas based on the reputation and circulation of the journal? The subject matter and relevance to your audience? The reputation of the researchers?

- If you use social media, how do you use it? To track new story ideas, find spokespeople, gauge interest in particular research topics? What tools do you use: blogs, Facebook sites, Twitter, etc?

- Are you more likely to report on new and unusual research findings if they have been flagged by a press release? Do press releases help you hone in on the salient findings in research articles and point you to the best sources? If yes, how? If not, what are the limitations?

- Prior to reporting on Dr. Zamboni's CCSVI theory, have you reported on treatments for multiple sclerosis?

- In general, aside from your own reporting on the topic, do you feel that news coverage of Zamboni's experimental medical procedure for MS was fair and balanced? If not, why not?

- The strong demand by MS patients for Zamboni's procedure has been attributed to media coverage. What are your thoughts on the public reaction to the story?

- How did you rely on the medical community to write your stories?

- Was the MS Society helpful in providing background, comments and sources for your stories?

- Did you ever ask if there were any corporate interests or consider a hidden agenda behind promotion of the new therapy?

- Do you feel that lessons can be learned from the way in which this story was covered?

\section{About the reporters}

Three of the five reporters - Picard, Blackwell and Crowe - have journalism degrees from Carleton University. Smith is a graduate of the Concordia University journalism program. Goomansingh studied journalism at Red River College in Winnipeg. Health reporters at The Globe and Mail, National Post, and CBC have received specialized training in the field, most notably a science journalism course offered jointly by Harvard University and the Massachusetts Institute of Technology through the Knight Foundation. Crowe said she has done several fellowships. Picard indicated that he has also taken courses offered by the National Institutes of Health in the U.S. and the Canadian 
Institutes of Health Information, among others. Of the five reporters interviewed, Picard has spent the most time on the beat and had the most specialized training.

Before the story first appeared on CTV's W5 and in The Globe and Mail about Dr. Paolo Zamboni's MS research, multiple sclerosis was not a hot health news topic. Crowe, Blackwell, Goomansingh and Smith said they had done fairly limited or no coverage of health news in the MS field, while Picard said "there's lots of action in that field and I would say I have covered it a fair bit."

\section{Finding story ideas}

The hook for the original story about Zamboni's hypothesis on blocked veins and MS was an article in the Journal of Neurology, Neurosurgery and Psychiatry. As indicated in Chapter 1, media research indicates that journals are a major source of story ideas for health reporters.

When asked about how he finds ideas for health stories, Picard said coverage is driven by medical journals because they vet and peer review the research. He looks for Canadian content and audience appeal when selecting stories. For his part, the Post's Blackwell leaves the medical journals to wire service reporters. While reputation of the journal is a big factor in story selection for some reporters, it isn't for others. It was, after all, the esteemed journal The Lancet that published a now discredited research article on the link between vaccines and autism, Goomansingh said. "So you can't just go by the reputation of the journal." The Star's Smith, on the other hand, said journal reputation is important. "I very rarely write about medical journals but ... if it's not CMAJ (Canadian Medical Association Journal) or The Lancet or JAMA (Journal of the 
American Medical Association), then I'm not even looking at it." CBC's Crowe also considers the reputation of the journal in story selection. "The Lancet, Nature, Science, some of the big journals, they have added weight - if not for me, for my assignment editors, so they would get more coverage in the media broadly."

While Goomansingh lists journals, medical websites and medical news sites among her sources of story ideas, CBC's Crowe said she sifts through a barrage of information from news releases, tips and medical journals. She says the volume of material sent to health reporters is overwhelming.

"What's happening in health and science journalism is there is just this incredible interest, a convergence of two factors. There is this incredible appetite and interest from the editors who line up the show and from the audience. At the same time, there is this volume of material being offered by all the journals and universities and research institutes, who just seem to be suddenly - I suppose it's not sudden, it has been evolving over time but it seems that it has just reached a fevered pitch - where they want coverage and they are always throwing experts and stories and studies at us ... Between the two pressures, we are just running to catch up all the time so it's no problem finding stories. In fact, the problem is trying to cover everything that we could do. We could do a dozen stories a day, easy, on these subjects."

Adding to the pressure of health reporting is the reluctance of researchers to talk to reporters in advance of publication of their work and the blockade of media specialists who control the flow of information between scientists and journalists, Crowe said. "There is this whole network of media people who represent the institution so it is very complicated now calling a scientist cold without having to go through a media relations person."

Blackwell, the only dedicated health reporter at the Post, sniffs out stories using a variety of sources, including news tips, decisions from courts and administrative tribunals and conference agendas. Smith, one of several health reporters at the Toronto Star, focuses on the intersection of government, health news and policy. She doesn't delve into 
a health story until it has already become an issue. Story ideas come from personal curiosity, reading other coverage and tips from sources.

Health reporters use social media - online technology tools that allow people to communicate easily - to track stories and to find people to interview on specific topics. Facebook and Twitter are used to listen to chatter, determine what people are paying attention to, and to find people who are more passionate, more involved and more connected to certain issues. In covering the Zamboni story, blogs and Facebook sites helped reporters identify patients who were seeking treatment, and to locate people with good or bad medical outcomes, Crowe said. Reporters said they sometimes rely on press releases to highlight research findings from scientific journals, especially to pull out contacts.

\section{Framing and balance}

With the exception of Picard and Goomansingh, health reporters had concerns about the framing of the first stories about Zamboni and his MS hypothesis - specifically those produced by CTV News and W5.

The Post's Blackwell said initial stories were anything but balanced. "They basically focused on the positives or potential positives and didn't really explore the shortcomings of the research or the doubts that many experts were expressing." Blackwell said journalists have to be careful about covering this kind of story. "It's very easy on this beat to either scare people or to give them great hope. . .In this case, some of that really positive, somewhat unquestioning coverage I think fed into this feeling amongst a lot of patients that 'this was it' - this was the great breakthrough that they had 
been waiting for. I think it really illustrates the pitfalls of less than thorough coverage of this kind of issue." In fact, Blackwell said he believes the two news organizations that broke the Zamboni story put a positive spin on news reports for about the first year before coverage became more tempered.

Crowe agrees that early coverage was controversial, a little bit excited and raised "people's hopes and expectations in kind of a heartbreaking way because science doesn't work that way." She said it is unlikely anyone will ever open a newspaper and read about the cure for a disease. "I think it was overly optimistic and possibly didn't have enough measured, sober second thought in it."

The Star's Smith used the word "breathless" to describe the packaging of the early news reports on Dr. Zamboni's research. "It was presented as a cure essentially. You know, I watched that (W5) report in full ... and I found it was presented in such a way that this was really going to be some amazing thing and it was so unproven ... I really think that played a big role in people getting maybe a little bit too excited and then disappointed when things weren't moving as quickly as they had hoped."

Goomansingh said that there were obvious questions about the research but she believes reporters tried to provide balance. "I think those efforts were made. Do I think they succeeded and everyone listened to both sides in the stories? I don't know. I hope so."

However, Picard, who co-authored the initial Globe story with CTV reporter Avis Favaro, believes "when all is said and done, I think the stuff was fairly even." However, he concedes the first front-page headline on Nov. 21, 2009 was overstated. "It's one of the banes of our existence - the headlines. The single biggest problem I ever have in my 
article is when the headline is misleading or exaggerated. I personally tell people I never use the ' $c$ ' word so I think if that word cure was in the story it was in a quote with a question mark behind it. So I am careful to try to never use that word cure. What have we ever cured? Smallpox? The list is pretty short. It's about one."

\section{Many factors at play}

Picard said a lot of variables came into play to make this story explode. Among them he lists desperation in the MS community, the lack of effective treatments for the disease, the relative youth of people who develop the disease, the role of social media in spreading the news, the timing of the story and how the stories were played.

For the initial page 1 story in The Globe and Mail, describing the 'breakthrough' treatment, Picard said the story really belonged to his colleague at CTV. "I just tagged on because we're the same company. So sometimes we do that where we just share stuff. . I was almost a typist in this." Picard said he took the CTV material and rewrote it for a print audience. "She had a wealth of material, a ton of material and I just sort of put it together."

Asked why the story seemed to generate so much more interest in Canada than elsewhere in the world, Picard said, "CTV has a lot of viewers. The Globe has a lot of readers. And we have more MS patients than anywhere else in the world. There are all kinds of reasons for it. And we have a very active MS community and l'd say a very divided one. So I think there are all these factors that played into it." 


\section{Caution required}

Health journalists acknowledged that a great deal of care is required in the reporting of stories on their beat. The CBC's Crowe said she tries to avoid errors and overplaying research findings by sending her stories to trusted expert sources for fact checking. "I always flip it out to a couple of other people to tell me if this is a big deal, or if I'm missing something and point out weaknesses in the study and that sort of thing, which is huge. I don't always interview them on camera but I almost always have that in my background notes."

Blackwell also exercises caution in writing about new therapies. "I generally don't write about news around new treatments that come on the market or are about to come on the market," he said. "As a health reporter, you are inundated with news releases by drug companies and the like about trial results for this or that drug ... Usually the press release will come complete with the doctor you can interview and the patient you can interview - sort of like a ready-made story."

As a rule, Blackwell says he doesn't do stories about new therapies because to do these stories properly requires in-depth research to put the development in the context of treatments already on the market. "It's also that, over the last several years, there has been one case after another where the drug has gone on the market and a year or two or three down the road, once it's gotten used more widely in a more typical patient population, you find there are often serious side-effects involved in it," Blackwell said. As a result, "there is little benefit in doing that kind of story early on and definitely pitfalls because you could be promoting something that is not of great benefit or that could be harmful." 
In terms of the Zamboni research, Blackwell said the research was preliminary. "And there were aspects to the story that would, to me, raise red flags: You had the physician who was essentially treating his own wife, which in Canada is considered unethical. The term (liberation therapy) that was used to describe it. The way that he was essentially kind of promoting these ideas when the evidence was very preliminary at best. All those things I think would cry out for you to take a skeptical approach."

That doesn't mean the story was not worth doing, he said, "and sometimes there is research being done on the peripheries of the medical research system that might not get the attention it deserves and media reporting might be what's needed to get the scientific community more interested. But, again, if you are going to do that, you have to take a hardnosed, skeptical look at it - not just sort of play it up as something that's sort of close to a cure that's been proven."

\section{The role of social media}

While reporters were not surprised by the public reaction to the story - especially because the therapy was framed as a potential cure - they were surprised by the evolution of the story, and how it was magnified and pushed by social media. "I think we learned a lot from this story. I think what we saw more than the power of media - the mainstream media has always had a fair bit of power - but I think what we saw was the ability of social media to really magnify things," Picard said. "You know, take one part of a story and really blow it up, just magnify it beyond what we ever imagined. I don't think we've seen it to that extent before." Picard said he has written hundreds if not thousands of health stories and "I have never seen something take on a life of its own like this one. ... 
I never thought this would be much of a story to be honest.... The only thing that was different was the reaction and that's not particularly in our control." He said journalists don't know how to deal with this magnifying effect.

The Star's Smith saw how her stories "spread like wildfire through social media." Social media helped people organize rallies, share information about clinics and medical tourism. Crowe believes mainstream media changed the trajectory of Dr. Zamboni's scientific research - and social media further pushed the cause. Without media coverage, she said the research would have followed a normal course - further research, testing of the hypothesis, refinement of research protocols, attempts to duplicate results and then standardization of treatments before clinical trials. "In this case, it went crazy and the social media allowed patients to set up for the first time completely original contact networks," Crowe said. "So it took off. I have never seen anything like it."

The role of social media in pushing media coverage of the Zamboni research is a prime case study of a growing phenomenon called participatory medicine, where patient groups are on top of the latest research and findings in a particular field in order to influence their care, Blackwell said. Further discussion of the role of social media will take place in Chapter 8 .

\section{Medical community}

Picard said his main frustration was that the medical community in Canada didn't want to speak at the outset of news coverage "so I think that helped skew the story. I think it's a mistake for medical people, for researchers to refuse to talk. And they have 
this 'oh, you know, we don't want to give this credibility.' Well, if you don't give it credibility, you give it free rein, right?"

Told that members of the medical community have indicated that they were upset about not being able to provide their perspective, Picard said he doesn't believe that to be true. He saw the transcripts of all the interviews for the story and a lot of people were contacted for comments, but didn't say much. Crowe also said, in the beginning, reporters were a bit adrift because nobody in the medical community would speak out. "It took about six months or so before a couple of people emerged, sort of made it their business to get up to speed on this whole field. And they could offer helpful, balanced assessments of what it meant."

Part of the problem, reporters said, is that many people in the MS field have seen other promising cures come and go and they didn't want to be involved. "But I think the medical community was pretty open-minded," Crowe said. "It is still pretty open-minded about it. ... They are actually taking a serious, serious look at this procedure and that is probably because of patient pressure that was probably triggered by media coverage." When criticisms emerged from pro-Zamboni groups about potential conflict of interests involving neurologists and the pharmaceutical companies, Blackwell began to rely on other specialists - vascular surgeons and interventional radiologists - to provide greater balance to his news stories. Goomansingh said she didn't feel blocked by the medical community and Smith said she relied on physicians to provide comment and found them patient and generous with their time.

Because of the story's folktale quality, Canadian researchers were reluctant to be cast as the bad guys. "The researchers we interviewed were all very cautious about what 
they said," Picard said. "Despite what they say now, no one said "this is total lunacy and it will never work.' No one ever said anything of the sort. It's all great to have hindsight 20-20. I've had this discussion with many scientists."

\section{MS Society response}

Picard said the MS Society was not particularly helpful to him as he put together news stories. "I'm not sure that's their role. They provided some experts to comment but they are more of a consumer group. I don't think they have to be up on the latest news stuff and research. I think they were aware this was floating around on the Web - we just happened to put it together and put it in the mainstream media - but it was out there. That's what people forget. People were already talking about this. They were already getting the procedure and we just sort of brought it out into the public eye."

CBC's Crowe also found the MS Society less than helpful. "They just weren't engaged in it. It took them by surprise too so we just didn't really use them that much. . . . In the early days, they seemed to be overwhelmed." From her perspective, Smith of The Star said the MS Society was helpful but always very careful and measured in their comments. "I knew they were coming under a lot of attack from patients. And I had maybe hoped for a more human, nuanced response from them."

Goomansingh of Global TV thought the MS Society was a good resource. "They were always very useful. They would give me the information I was looking for." Blackwell of The Post said he didn't rely on the MS Society for his stories because he never really felt the need. 


\section{Corporate interests}

Picard dismissed concerns that the media had not focused enough attention on the corporate interests promoting the new therapy. "You know, you're not going to get rich selling a Doppler patent. Let me put it this way: If it was about a drug, if he (Zamboni) was thinking of developing a drug that could make billions of dollars that would have been much more of an issue. I didn't see this as having the danger of that corporate aspect to it too much. You know, what Zamboni had was he had a really compelling personal story. That's what made this story different from many others we wrote. You know, his wife and all that. It's all lovely," Picard said.

Smith disagreed, saying more could have been written about commercial interests. "But that is an untold story - these travel groups - and that is one thing I still hope to write about at some point," she said. Blackwell acknowledged journalists should have been asking questions earlier about who was profiting from the therapy. Goomansingh said reporters always need to follow the dollars, but probably didn't in this story. However, the limitations of television meant that there was very little opportunity to flesh out stories and pull in salient details, she said. "I think it was not as big a focal point in the stories as it should have been."

\section{Public response}

Picard said he is often asked about his role in the coverage of this story and people ask him if he feels bad for making such a fuss about the therapy. "I don't at all. I still contend if you go back and read the first story it was pretty fair. To me the biggest problem happened when people selectively took stuff out of my story and Avis 
(Favaro)'s story and said 'this is what The Globe said.' The Globe said that, but it said many other things. . . I've gone back several times and looked at that story because people criticize it and I don't think I'd change anything. I didn't write the headline. I'd certainly change that. “

Picard also said the CTV story was perfectly legitimate. "It was good TV," he said. "Did it exaggerate things? Of course. But we do that all the time in the media. We selectively write things. I think (the reporter) did a good piece. She's getting crapped on too much for it, so I will defend her because she won't defend herself."

Asked if the news media should feel in any way responsible for the hundreds or possibly thousands of people who have travelled from Canada to receive the therapy, Picard said the media were enablers, "but I don't think we wrote them plane tickets or sent them off or anything. . . I think we forget that people do this for all kinds of stuff." Picard said he has been around long enough to see people seek out novel and untested treatments. "I remember when hundreds of people used to go to Mexico for Laetrile treatments (for cancer) and that's been totally discredited. But this happens over and over again. Now it's just easier to find them because they post on their blogs and on their websites. . I guess the question is should we have written about this in the first place? I think so. I think it was legit, given the size of our MS community."

Picard argues that the majority of people with MS in Canada read the story and "had a perfectly sensible response which was 'oh, that is interesting. We will have to see how it pans out." Picard feels the same way about the therapy today as he did when he wrote the initial story, which is that it will probably work for a very small percentage of people with MS. "I've written about a lot of these things over the years and that's how 
they usually pan out. MS is a really complicated disease. It affects different people differently. My feeling was this is like a new heart treatment - it will tend to work for one very small microcosm of the entire community. And that's what I felt about this. I don't feel any differently now. We had some doubts about the whole biological plausibility. It was a bit dubious. Some people said that. I don't think they said it forcefully enough. Also we've written a lot of follow-up stories about this and some of them have been probably too critical. There's a swinging of the pendulum there."

Since initial coverage, The Globe and Mail has changed its approach. "I think there was a recognition that it was treated a little too softly," Picard said. "When people started speaking out and denouncing it, it's not like we refused to do that. We were happy to jump on that bandwagon as well. “

The Star's Smith said she was not surprised by public reaction to media coverage of the therapy because "the idea that this would be presented as something that would fix things really quickly, even if not forever, it's understandable people got very excited." The rallies, websites, letters to the editor and enormous public outpouring to the story "played into Dr. Zamboni's hands," Smith said. "This is someone who himself maybe didn't behave the same way as a researcher who was purely interested in advancing knowledge in a sort of peer-reviewed way would have acted. He was trying to create a lot of buzz around his own research ... because he didn't feel it was getting the attention it deserved." Smith said Dr. Zamboni has played a large role in portraying himself as a hero - "and a bit of a martyr as well I would say. So, no, it doesn't really surprise me that this narrative has built up around patients versus doctors and government versus patients and also science versus politics, as well." 
Blackwell said he was initially taken aback by the public response. "In retrospect, I can understand to a certain extent why this has happened in light of that initial media coverage. It probably was not the only factor but that W5 piece especially had a real impact. ... If you go back to that period - late 2009, early 2010 - everyone was talking about it (on online forums.) There are all kinds of websites that have links to that original W5 piece so I think that did have a major impact. Again, it may not have been the only thing that contributed to this patient reaction, but I think it was definitely a major factor."

Despite the logic and rigor of science, reporters indicated that they were affected by seeing the personal impact on individuals who received the therapy. Smith described the joy of a woman she followed into surgery in the U.S. who was feeling so much better. "No matter how many times you say this is experimental or Zamboni's findings were simply preliminary ... how do you balance that when you see a person walking, who says 'I haven't been able to do this in months or years?' " asked Goomansingh.

Crowe said journalists felt the brunt of public anger when they reported on findings that contradicted Dr. Zamboni's original work.

"When this came along as a simple, straightforward way to give these people hope, it just took off. So, yes, I was surprised and concerned in my own work about not fuelling that. You know, trying to keep it responsible, which wasn't easy because eventually the patients didn't want to hear anything that was negative. One story I did for the end of last year was talking about how the story had evolved essentially in real time over the course of a year from, originally, this sort of breakthrough idea to a death. ... It's a lot more complicated than it seems. The effectiveness doesn't seem to be persisting. .. It's not straightforward and patients are not happy about that. So, it's a shoot-themessenger sort of situation and we get a lot of letters from people who are complaining when we do stories."

And there is anger towards the medical community for failing to embrace a new idea,

Crowe said. Smith witnessed that when she covered a meeting of provincial health 
ministers, at which the therapy was discussed, and some of the physicians who spoke at the meeting were too nervous to talk to reporters on the record, prompting her to write a feature story on the public backlash towards the medical community.

\section{Lessons to learn}

Lessons can be learned from the way the story was covered, journalists said. "I just talked about this to a group of neurologists at a conference and I said we all can learn from it," Picard said. "I think scientists should learn to not keep quiet. I think journalists should learn to be a little bit more cautious with their approach, especially when things get magnified by the social media. I think we have to learn to be much more reactive much more quickly. So, again, we all have lessons to learn. The MS Society could learn stuff. They have to be a lot quicker off the draw too."

As for lessons, Blackwell feels this story "underlines the influence and power that the media have in covering health issues and the impact that our stories can have, especially on patients. I think it shows you really have to be responsible and balanced and explore all facets of the story." He calls it a great case study on why health reporters have to be cautious. "It's an inherently dramatic beat and I don't think you have to over-do it to write compelling stories so there are lots of reasons not to over-do it as this story shows." Goomansingh said the story illustrates why health reporting needs more context, something that is difficult to provide in television news. Smith said media coverage of the Zamboni theory proves that medical reporters need to always take a step back, read the research and try to check information in many different places. 
Asked if there were lessons for the media to learn from this story, Crowe said the news media cannot be viewed as a single entity. The news media is "thousands of individuals - each with their own ideas of the way things should go and each with their own pressures in terms of objectives. . . So I don't think there is any way for the media to learn a lesson. I think individual reporters, for sure, will take away stuff from this but ... if tomorrow, the same thing happened with another disease it would be exactly the same." Asked if the public will learn from this story, Crowe said:

"Where there is desperation, there will always be a desperate search for hope ...The thing is, I would like to think that lessons would be learned. I think that the CBC, and I know this sounds self-serving, but I think we really did come along later and were skeptical and really did try to dampen down some of the hysteria and did try to ask tough questions. And we were the ones who broke the story about someone dying from it. So, lessons learned. You could talk about whether the public is becoming more sophisticated overall in the way they read health news because they are constantly being promised this cure, that treatment, this breakthrough. We're reading headlines as though breakthroughs are happening every day but they are seeing in their own experience that they are not actually seeing evidence of this. I think there may be some sort of sophistication evolving in the way to interpret these sorts of things more objectively, but I don't know. I guess I'm saying I'm not sure. I guess I am saying that there are lessons that could be learned. Will they be learned? Probably not because the next story will be different enough in its circumstances and we will just do it all again."

\section{Conclusion}

The five health reporters interviewed for this research project provided valuable insight into news coverage of the Zamboni treatment for multiple sclerosis. Some of their observations confirmed findings in the literature review - for example, journalists rely on medical and scientific journals for story ideas, their stories have a major impact on their audiences, they face huge time constraints and they confront a powerful new force in social media. 
Three of the five reporters felt early stories about the treatment were over-hyped, failed to provide balance, framed the research as a cure and primed the audience to believe that the discovery would change people's lives. The stories set the agenda for political and public discussion around the therapy. At least two of the journalists indicated that the stories lacked a reality check. Reporters from CBC and The Toronto Star also mentioned that it was unusual for a scientist to hype his own work. One of the journalists who worked on the first print story felt the issue had been treated with balance, but was magnified and misconstrued by social media. He said this new pressure is something mainstream media must come to terms with.

One of the reporters said that new discoveries involving drugs and therapeutic advances should not be reported until large-scale, long-term studies have been completed. Three journalists said the Zamboni story illustrates why health reporters should be especially skeptical and seek out expert comment. One of the journalists said health stories have so much potential impact they should always be vetted with outside experts before publication.

All reporters said the Zamboni story provides the clearest example to date of the magnifying effect of social media in health news. They also said it delivers lessons to journalists, the medical community and health groups. Those lessons are: Journalists need to be wary of the impact of their words and they need to do a better job investigating commercial interests behind new therapies. News editors need to be careful because in this noisy universe there is a tendency to be more attention-grabbing when writing headlines and promoting stories. Physicians and the health groups should speak up early and forcefully if they have concerns about questionable research. 
In the end, however, CBC's Kelly Crowe said it is unlikely that these lessons will stick because "the next story will be different enough in its circumstances and we will just do it all again."

\section{References:}

1. CTV. Personal correspondence. June 21, 2011.

2. Picard, A. Personal interview. June 20, 2011.

3. Blackwell, T. Personal interview. June 20, 2011.

4. Smith, J. Personal interview. June 22, 2011.

5. Crowe, K. Personal interview. June 21, 2011.

6. Goomansingh, C. Personal interview. June 22, 2011. 


\section{Chapter 6: Personal stories}

This chapter will present the personal stories of five people who have multiple sclerosis. It will examine their reaction to news reports about Dr. Paolo Zamboni's research linking blocked veins to MS, their thoughts on how the news media covered the story and their personal reflections on lessons to be learned.

To recruit people for this research effort, a poster and project description were sent to the MS Society (Ottawa branch) on two occasions but no one responded. As a result, research participants were identified through word-of-mouth in the Ottawa area. Study participants were told they could be interviewed at the location of their choice or on the telephone. Each individual was provided with details of the research initiative and conditions of the Carleton University ethics approval were carefully described and followed.

Participants include three people who have undergone the vein-widening procedure, one person who has not and another who received a successful stem-cell transplant to treat her disease.

\section{Evan Thornton, 50, online media specialist}

Evan Thornton said he felt like the poster boy for "Liberation Procedure" in 2010 after travelling to Poland to see if the therapy could slow the progression of his disease. [1] Accompanied by a CBC producer who documented the trip, Thornton blogged about the experience and reported positive results, including an immediate sensation of warm hands and warm feet. Before the procedure, he was tripping over his own toes. Months 
afterwards, improved health meant that he could begin jogging. For several months in 2010, Thornton was a go-to person for the media as they sought patient reaction to medical and political developments related to the Zamboni research.

Thornton was diagnosed with the relapse-remit form of MS in 2000 at age 40. "Other than the first few bouts of it I had early on after diagnosis, I was living fairly normally and probably most people who didn't know me wouldn't know I had MS," said Thornton, who takes medication to slow progression of the disease and to ease symptoms. But, by 2009 , his hands and feet had grown colder and he began to develop a condition called dropped foot, an inability to raise the front part of his foot due to weakness. "I could see (the disease) was starting to progress," said Thornton, who has a daughter in high school and another in university. He worried about the future.

Thornton first heard about Zamboni's liberation procedure from a report on CTV's W5 in late November 2009. "It seemed everybody I knew saw the W5 show. Everyone was emailing me and leaving me Facebook messages: Have you seen this? Evan, have you seen this? Evan, I just wanted to make sure you've seen this. And it was just a flood and it happened really within 24 hours of that show. And people were sending me links to the video on the CTV website. That was really unlike any response to an MS story that I had ever heard before ... In this case it was coming through the mainstream media that there was something very hopeful going on."

Thornton's brother Duncan, a Winnipeg writer and researcher who also has MS, began to follow up on the media reports. He had already heard whispers about the procedure through online social networks and became more intrigued in the wake of Canadian media coverage. From the start, the brothers didn't see the Zamboni therapy as 
a way to cure their disease, rather as a way to halt the progression of symptoms. For them, slowing or stopping the onset of disability would be enough.

The brothers talked on the phone throughout the winter and decided to take action when their uncle, a Manitoba radiologist, indicated there could be something behind Dr. Zamboni's research. “Once my own uncle was saying, you know, you guys should really take a good look at this, I said to Duncan one day, look, you book the scans, you book the appointment in Poland and I will go with you," Thornton said. His initial plan was to travel with his brother to provide support and to get scanned for blockages "but then my wife intervened and she said, look, if you are going all the way over there ... if the scans show positive, just have it done."

Thornton, an experienced blogger, began to write about his plans and to discuss the trip with friends, including a freelance journalist who decided to pitch his story to The Globe and Mail newspaper. Before long, stories about the brothers' planned trip to Poland appeared in print and on television news, and Thornton developed a following on his Arterial Excursions blog (http://evanthornton.wordpress.com).

In March 2010, the brothers travelled to Katowice, about an hour from Krakow. The radiology and imaging company involved in their diagnosis was headquartered at the hotel where they were staying. A driver ferried them to and from hospital. After being scanned, it was revealed that both men had blocked veins in their necks and could benefit from the treatment. A CBC Winnipeg producer stood by Evan Thomton's side throughout the operation and chronicled the experience. At home in Canada, his wife and two daughters watched the procedure unfold on television. "We were miked up pretty much the whole time we were away," said Thornton. "I woke up the next morning with 
warm hands and feet and they were actually sweaty." Blood flow had been restored and a stent had been placed in his jugular vein to keep it open. "It was incredible. Such a difference in your circulation." After the procedure, the brothers were instructed to stay at the hotel for two days and to report to the hospital if there were any complications before heading home. There were no complications for either of them and they returned home to a wave of media attention. "There was so much media before and after, I forget just what came when, but there was a lot of interest."

While he believes media coverage was, overall, quite good, Thornton said the Zamboni story provides an interesting case study of the shortcomings of health news coverage. "The way the media in Canada appreciate this story is ... miracle cure or hoax. And, you know what, if you can frame it like that, some kid first year out of Carleton Jschool can write that story," he said. "Quite frankly, you can't get away with that with foreign policy or economics or international development because there is a whole cadre of commentary - people who editorialize, taking apart stories for the real motivation and what is driving them. You don't have people taking apart health stories asking what are the real drivers for this therapy, how does it relate to government policy, how does it relate to who is spending on them, and where are they getting the money from?"

Thornton has concerns about the role of the pharmaceutical industry and the link between neurologists who oppose the therapy and commercial interests, an angle he feels has not been fully explained. While his family doctor and neurologist were supportive of his decision to seek treatment, Thornton sees the Ottawa MS Clinic as "the enemy" with vested financial interests they need to protect. This is an angle that required further media attention, he said. Thornton also has an issue with the government, refusing to pay for the 
procedure when angioplasty is routinely performed on cardiac patients. "The only people who cannot get veins unblocked are people who are diagnosed with MS because they are a red flag. They are the property of the neurological industry." He feels governments are compromising the health of their citizens by forcing them to leave the country for what could be routine medical care. The role of lobby groups and competing interests were not highlighted enough by news media as they described the issues, he said.

\section{Margo Murchison, 56, former teacher}

Margo Murchison, 56, who was diagnosed with MS in 1982, remembers exactly where she was on Nov. 21, 2009. Throughout the evening she watched and re-watched the CTV program W5 on her satellite TV as the show was broadcast in one time zone and then the next. [2] "When you've got a chronic illness, you live on hope. It was so exciting to see," she said. The same day, her mother bought eight copies of The Globe and Mail newspaper, which featured the story on most of the front page, to share with friends and family members. "I was really excited about all of this."

Murchison's multiple sclerosis began at age 27 with two curled fingers on one hand and what she thought was a pinched nerve. "It was sort of like gingerale in my brain and a short circuit that would go wup,wup. And for 10 seconds I couldn't move those two fingers," the former teacher said. Tests ruled out an aneurysm, brain tumour and epilepsy, among other things. "In 1982 they knew how to spell MS and that was about it. And they said, given your age, it might be MS and you won't know until you get another attack. There were no MRIs or anything at the time." Three years later, she had another attack and suddenly went blind in one eye. A diagnosis of MS was confirmed and, other 
than causing her to go blind a couple of times when she was under stress, Murchison said the disease didn't have a huge impact on her life for the first 10 years.

And then the MS began to progress. She started to limp. She grew weaker. Eventually, Murchison had to take disability leave from her beloved primary school teaching job because she couldn't get around. Today, she uses a scooter for mobility. She cannot stand or walk. Homecare workers give her showers and help her to get dressed. "My brain still works fine but my body is not very cooperative."

So when she watched W5 and read The Globe and Mail and heard about what she thought was a potential cure for MS, Murchison was over the moon. "There has always been the eureka moment when somebody tries something that no one else has thought of and wow it worked. Magical things happen and maybe this guy was just lucky," she said. "You know, he wanted his wife to be cured and he tried so hard and ... wouldn't that be amazing if this guy just happened to trip on something that actually worked ... I am a very optimistic person anyway, but for somebody who is depressed what a lift that would give them."

A day or two later, Murchison attended a scheduled public lecture, a research update presented by her neurologist Dr. Mark Freedman. "Every once in awhile he will speak on the latest research and drugs and everything. So we go into the room and there are about 300 people there and everybody has The Globe and Mail. They are all reading the story, all expecting him to say 'thanks for coming, we've got the cure, you can go home now.' Everybody's expecting that, right? And he didn't start talking like that. He started talking about all these medications and the drug trials, which any other year we 
would have been so excited to hear about. But nobody wanted to hear that. We just wanted to hear that we don't need these drug trials. We are all cured."

Freedman faced an angry crowd when he questioned Dr. Zamboni's research and told audience members he had spoken to the Italian scientist and his work didn't hold weight, Murchison said. He indicated that improvements in patients were subjective and that, as far as he could see, no one was jumping off their scooters because they'd been cured. Murchison said her doctor indicated that veins weren't like arteries - they were fragile and the procedure was potentially dangerous.

For her part, Murchison had complete faith in her doctor's opinion. "I completely trust his judgment, but other people who don't know him or are more skeptical, they were angry. I was not angry. I was disappointed that night. I was still hopeful because of the other drug things he had talked about. But I thought, okay, he has talked to the guy. He knows so much. I have great faith in his knowledge. When he tells me there is something safe to do, I will do it. If he told me to fly to the moon because there is a cure there, I would go. But once he started talking about how complicated trials are, I thought 'yeah, this is too good to be true."'

She didn't believe conspiracy theories about the pharmaceutical industry opposing a cure. Murchison never considered jumping on a plane to seek treatment. It's difficult enough for her to get in the car and travel to the nearby shopping mall, she said. Murchison feels more research is needed but something can be learned from studying people who have had their veins unblocked. Her friend, who is in a wheelchair, travelled to Mexico for the procedure and noticed only moderate subjective changes that disappeared over time. 
What does Murchison think about the way the media covered the story? "I was fine with it actually. I am a media junkie anyway. I love seeing things about MS research, even if I don't really think this is the answer it's still keeping MS in the news. And maybe people will donate. And maybe there will be something to do with this Zamboni thing and people will learn something from it. Maybe it's not the Zamboni procedure we need, maybe we need some kind of blood thinner or something that keeps the blood flowing better in our veins. Who knows what they will learn from this?'

A side benefit, she said, is that MS is finally on the radar. People know about it and are talking about it. Murchison said she feels "embarrassed for (the reporter) who broke the story. She did this fabulous job and it was super convincing and I thought, oh, now this is a little embarrassing because it is not as amazing and immediate as she portrayed it."

Murchison remains optimistic. "If there were an actual cure, I would sell everything I own to go and get it done. Nothing would be more wonderful for me. I wouldn't care about any material possessions. All I want is to be able to stand up. Then I could go back to teaching."

\section{Andrew Katz, 52, former businessman and consultant}

“Holy crap. That pretty much was everyone's initial response: Holy crap. You know the thing about living with MS - and I am talking for myself, of course - is that every single day you are constantly reminded of the fact that there is no cure. So when something like this comes up you are saying to yourself, wow, it may be finally here ... For a blood flow problem to be the cause of this made a lot of sense." 
That was the reaction of Andrew Katz, 52, father of three and a former consultant, as he watched the first television reports on Italian vascular surgeon Paolo Zamboni's radical approach to MS. Almost 30 years earlier, blurry vision and a habit of missing tennis balls convinced Katz [3] to seek medical attention. Eventually, he received a diagnosis of MS. Other than clouded sight, Katz felt well during the next 10 years. He finished university, started a stressful job in sales, travelled a lot and married his sweetheart Jen. He had relapses in his condition, but nothing serious enough to cause him to miss work. "Perfectly normal life except for the fact that I knew I had MS," said Katz, who has secondary chronic progressive MS, a slow-moving form of the disease. Then, gradually, his symptoms became worse. There was weakness and numbness. He used a cane and then a walker and, three years ago, moved to a wheelchair.

Katz has lived through 20 years of claims of false cures for MS, many of which he is happy to list: the Swank diet to limit fat; the healing power of goat testicles; drug therapies that were supposed to be game-changers; and immuno-suppressant drugs. "So when this came along, which was very, very different, I really started to think, wow, this could be it."

After the initial report on CTV, "the telephone lines were aflutter" and Katz and his friend Rebecca Cooney, who also has MS, decided to take action. They created the website msliberation.ca, attended a conference at McMaster University where they met Dr. Zamboni and connected with Hamilton imaging specialist Mark Haacke. Soon, they began to organize rallies, write letters to the federal health minister urging action, and join forces with Toronto Liberal MP Kirsty Duncan to push for clinical trials. 
Katz thought early news reports on CTV and in The Globe and Mail were sensational, but he believes reporters have worked hard to avoid over-hyping the story. "The media on the one hand has helped promote and let a lot of people know about this but they have also been guarded. They have been very careful, I find, and for good reason. Like I said, lots of these wonder therapies have come up before in the past and they have been nothing so they have been careful not to jump on it and go crazy about it."

While his neurologist did not support the Zamboni hypothesis, Katz was determined to give CCSVI therapy a try. First, he heard about a clinic in India that offered to do the procedure at no cost to four Canadian patients if they could pay their own airfare and expenses. It was a promotional offer from a medical tourism outfit in Toronto, aimed to garner Canadian interest in a clinic. In June 2010, Katz went to India. A vascular specialist found nothing. The procedure was not performed. "The two other ladies who I went with did have the procedure and have seen big benefits. So then when I came back, yeah, I was kind of dejected. I had just spent three thousand bucks to go to India to watch cows poop on the street."

But Katz was not prepared to give up. He followed up his diagnosis with Dr. Haacke and eventually went to see another specialist in New York, who indicated that he was, in fact, a candidate for treatment. This time, the physician threaded a catheter into his jugular veins and found that Katz had faulty valves and a problem called reflux that was causing the blood to flow back into his brain and for toxic levels of iron to build up. MS, Katz said, is a symptom of this iron build-up, which damages blood vessels and causes the immune system to kick in. 
“MS is not an autoimmune disease. And that's why they haven't been able to figure out what triggers the autoimmune system to react the way it does. Is it a disease? Is it having something happen at birth? Is it vitamin D? It's a vascular problem. It is blood flow," Katz said. "It is not an immune system that all of a sudden decides to go ballistic and attack itself like with arthritis. It is a response to a vascular blood flow problem."

When it was determined he could benefit from treatment, Katz's community rallied around him. His neighbours raised $\$ 4,000$ to help pay for the procedure in New York; his former workplace contributed an additional \$3,000 towards the treatment. Having his jugular veins popped open with balloons "was very painful, very painful . . . What they are finding is there are two different forms of this problem. One is the veins are narrowing. They don't know why. Is it a congenital thing? Are you born with it? They don't know. That's what causes the reflux. The other form is the one I had - valves. Both are treated the same way with balloon angioplasty." Treatment was followed by three weeks of blood thinners. Katz did not have stents placed in his veins, which he believes is unsafe.

In terms of results from the procedure, Katz said his feet have not swollen quite as much and the jury is still out on whether treatment will slow the progression of his disease. "MS is considered a brain injury, very much like head injuries and so forth. Do I expect for things to change that quickly? Will it ever change? I don't know, maybe not. Will it stop progression of the disease? That I will know within a year. If it stops the progression, I have won. If I don't get better, I don't care. Just stop the progression of the disease. That's like the holy grail for MS." When the disease worsens, individuals can lose the ability to move, to think and to eat. 
Katz is angry with governments for inaction and for failing to provide treatment to Canadians. "For the government to say that it's too dangerous ... It's too dangerous? You don't want to support something that has already been shown anecdotally to be fantastic compared to all the other crap you continue to tell us to take like the $\$ 20,000$ in immunosuppressant drugs?" He is angry with the MS Society, which he sees is blocking a new and novel approach to the disease. He blames neurologists and drug companies for lining their pockets with revenue. "Conspiracy theory. Do you know what MS is worth to the pharmaceutical industry? Something like 10 to 12 billion dollars a year. Billion with a B. If this procedure were to become very common, how much do the pharmaceutical companies lose? Ten to 12 billion dollars a year because the drugs are $\$ 20,000$ to $\$ 30,000$ a month. So the question is: Are they involved in suppressing this new procedure? The MS Society and the pharmaceutical companies together?"

Katz is thankful the media brought to light a new way of looking at MS and a potential lifeline for so many people and their families who are living with the disease.

\section{Jennifer Molson, 36, research coordinator}

Jennifer Molson was 21 when she was diagnosed with multiple sclerosis. [4] It began suddenly one morning with a feeling of pins and needles in her fingertips. Within a week, weakness spread the whole way up her arm. At the time, Molson was working full time and spending five days per week training in the gym in an effort to become a police officer. She suspected a pulled muscle or a pinched nerve. She even feared a stroke. "I am looking for some red flags because by this point is has been a week and I can't move my arm, right?"' Her family doctor diagnosed carpal tunnel syndrome, but to Molson it 
didn't make sense. She was referred to a neurologist, who ordered an MRI, and within days she learned she had a rapidly-progressing form of MS. She was sent to Dr. Mark Freedman at the Ottawa Hospital's General campus.

"At this point, I had to re-evaluate what I wanted to do because obviously now being a cop is out of the question, so I went back to school to do administrative work, where I would be sitting at my desk," she said. Five years later, she was so severely disabled that she could no longer work. "I needed to have people shower me, blow dry my hair, cut my food, help me get dressed. In a five-year span I went from being physically active, running, trying to be a cop, living a very active lifestyle to, in 2001, being dependent on people to help me with day to day stuff."

Molson was living with her boyfriend, Aaron, who "was pretty much doing everything for me. ...We were 26. You know, people are getting married or having babies or whatever or starting their life and here we are with him cutting my food and dressing me. That's something you expect when you're elderly, right, not in your mid20s."

Molson moved into a rehabilitation centre for three months, where she received intensive physiotherapy and was to be fitted for a power wheelchair. Later, when she was hospitalized with a severe MS attack, Dr. Freedman talked to her about his plan to work with Dr. Harry Atkins to do stem cell transplants to alleviate MS symptoms. After two MRIs to study lesions on her brain, it was determined that she was a candidate for the transplant if she wanted to participate. "He had to submit all my medical information to a medical review board to make sure I met the criteria to be included in the trial. There were quite strict criteria ...The point was to stop the disease where it was. You're not 
going to get better but you're not going to get worse. It's really more about quality. You still have some function so we want to keep you there. We don't want to do it on people who are already past that point where it won't do anything for them, you know. So on top of my physio in the morning I had walking classes for an hour a day just so I would be able to walk the distance to be included in the trial."

Molson said stem-cell treatment was her last hope. "If I didn't do this and it proved to work and I missed that window I would be kicking myself, right?" The trial began in September 2001 and Molson's transplant was in July 2002. "I had baseline tests. I had to do walking tests, a math test to see function. I had to have heart scans to see if my heart was strong enough for the chemotherapy. I had to have breathing tests to make sure my lungs were functioning okay. I had to have spinal taps, MRIs, imaging, blood work - every other week they would take 32 vials of blood. It was really intense. Every day leading up to the actual transplant it was one test or another."

Molson was nervous. She had to sign consent forms indicating she understood the risk of seizures, liver and bladder damage and death. "So we were very well informed going into it what the risks were." She said she knew she was really desperate when the possibility of death seemed like a good option.

Treatment turned out to be grueling; 10 days of intensive chemotherapy and the stem cell transplant. Molson said she threw up for a year. "It was rough. I won't lie. When Dr. Atkins says it takes a year until you start to feel human again, he wasn't joking." She told her fiancé Aaron that "if it doesn't look like I am going to make it through, you have to get a minister and we are going to get married because it's better for 
you to be crying over a dead wife than a dead girlfriend." They married 11 months after her transplant.

She first started to notice improvements in her condition about two years later. Little things, like not having to hold the railing on her way downstairs. Then walking downstairs while carrying books, or going to the mailbox without her cane. By 2005, she returned to work part-time. The next year, she went to work full-time as a research coordinator at the Ottawa Cancer Centre. Today, she is a downhill skier, she drives a standard and she travels. "We went to New York City and we walked the whole island in five days." Molson's story received widespread coverage in the news media and the success of the trial was featured in news reports across the country.

More than five years after she got her life back, Molson said she is disheartened by media coverage of Dr. Zamboni's liberation therapy for MS. She watched W5 when the medical 'breakthrough' was revealed. "He's saying he found the cure for MS. But yet these people are still taking MS medication. How can you say you have cured a disease when you are still taking disease-modifying drugs for that disease? I am not on any MS medication. I am on nothing." She said she has been scanned from head to toe "and I have had no blockages in my veins, none at all." Despite widespread news coverage of her recovery - even an appearance on W5 two years earlier - no media outlet ever contacted her for perspective. She would have told them not to come out of the gate saying this is the cure. "They never said that with me. Dr. Freedman and Dr. Atkins said the hospital is transplanting patients with their own stem cells and they are having some success. I think that's how they should have done it." 
Molson has serious concerns with patients travelling to receive untested procedures in foreign countries with no medical records and no follow-up. She said patients are not getting the full picture. They aren't being told the questions to ask. "I know what it's like to be desperate. I was willing to die, to take the chance that I could die to get better." But her procedure was carefully planned, involved rigorous research guidelines and protocols, ethics board approval and she was informed of all the risks. She said she has heard through her work in the hospital that a lot more people may have suffered complications from the "liberation procedure" than news stories indicate. "There have been lots of complications. A few people have died because the stents have gone into the heart and killed them. Somebody else had a stroke because the stents are meant for arteries and not your veins and they were throwing clots."

She believes that, unlike the harsh therapy she received to treat her MS, Dr. Zamboni's work has appeal because it is a quick fix - after minutes on the operating table people are seemingly better. She also rejects the conspiracy theory circulating on social media networks about neurologists and pharmaceutical companies. After her treatment, Molson no longer required any medication for MS, and Dr. Freedman was behind it. "He has given me my life back. I have a second chance at life."

\section{Rebecca Cooney, 43, former federal public servant in the finance sector}

The first thought she had after learning about Dr. Paolo Zamboni's approach to MS on CTV's W5 is "this makes a lot of sense," said Rebecca Cooney, [5] an Ottawa mother of two teenage girls. "I started to cry. I literally started to cry." 
Cooney was diagnosed with relapsing-remitting multiple sclerosis at age 25 , but believes the disease began a decade earlier. On and off numbness advanced to the point where she couldn't use her left hand, however, through diet and exercise her symptoms were controlled. Cooney got married, had two children and then, about six years ago, her symptoms returned with a vengeance. She gave up running. She stopped skiing, playing basketball and tennis. She was diagnosed with secondary progressive MS and tried a number of medications that provided no relief until five years ago she could no longer work.

After learning about Dr. Zamboni's research and talking to other people with MS, Cooney and her friend Andrew Katz decided to start a website to share information. "I have never set up a website. I have never done that in my life. . . My background's in finance. I didn't know what I was doing but I did it ... We wanted a place where we could put information. And it started off being a local little thing and it just snowballed." Cooney began searching the web for more information. She emailed McMaster University imaging expert Mark Haacke and then travelled to Hamilton to meet Dr. Zamboni and physicians from Poland, Kuwait and the United States, who were also proponents of the theory.

She arranged for Haacke to meet with a Liberal member of Parliament and the city manager of Ottawa, as well as to speak at a local MS meeting. She called a local CBC television reporter to cover the talk. Cooney said the news media largely focused on the human aspect of the story and failed to fully probe the science. Because of interest in her website, Cooney began doing a lot of media interviews. 
In February 2010, Cooney travelled again to Hamilton to get her neck veins scanned. She discovered her two jugular veins were 90 per cent blocked.

Her neurologist refused to refer her to a vascular specialist. Then she heard about a clinic in Albany that could do the $\$ 5,000$ procedure. In May, 2010, "I had it done. It was more painful than people said it was. ... It was like going to the dentist getting a root canal, but it lasted $\mathbf{4 5}$ minutes. I went out to dinner that night and then, for the first time in five years, every week I got better." Cooney said she could lift her leg higher, she had more energy, her skin colour, heat intolerance and incontinence improved. "And then, all of a sudden it stopped after five weeks."

Cooney's fatigue and incontinence returned. When no one in Canada would do a diagnostic scan of her veins to see if there was another blockage, she returned to Albany for a second procedure and agreed to have three stents dropped into one of her jugular veins. The same day, the veins clotted and attempts to reopen them were unsuccessful. Cooney was placed on blood thinners. On her return home to Canada, Cooney began to have chest pains and wanted to have another scan to see if her stents were full of clots. It took weeks for another scan to confirm that there was no blood flow. By that time, it was too late for doctors to do anything. "The stents are there," she said, pointing at her neck. "I am on blood thinners so the clot doesn't get bigger. But the clot is there and they can't do anything about it." A surgeon suggested removing the blocked jugular, but she declined. She said the medical community has treated her with animosity for having the procedure. "It was like I was a murderer or something, like I had done something immoral." 
Because of news reports about a southern Ontario man who died trying to have blood clots around his stents unclotted in Costa Rica, Cooney decided against another intervention. "I decided not to have it done and that was pretty directly because of the media. And my view is I have two kids, I am still functioning and my priority is to be well enough to take care of them and my husband."

While she believes news reporting was generally good, Cooney blames the media for turning the medical establishment against patients by over-hyping the procedure. She also feels that there was not a big enough link made between pharmaceutical company funding and medical research. Cooney believes physicians are getting most of their information from the mainstream media, instead of from medical journals, while patients are reading journal articles and educating themselves from a whole variety of sources.

She said, as of April 2011, there were more than 20 people in Ottawa who had had this procedure done and, for everyone except her and Katz, the difference has been amazing. "One lady was walking with a walker and she hardly uses the cane now. When you see people and you've known them for a long time and you see the difference, it's really phenomenal. And it is hard not to get hyped up about it.

"The thing is because I had such good results I believe in the procedure even more than I used to. I have been through it twice and I have seen what it's like to have an open vein. It's definitely not a cure, but it is a treatment."

\section{Conclusion:}

Based on this sample of five individuals, it is clear the mainstream media coverage of the Zamboni therapy had an impact on people living with MS. Four of the 
five individuals interviewed indicated that early news reports generated a lot of hope for them personally. The fifth individual is someone who was successfully treated with stemcell therapy and questioned the validity of the Zamboni research.

People living with MS viewed media coverage from different perspectives. Some thought stories were too simplistic, while others did not. Some thought the stories were balanced and objective, while others disagreed. All were pleased that media coverage raised public and political awareness about MS. They also remarked on the role of social media as a distribution tool for mainstream news stories. (The role of social media is probed in Chapter 8.)

Among criticism of news coverage, individuals said the news media failed to highlight the money trail in this story. Some felt the pharmaceutical industry was trying to discredit Dr. Zamboni's research over fears of collapsing MS drug sales. (That angle was never investigated.) Others felt the media did not look at who was profiting from the new therapy, including physicians, foreign clinics, medical tourism promoters and device manufacturers. (This angle was also not the focus of reporting.)

The woman who underwent stem-cell therapy for MS felt news reporters should have looked at other therapies for the disease and described the rigorous approval process for clinical trials. This would have helped to contextualize patient anger over the slow response to Zamboni's approach.

One patient who received treatment twice in the U.S. argued that the fuss made by Canadian media over the Zamboni procedure created such a political stir it ended up restricting access to neck scans in this country. Without the media spotlight, scans could have been done under the radar, she said. She also argued that media hype created 
tension between the medical community and MS patients. Recent coverage of complications, however, has provided people with a clearer picture of some of the risks behind the procedure and influenced their decision-making.

\section{References:}

1. Thornton, E. Personal interview. Feb. 21, 2011

2. Molson, J. Personal interview. March 10, 2011

3. Murchison, M. Personal interview. March 23, 2011

4. Katz, A. Personal interview. March 25, 2011

5. Cooney, R. Personal interview. April 8, 2011 


\section{Chapter 7 - Research funding agencies respond}

This chapter will examine the response of research funding agencies and professional associations to media reports on the potential link between blocked veins and multiple sclerosis. In particular, it will look at discussions involving the Canadian Institutes of Health Research (CIHR), one of three federal granting councils, and the Multiple Sclerosis Society of Canada, a health charity and national voluntary organization that supports MS research. Also examined will be media releases issued by CIHR and the MS Society as well as material posted on their websites, position statements and news releases issued by professional associations and provincial ministries of health.

As indicated, research for this study covers the period Nov. 2009 to Dec. 2010 and, as a result, more recent developments, including a CIHR working group decision in June 2011 to recommend federal government funding for a pan-Canadian clinical trial, will not be part of this analysis.

Both CIHR and the MS Society were reluctant to participate in this research study. CIHR's media relations department declined an in-person or telephone interview to discuss its handling of the topic. However, CIHR media specialist David Coulombe agreed to provide written answers to questions. It took several weeks to receive the responses.

Stewart Wong, Senior Manager of Communications and Media Relations at the MS Society of Canada, indicated the society was not interested in participating in this 
study because questions involved "internal operations and/or commentary about media and media treatment." [1]

The following questions were submitted to the two organizations for consideration:

- How many interviews has your organization given to news media on this topic since the story received widespread national attention in November 2009?

(Specifically, the time period Nov. 2009 to Dec. 31, 2010.)

- How did you choose a media spokesperson?

- How many news releases were issued, press conferences organized, public forums held, briefings organized as a result of news coverage between Nov. 2009 and Dec. 2010?

- Did you have areas of concern around how the news media covered this issue?

- What challenges were created for your organization?

- Are there any news outlets that you feel did a particularly good job covering the debate?

- What was the role of social media - blogs, Facebook, YouTube, etc.?

- What was the response from your donor base? (MS Society only.)

- What has your organization learned?

As the organization that determines medical research priorities for Canada, CIHR received considerable attention during the debate over federal government funding for clinical trials of the Zamboni procedure. Between Nov. 2009 and Dec. 2010, CIHR's president Dr. Alain Beaudet gave eight interviews to news media on the topic of clinical trials for the MS "liberation procedure" - for Dr. Beaudet, more interviews on this topic than any other single topic during the same time period. [2] Dr. Beaudet was designated as the CIHR spokesperson for most media inquiries on MS and CCSVI. "Given the controversial and high level nature of the MS issue, it was established that the president's involvement in media interviews was essential," according to CIHR media relations. [3]

The MS Society of Canada issued four news releases on MS and CCSVI between Nov. 2009 and Dec. 2010 - the first was two days after the initial W5 report on Zamboni. These releases are posted on the society's website. [4] 
- Nov. 23, 2009: MS Society invited applications for research operating grants to investigate the procedure, acknowledging the concept needs to be validated and findings reported were preliminary.

- May 5, 2010: The society urged the federal government to provide $\$ 10$ million for research into chronic cerebrospinal venous insufficiency (CCSVI) and MS.

- June 11, 2010: MS Society of Canada announced funding of $\$ 700,000$ for seven investigative research studies into the possible link between CCSVI and MS.

- Sept. 16, 2010: The society announced it had set aside $\$ 1$ million for an eventual trial into CCSVI. The release said: "The MS Society has advocated for more research since the CCSVI theory became widely publicized in the fall of 2009."

The fourth MS Society release came several weeks after an Aug. 26, 2010 meeting, organized by CIHR in collaboration with the MS Society of Canada. The meeting brought together 23 top researchers and three observers to discuss the scientific merits of Dr. Zamboni's research. Meeting participants included senior officials with CIHR, the MS Society, the U.S. National Institutes of Health and researchers at hospitals and health-research institutes across Canada and the United States. One individual living with MS, who did not want to be publicly identified, also took part. Deputy health ministers from Saskatchewan, Newfoundland and Labrador and Health Canada participated as observers. [5] 
At least five documents were produced by CIHR from the Aug. 26 meeting: a news release and a lengthy "Summary Report" (both posted at www.cihr.ca) [6], and three internal documents, which were not posted on the CIHR website. The internal documents were used in the writing of the Summary Report. They include:

- a two-and-a-half page document, entitled "Executive Summary" [7], which includes the overview, objectives, a summary of the plenary discussion and research priorities;

- a three-page document, entitled "Open Discussion" [8], with a list of 40 key discussion points from the plenary; and,

- a two-and-a-half page list of "Research Priorities" [9], summarized in 26 key discussion points.

The three internal documents were obtained for this study through an Access to Information request made in April 2011. These documents, received on May 24, 2011 from Manon van Riel, coordinator of Access to Information and Privacy at CIHR, include comments from the participants on the media's role in fuelling controversy. These opinions were not included in the public "Summary Report" posted on the CIHR website. (www.cihr.ca)

Documents reveal that scientific experts who took part in the CIHR meeting felt the media had played a major role in promoting misinformation about the vascular theory for MS and potential benefits of Zamboni's surgical procedure. Selected comments from the discussion, which were not attributed to specific individuals, include:

- "The media created this situation and have provided no opportunity for rebuttal. Ways need to be found to tell the full story and comment on increasing reports of 
lack of effect. The problem is that the media are extremely selective about what they publish and can skew information any way they want."

- "There are other promising studies and avenues of investigation that ought to be highlighted with as much enthusiasm."

- "People who have not had symptomatic improvements of any kind or have had post-operative complications have few places to publicize their anecdotes."

- "If the hypothesis is confirmed not to be true, it will take years for people to recover from the fall-out."

- Any grant application submitted for a project with no clinical, epidemiological, biological, or other rationale would never be approved, so why should this be?

- The scientific stance has been that the findings are not based on evidence, so they have no value; the politicians have responded by asking scientists for evidence. Telling them it's not worth looking for it is contradictory."

According to the Executive Summary of the meeting, participants "agreed overwhelmingly that the study was flawed in a number of ways and offered no evidence of greater vein abnormalities in MS patients than in the control group." They agreed it would be premature to conduct a clinical trial until there was further evidence of vascular abnormalities in people with MS. They said there is no evidence angioplasty benefits MS patients, the use of stents to keep veins open was risky and more research was needed. However, the group acknowledged that if evidence from studies under way - especially seven investigative projects funded by the MS Society of Canada - showed a link 
between CCSVI and MS, there should be support for a national clinical trial. A working group was established to stay on top of the issue.

On Aug. 31, 2010, CIHR hosted a news conference to announce the results of its August 26 meeting and to make recommendations to the health minister on funding for clinical trials. Dr. Beaudet said "there was unanimous agreement from the scientific experts that it is premature to support pan-Canadian clinical trials on the proposed 'Liberation Procedure'. There is an overwhelming lack of scientific evidence on the safety and efficacy of the procedure, or even that there is any link between blocked veins and MS." [10]

According to CIHR's media relations department, 15 reporters attended the news conference via teleconference to hear the group's decision on the merits of the research and its recommendation on clinical trials. The news conference resulted in considerable news coverage: more than " 300 mentions in media," according to CIHR.

In a paper in Open Medicine, health policy researchers Dr. Andreas Laupacis of the University of Toronto and Dr. Arthur Slutsky criticized ClHR's handling of the review.

Given the controversy, and given the way this issue has galvanized the public, the decision about whether to conduct a clinical trial should be informed by the public. We believe that members of the public, beyond three employees of the MS Society and one anonymous person with MS, should have been included on the Joint Invitational Meeting panel. By "members of the public," we do not mean only patients with multiple sclerosis or advocates for MS patients, but also thoughtful citizens without MS who can consider all points of view, deliberate about them, and contribute to informed recommendations. . . Even had greater public membership on the panel not changed the recommendations made in the report at all, or had the committee not been able to come to a consensus, the very fact that members of the public were on the committee would likely have increased the legitimacy of the report in the eyes of the public (although not in everyone's). [11]

In a June 2011 interview for this study, Dr. Laupacis said greater public involvement would have ensured decision-making truly reflected public values. [12] Another approach 
CIHR could have taken in the context of media attention "would (have been) to say that there are quite literally thousands of Canadians leaving the country to have this procedure. They're coming back, they're being treated here afterwards, they're paying their own money, it's very expensive, we don't know the quality of care of the different places they are going around the world and ... public policy would suggest that it is really important for us as a health-care system to know whether this works or not."

For his part, Ottawa neurologist and MS expert Dr. Mark Freedman said in an interview the discussion by the expert group at CIHR was "exactly what I expected. The data are not there." Dr. Freedman said the MS Society is the best advocate for the patient, should not jump on the bandwagon to support every new idea, and the media forced the issue on the MS Society, leaving it with no choice but to respond. [13]

On Sept. 1, 2010, Health Canada held a press conference and issued a news release to accept CIHR's recommendations. Health Minister Leona Aglukkaq said "we await the outcome of studies currently underway that are exploring the relationship between MS and venous malformations. These studies will inform decisions about moving forward with any pan-Canadian clinical trials on a treatment to unblock veins." [14] She established a scientific expert working group to monitor research.

The MS Society, meanwhile, focused its messaging around the seven research projects it was supporting into the link between MS and CCSVI and put a positive spin on its efforts to advance science while trying to stay away from the political decisionmaking.

Although the MS Society did not want to talk about its media relations strategy or the impact of news reporting on the organization, Senior Communications Manager 
Stewart Wong said in an email exchange that he would go on the record to say "we learned through the course of the year that there was a voracious appetite for more information on this important topic, unlike anything we'd seen previously. As a result, we took the unprecedented step of creating a website dedicated solely to the topic:

www.ccsvi.ca." According to Wong, "this type of approach to information dissemination by the MS Society has never been applied to any other treatment theory of MS. It was a unique situation that called for a customized solution." [15]

The comprehensive website - www.ccsvi.ca - provides scientific background on Zamboni's hypothesis, position statements of research organizations, web links, video of public information sessions, a description of the procedure, a list of questions to ask health professionals before considering the procedure, news updates, press releases, a forum to share experiences and stories and a place to ask questions. The site, which obviously required significant effort and research, was launched in early 2011. It is interesting to note the majority of testimonials in the patient forum support vein-widening therapy.

In reaction to media coverage and public response over the issue, many health funding agencies and research organizations issued policy statements and press releases in 2010. Many of these statements have been posted on the ccsvi.ca website. Among them:

Alberta Health Services, Feb. 16, 2010: Alberta Health Services warned that the Zamboni theory is only a hypothesis. Independent and controlled studies were required to prove, discount or better understand the results; the nature and frequency of the risks are not fully understood and it cannot be supported as standard practice. [16]

Association des neurologues du Quebec, March 22, 2010: The association called for calm in wake of media reports. "The presentation of this study by W5 on CTV last November ... has raised great hope among patients with multiple sclerosis. . . Contrary to 
the impression that is conveyed by the media, the results published by Dr. Zamboni do not suggest that angioplasty is a cure for the disease. Patients treated continue to suffer from active multiple sclerosis. The ANQ believes that because of the risks involved in this type of treatment and since the benefits appear to be limited, for the time being, it is preferable for patients with the disease to wait for the results of further research." On May 7, the association said again the procedure was risky and the benefits are unclear and urged people to wait for more research. [17]

Ontario Health Technology Advisory Committee, May 2010: OHTAC released a document that said it was unable to make a recommendation on the treatment due to the paucity of evidence and encouraged people to participate in clinical trials. [18]

Canadian Network of MS Clinics, July 2010: On its website, the organization warned patients to be wary of the potentially dangerous procedure that could lead to nasty complications. "A recent flurry of newspaper and TV stories . . . has created a lot of hope and interest among the MS community ... The MS community has seen and heard of many "treatments and claimed cures" over the years, which have usually turned out to be false. CNMSC strongly recommends that patients DO NOT seek to have their veins studied by techniques that have not been standardized, nor should patients be asking for treatments based on these findings that have not been proven." In a posting for physicians on its website, CNMSC stated: "Not surprisingly, our patients, who respect the word of our national newspaper and TV network, now believe that this 'liberation treatment', as it is referred to, is a quick cure for MS and they are demanding to be investigated and treated for their perceived venous anomalies." [19]

Alberta Health Services, August, 2010: The agency warned people to "be careful where they get information and where they go for treatment. . . People with MS should be wary about getting information solely from media stories and reports or from patient's "blogs." They should seek out expert advice from knowledgeable MS caregivers and experts, and should carefully determine the credentials of any centre offering "liberation" treatment. [20]

The Society of Interventional Radiology, Aug. 26, 2010: The group released a statement indicating published research into the Zamboni theory was inconclusive and more research was needed. SIR's position statement was endorsed by the Canadian Interventional Radiology Association and was published in the September Journal of Vascular and Interventional Radiology. [21]

Association of Faculties of Medicine of Canada, Sept. 21, 2010: AFMC issued a press release saying it supported the CIHR recommendation regarding clinical trials on liberation procedure for MS. [22]

College des medicines du Quebec, Nov. 9, 2010: The Quebec physicians' organization said current knowledge does not allow for physicians to practice this treatment, which is not recognized by the medical community. [23] 
These position statements indicate that the medical research community in Canada was wary of media stories into Dr. Zamboni's so-called liberation procedure, and urged caution among members of the public. The Quebec Association of Neurologists and the Canadian Network of MS Clinics directly blamed the media in their statements.

Provincial governments called for more research funding to validate Dr.

Zamboni's CCSVI theory despite skepticism expressed by the medical community. Within weeks of CIHR's announcement indicating insufficient evidence to proceed with clinical trials, the provinces took action in response to public pressure:

- Newfoundland and Labrador, Sept. 13, 2010: The provincial government announced plans to fund $\$ 320,000$ or more for an observational study of MS patients who have undergone the procedure. [24]

- Meeting of provincial health ministers in St. John's, Sept. 14, 2010: Health ministers affirmed their support for studies into the effectiveness of liberation therapy and say they will work together to advance scientific research. [25]

- Manitoba, Oct. 15, 2010: The health minister announced plans to set aside $\$ 500,000$ for a clinical trial once there was evidence to show the procedure was safety and effective. [26]

- Saskatchewan, Oct. 19, 2010: The government of Saskatchewan made $\$ 5$ million available to the Saskatchewan Health Research Foundation (SHRF) for clinical trials. SHRF will provide money to the top researchers chosen through a competitive process. [27] (Note: SHRF later announced that proposals assessed by a research panel were unworthy of funding.) 
- Alberta, Dec. 16, 2010: Alberta committed to study the MS treatment, providing up to $\$ 1$ million for observational studies and funding for clinical trials when the procedure was deemed safe and effective. [28]

In effect, provincial governments ignored the advice of MS research experts and decided to proceed with investigative work (or, at least, announce plans to proceed). These decisions fly in the face of conventional scientific peer-review processes and demonstrate how public pressure and media attention precipitated political action.

\section{Personal perspectives}

MS specialist and neurologist Dr. Paul O'Connor, scientific and clinical adviser to the MS Society of Canada, said the "whole story would not have existed in Canada without the active media involvement in promoting it." [29] He said the MS Society was in a difficult position after news reports heralded the Zamboni research as a potential cure for MS. "I think that, like with everyone else, it has been a challenge for them to deal with patient expectations, patient beliefs regarding this therapy," Dr. O'Connor said. "You're dealing with a constituency that wants a cure for MS, and they want it now ... if you go on Facebook you'll see all sorts of mean things said about neurologists and the MS Society."

Media coverage has led to a diversion of research funds for the MS Society and other organizations, but it has also brought new money to the cause. "I know for a fact that there are people who donate to the MS Society nowadays who say specifically I want this money to go for CCSVI research," Dr. O'Connor said. 
From the perspective of some people living with MS, inaction by the MS Society on the issue led to a great deal of public anger and frustration with the organization. "This is deeply, deeply frustrating and it was left to us to peel back the connections and what we soon figured out is the MS Society is (in bed) with the neurological, neuroscience, pharmacological industry," said Evan Thornton, [30] an Ottawa man with MS who went to Poland for vein-widening therapy and blogs about the issue. "So the voices around the table and the people making decisions, the neurological advisers to the MS Society are the neuroscience industry. It lost a lot of credibility for the MS Society and a lot of people who have MS, it has probably hurt their fundraising."

Andrew Katz, also of Ottawa, went to India and the U.S. for treatment and feels contempt for the MS Society. [31] This is a common theme on MS patient blogs and websites. Rebecca Cooney, who also travelled to the U.S. for vein-widening therapy, believes the MS Society is no longer a representative of people with the disease.

"For them not to insist that CIHR research this, why? Wouldn't you think they would want CIHR to do this? What's it to them? ... Since when are you in bed with CIHR? You are not there to be in bed with them, you are here to represent us,' she said. [32] "To me it's bizarre. To me they are supposed to be advocates for us."

\section{Conclusion:}

Media coverage of Dr. Zamboni's MS hypothesis generated a great deal of emotion, reaction and study on the part of research funding agencies, patient groups and provincial governments. It's clear that divisions were created in the MS Society over its handling of the issue, and the health charity was forced to put sizable resources and time into responding to news, issuing press releases and creating an elaborate and robust 
website. This was the first time a response of this kind was required by the MS Society to any issue. Despite these efforts, the issue was divisive and, as a result, a large number of people living with MS lost faith in the society.

The Canadian Institutes of Health Research was also put on the hotseat - and the president of the federal granting council participated in more media interviews on CCSVI than any other topic in 2010 . The CIHR responded to public concern by bringing together research experts to discuss the merits of the issue - likely requiring considerable time and money. Interestingly, discussions at the CIHR-sponsored meeting in August 2010, obtained through an Access to Information request, reveal that some research experts felt the media were totally to blame for the hype and hysteria around this issue. The Quebec Association of Neurologists and the Canadian Network of MS Societies also blamed the media in public statements. Alberta Health Services warned people to carefully select their sources of information and to seek expert medical opinion.

Amid the clutter of media coverage, professional societies and medical associations felt the need to put out position papers and press releases on MS and CCSVI - at least eight statements were issued on the topic in 2010. Meanwhile, several provincial governments disregarded expert advice and proceeded to announce plans to fund research into the Zamboni procedure in the wake of public pressure.

More than a year later, tensions and uncertainty remain. Reluctance on the part of the MS Society and CIHR to participate in face-to-face interviews for this research study may point to an ongoing reality: communications professionals are concerned about potential damage to their organization and to relationships with the media if they question 
news coverage, further reinforcing the powerful role of journalists to set the agenda for public and political discussion.

\section{References:}

1. Wong, S. MS Society of Canada. Email communication. June 16, 2010.

2. Cockburn, C. Media Relations Office, Canadian Institutes of Health Research. Email communication. August 9, 2011.

3. Coulombe, D. Media Relations Office, Canadian Institutes of Health Research. Email communication. July 20, 2011.

4. MS Society of Canada news releases. Retrieved from: http://mssociety.ca/en/releases.htm

5. Canadian Institutes of Health Research and MS Society of Canada. (2010, August 26). Joint Invitational Meeting on Multiple Sclerosis Research: Participants list. Retrieved from: http://www.cihr-irsc.gc.ca/e/42381.html\#s6a

6. Canadian Institutes of Health Research and MS Society of Canada. (2010, August 26) Joint Invitational Meeting on Multiple Sclerosis Research: Summary Report. Retrieved from: http://www.cihr-irsc.gc.ca/e/documents/MSSummaryreport_e.pdf

7. Canadian Institutes of Health Research and MS Society of Canada. (2010, August 26). Joint Invitational Meeting on Multiple Sclerosis Research. Executive Summary. (Obtained through Access to Information Request.)

8. Canadian Institutes of Health Research and MS Society of Canada. (2010, August 26). Joint Invitational Meeting on Multiple Sclerosis Research. Open Discussion. (Obtained through Access to Information Request.)

9. Canadian Institutes of Health Research and MS Society of Canada. (2010, August 26). Joint Invitational Meeting on Multiple Sclerosis Research: Research Priorities. (Obtained through Access to Information Request.)

10. Canadian Institutes of Health Research. (2010. August 31). CIHR makes recommendations on Canadian MS research priorities. [News release.] Retrieved from: http://www.cihr-irsc.gc.ca/e/42382.html

11. Laupacis, A., Slutsky, A. Endovascular treatment for multiple sclerosis: The intersection of science, policy and the public. Open Medicine, 4(4). Retrieved from: http://www.openmedicine.ca/article/view/443/366 
12. Laupacis, A. Personal interview. June 29, 2011.

13. Freedman, M. Personal interview. Jan. 31, 2011.

14. Health Canada. (2010, September 1). Government of Canada accepts recommendations on MS research. [News release.] Retrieved from: http://www.hc-sc.gc.ca/ahc-asc/media/nr-cp/2010/2010 148-eng.php

15. Wong, S. MS Society of Canada. Email communication. June 16, 2011.

16. Alberta Health Services. (2010, February 16). Alberta Health Services statement on venous imaging and venous angioplasty in Multiple Sclerosis (MS). [Position statement.] Retrieved from: http://www.albertahealthservices.ca/feat/ne-featposition-statement-ccsvi-ms.pdf

17. Association des neurologues du Quebec. (2010, March 22). The Quebec Neurologists Association calls for calm. 22 March 2010. [News release.] Retrieved from: http://mssociety.ca/ccsvi/resources/20100322_qcneurologists_release.pdf

18. Ontario Health Technology Advisory Committee. (2010, May). OHTAC Recommendation. Multiple Sclerosis and Chronic Cerebrospinal Venous Insufficiency. Retrieved from: http://www.health.gov.on.ca/english/providers/program/ohtac/tech/recommend/re c ccsvi 20100611.pdf

19. Canadian Network of MS Clinics. (2010, July). CCSVI and its possible relationship to Multiple Sclerosis. [Web content.] Retrieved from: http://www.cnmsc.org/CCSVI-multiple-sclerosis-patient.aspx

20. Alberta Health Services. (2010, August 6). Multiple Sclerosis (MS) and Chronic Cerebrospinal Venous Insufficiency (CCSVI). [Information Sheet.] Retrieved from: http://www.albertahealthservices.ca/feat/ne-feat-ccsvi-ms-info-sheet.pdf

21. Society of Interventional Radiology. (2010, August 26). Society of Interventional Radiology supports research for new M.S. treatments. [News release.] Retrieved from: http://www.sirweb.org/news/newsPDF/Release JVIR MS final.pdf

22. The Association of Faculties of Medicine of Canada. (2010, September 21). AFMC supports CIHR recommendation regarding clinical trials on liberation procedure for MS. [News release.] Retrieved from: http://www.afmc.ca/newspress-releases-details-e.php?pid $=63$

23. Collège des médecins du Québec. (2010, November 9). Multiple Sclerosis and Chronic Cerebrospinal Venous Insufficiency. [News release.] Retrieved from: 
http://www.cmq.org/en/Medias/Profil/Commun/Nouvelles/2010/2010-1109/communique.aspx

24. Government of Newfoundland and Labrador. (2010, September 13). Province to fund observational study of MS patients. [News release.] Retrieved from: http://www.releases.gov.nl.ca/releases/2010/health/0913n07.htm

25. Fitzpatrick, M. (2010, September 14). Health ministers to consider controversial trials for MS treatment. Postmedia. Retrieved from:

http://www.vancouversun.com/health/Health+ministers+consider+controversial $+\mathrm{t}$ rials+treatment $/ 3522010 /$ story.html

26. Government of Manitoba. (2010, October 15). Manitoba invests in multiple sclerosis support and research. [News release.] Retrieved from: http://news.gov. $\mathrm{mb} . \mathrm{ca} /$ news/index.html?archive $=$ \&item $=9963$

27. Postmedia News. (2010, October 20) Saskatchewan takes Canadian lead in MS liberation treatment trials. National Post, p. A7.

28. Government of Alberta. (2010, December 16). Alberta commits to study MS treatment. [News release.] Retrieved from: http://alberta.ca/acn/201012/29688F01DDE29-0DD7-1BF7C08FCC884BD11EA0.html

29. O'Connor, P. Telephone interview. Feb. 11, 2011.

30. Thornton, E. Personal interview. Feb. 21, 2011.

31. Katz, A. Personal interview. March 25, 2011.

32. Cooney, R. Personal interview. April 8, 2011. 


\section{Chapter 8: The power of social media}

Physicians, researchers, patients and journalists agree that social media played a major role in advancing the story of Dr. Paolo Zamboni's research into multiple sclerosis. The new and powerful reality of social media has been a subtext of every chapter in this study. Facebook, blogs and YouTube magnified media coverage, rallied supporters, helped form national and international coalitions, pushed story ideas to health reporters and worked to influence national and provincial research agendas. Social media also changed the way the mainstream media communicated with the public, members of the public reached out to the media, and governments and organizations shared information. This chapter will attempt to further describe the role and impact of social media on news coverage and public opinion.

For the most part, analysis will be qualitative because it is difficult, if not impossible, to quantify the scope and reach of social media. There are hundreds of thousands of websites, blogs, Facebook pages and YouTube videos dedicated to Dr. Zamboni's CCSVI research, with new ones springing up daily. Using the Google search engine, for example, there were $6,650,000$ results for "liberation therapy", $1,140,000$ results for "CCSVI" and 657,000 results for "Zamboni MS" on Aug. 16, 2011. A search of Twitter found many individuals, clinics and organizations sending out 140-character messages (or tweets) about "liberation therapy." Among them \#ccsviRx, which has sent over 12,000 tweets from a clinic in Tijuana, Mexico about the benefits of therapy and its diagnostic and treatment services. A YouTube search for the acronym "CCSVl" turned up 3,200 results. There were 249 results for "liberation therapy" on YouTube and 522 results for "Zamboni MS". But numbers don't even begin to tell the story. 


\section{All roads lead to social media}

Reporting on Zamboni's research on MS began with social media and lives on through social media. According to the journalist who broke the story about the liberation procedure, her first report was triggered by online discussion. It is "the number one subject on the internet chat sites among MS patients, which is one reason we went to Italy," CTV medical specialist Avis Favaro indicated on Canada-AM in the lead-up to her exclusive report on W5. [1]

As soon as the story broke on CTV and in The Globe and Mail, online media once again snapped into action. Evan Thornton, an Ottawa man diagnosed with MS 10 years ago, received emails and Facebook messages almost immediately - all containing links to the news stories. [2] Rebecca Cooney received an email alert from the local MS Society, advising her to watch the W5 program in Nov. 2009. Once the program aired, she began to connect with others online who had seen the story and wanted to share their thoughts and experiences. [3] Within weeks, she learned how to set up a website and created MSliberation.ca to begin to mobilize people to push for the therapy.

Facebook sites were created within days of the CTV special report. Reporters who covered the issue often referred to the following sites: Ccsvi Facebook; Ccsvi Facebook Toronto; Ccsvi Facebook UBC; Ccsvi Facebook Calgary; Ccsvi Facebook Ottawa; and Ccsvi Forum. Sites became a place to share information among patients but also a place where journalists could find people to interview for their stories, track individuals contemplating the surgery and meet people travelling abroad for treatment. A commentary in Nature describes the "extraordinary mobilizing power of the media and 
the Internet." [4] "More than 500 Facebook groups, pages and events dedicated to promoting vascular treatment for MS have emerged in less than two years and amassed tens of thousands of participants," the authors state. "Indeed, the case indicates the unprecedented pressures that politicians and funders worldwide can now face to alter research priorities even in the absence of credible scientific evidence."

The result of online chatter was immediately apparent to physicians who treat people with MS. Most patients seemed to be on Facebook, says Toronto MS specialist Dr. Paul O'Connor, national scientific adviser to the MS Society of Canada. "They would all say they were checking things out on the Internet. . . I was surprised at the power of social media to mobilize, to organize a disparate group of people." [5] Patients came to appointments armed with journal articles and news stories retrieved online.

Using social media, rallies were organized. People blogged about their experiences. [6] YouTube videos, posted by individuals and by foreign clinics, included testimonials from people who received the therapy. A video from Apollo Hospitals in India, for example, features interviews with Canadians who had just undergone the procedure. [7] "My hands felt warm. My feet felt warm. This is fantastic," Paul Stock of Canada says into the camera. In addition to professional quality videos produced by clinics and hospitals, many individuals documented their personal improvements on homemade videos posted to YouTube. [8, 9]

Patients used social media to share contact information for clinics, names of doctors [10] and details of medical care. Special interest groups posted roundtable discussions and seminars on the topic. [11, 12] Ads began to pop up on MS websites for medical tourism packages. Links to news stories and dedicated MS "liberation therapy" 
websites and blogs [13] were shared online. People with MS and their families also spilled their anger towards neurologists who spoke against the therapy. For example, there are Facebook sites dedicated solely to lampooning MS specialist Dr. Mark Freedman, a vocal skeptic of the Zamboni therapy. [14] "With the assistance of social media a lot can be said about you, such as that you're in the pocket of a pharmaceutical company, that can make the people who listen to you have a bias of their own," said Dr. O'Connor.

\section{Personal appeal and power shifts}

When Thornton travelled to Poland to have the veins in his neck unclogged, he blogged throughout the experience [15] and the link to his blog was posted on news websites across the country. At the same time, $\mathrm{CBC}$ television filmed the medical procedure. Thornton said there is no question that social media changed the way news was shared among people around the world, and influenced public opinion. "Firstly, a story can propagate incredibly quickly," Thornton said. Television news reports were integrated into social media. New reports were embedded in blogs. Local stories were shared with people across the country. Social media "turns local mainstream media coverage into national coverage," Thornton said. "It can take a local story and make it an international story at the drop of a hat. Social media amplifies the buzz around the news treatment, certainly. And it probably feeds demand."

Thornton said use of social media is a two-way street. "Most journalists I know are tracking their Twitter or tracking their Facebook. They are using their Blackberries and iPhones and they are integrated into the social media world ...I think they just 
amplify each other. Certainly, I think working journalists constantly use these social media tools anyway. Again, that blurs the distinction for me," Thornton said. He said reporters contacted him for interviews via Twitter and Facebook.

Andrew Katz, who travelled to India and then to the U.S. to receive treatment for his MS, said he used social media to organize rallies in every major Canadian city in order to put pressure on federal and provincial governments to take a serious look at Dr. Zamboni's research. [16] "I was able to sit here at my computer and organize those rallies without any difficulty at all," said Katz, who uses a wheelchair. "It would have been a lot harder to do if we didn't have the Internet, right, . . . but Facebook helped me meet people in Vancouver. So it worked out well." Popular websites, including mspush.ca and msliberation.ca, played a huge role "in communicating, in sharing ideas, in getting the word out," Katz said. "Even globally. I have been in touch with a neat website in Switzerland. It's fantastic. You could never have done this 10, 15 years ago. You could never have got what we were able to without social media." Within a year, Katz said, "we forced the government to blink." Part of the reason for the success was a constant stream of news updates, allowing people to react and share information within minutes. Jennifer Molson, an Ottawa woman who received stem-cell therapy for MS, said what has struck her "with this whole Zamboni treatment is that it is now patients driving the media." [17] Cooney, who was treated twice in the U.S. for MS, said patients are much better informed than ever before because of social media. People are following news reports, reading studies and scholarly journals. They are pushing information to health-care providers, instead of the other way around. "What I think is really huge is that the distribution of power has changed," Cooney said. "The neurologists and the specialists 
don't have a monopoly on information any more. And I think that changes the game a lot because you can't just go to your doctor and have him say 'I know what's best for you and go away.' It doesn't work that way any more.... I go to my computer and I will have 10 emails from people and all these different publications. Once you have the network set up everybody feeds it."

Globe and Mail columnist Margaret Wente has cautioned about dangers in letting patient pressure and social media determine research funding priorities. "Social networking has added a new dimension to the uproar. Outraged patients are connecting in online forums and Facebook groups with names such as MS Uprising. They're drafting online petitions and launching campaigns to divert donations away from traditional MS groups, which they think have been too slow to act. They even have a YouTube channel." [18] "Medical funding is too important to be driven by popular demand instead of facts."

In the Nature commentary, [4, p. 411] Chafe et al write: "Unproven treatments have long been proposed, and tried, for diseases. Tools such as Facebook and YouTube make it considerably more likely that patients will learn about such therapies, without necessarily learning about their potential limitations. Similarly, the mobilizing power of social networking means that unprecedented pressures can be applied to politicians and research funders to expand access to procedures for which there is little scientific support."

Somewhat ironically, after the death of MS patient Mahir Mostic due to complications from a liberation procedure, Dr. Zamboni urged people to stay away from blogs and "to refer just to what was published". [19] And yet, Zamboni himself describes the CCSVI procedure in a YouTube video, complete with background music. [20] He set 
up his own YouTube channel in Oct. 2009 and uploaded a Doppler demonstration on Nov. 11,2009, about a week before the first news stories on his research appeared in Canadian news media.

Because patients are using new communications tools and sharing information via social media, Dr. Andreas Laupacis of the University of Toronto said scientists and medical specialists need to join the conversation. "I think if we don't somehow get engaged in the space we're just giving it up to the people that may not be very evidencebased," Dr. Laupacis said in an interview. [21] Dr. Michael Hill of the University of Calgary agreed that "social media is changing the world. There's just no doubt about it and, I think, probably for the better because people can communicate and communicate things fast. But we are, as a society, going to have to realize that sources of information are still critically important to understand what's going on." [22]

\section{Joining the conversation}

It was described in Chapter 7 how the MS Society created a website and online patient forum. The society also has a Facebook page [23] and Twitter account (@mssocietycanada) with more than 3,300 followers [24] and a YouTube channel, where it broadcasts information sessions and public forums. [25] The MS Society declined to comment on how it used social media to communicate with its stakeholders on CCSVI, but a review of these three online tools indicates that it used all three extensively to reach out to Canadians on the topic. For its part, the Canadian Institutes of Health Research (CIHR) said it used social media to interact with journalists and the public about MS.

According to the media relations department "CIHR used its corporate English and French Twitter accounts to tweet to its followers information and communication 
products (news releases, web texts, announcements, etc.) about the recommendations and priorities regarding the MS file available on CIHR's webpage. CIHR also tweeted information and provided links to communication products regarding the Government of Canada's decision to accept CIHR's recommendations. CIHR's media Twitter account (@cihr_irsc_Media) re-tweeted this information to allow journalist followers to see the tweets and links." [26] Through social media, organizations and governments have changed the way they interact with the public and how they disseminate messages to journalists in an effort to push information out faster, to reach broader audiences and to join online conversations.

\section{Impact on news media:}

Throughout this study, reporters have indicated that social media played a huge role in media coverage and the spread of information related to Dr. Zamboni's MS research. In fact, the five health reporters interviewed in Chapter 5 said they have never seen any health topic explode on social media like this particular story. The Globe's André Picard said the magnifying effect of social media has had an impact on mainstream journalism but no one has figured out how to deal with it. [27] The five reporters interviewed in Chapter 5 also indicated they used social media to find people to interview, monitor conversations and to track stories.

In an article on the jsource.ca website (part of the Canadian Journalism Project), CTV Calgary reporter Karen Owen described the challenge covering MS "liberation therapy" in the current online environment. "Professional journalists need to develop methods of incorporating and accepting the new age of participatory news without giving 
up total control and journalistic standards-especially when they're covering controversial stories about unproven treatments." [28]

\section{Conclusion:}

Social media played a central role in the evolution of news coverage of Dr. Zamboni's MS research. Mainstream media stories legitimized social media reports by covering a story that surfaced through online chatter. Patient groups used social media to share mainstream media stories and to provide instant reaction to new developments, organize rallies and develop advocacy campaigns. Local stories became national stories and then international news in a matter of minutes. Patients shared scientific research and became better informed than ever before.

Online tools also helped journalists track stories, find people to interview and monitor conversations. Private clinics and physicians reached out to Canadian patients through social media and people developed large online contact networks. At the same time, online tools were used to sometimes unfairly criticize people who spoke out against the research, raising questions about the tone and quality of online conversations.

Citizen journalism or participatory journalism flourished on YouTube, blogs, Twitter and Facebook sites. People wrote about their own experiences and posted videos from foreign surgical suites and uploaded before-and-after footage. This eliminated the filter of mainstream media coverage.

For journalists, the new reality of social media poses huge challenges, which require further research and perspective. 


\section{References:}

1. Favaro, A.; Laflamme, L. (2009, Nov. 20) MS Treatment. [Broadcast transcript]. CTV NEWS. Retrieved from: http://www.fpinfomart.ca/.

2. Thornton, E. Personal interview. Ottawa, ON. February 21, 2011.

3. Cooney, R. Personal interview. Ottawa, ON. April 8, 2011.

4. Chafe, R.; Born, K., B.; Slutsky, A., S.; Laupacis, A. The rise of people power. Nature, $472,410-411$.

5. O’Connor, P. Personal interview. February 11, 2011.

6. Appolo Hospital India. Retrieved from: http://liberation-treatment.com/letter-appolohospital-india

8. My sister's experience with liberation therapy for multiple sclerosis. [YouTube video]. Retrieved from: http://www.youtube.com/watch?v $=4 \mathrm{R} 7 \mathrm{r}$ (GHdsco

9. MS after liberation. [YouTube video]. Retrieved from: http://www youtube.com/watch?NR=1\&v=R7G3vkwd3yI

10. Liberation treatment [website] Retrieved from: http://iberationtreatment.com/liberation-treatment/doctors

11. CCSVI Alliance. Roundtable discussion. [YouTube video]. Retrieved from: http://www.youtube.com/watch?v=JZVmOwl rL6o\&feature=youtu.be

12. CCSVI Alliance. Retrieved from: http://ccsvi.org/index.php/the-basics/intro-to-ccsvi

13. MS, CCSVI, liberation surgery and me. [Personal blog]. Retrieved from: http://iamsickofms.blogspot.com

14. Can CCSVI get more fans than Mark (pill pusher) Freedman? [Facebook group]. Retrieved from: http://www.facebook.com/group.php?gid=110929925605937\&v=wall

15. Arterial excusions. [Blog]. Retrieved from: http://evanthornton.wordpress.com/

16. Katz, A. Personal interview. March 25, 2011.

17. Molson, J. Personal interview. March 10, 2011.

18. Wente, M. (2010, July 29). The explosive politics of MS. The Globe and Mail.p, A13. 
19. Allen, K. (2010, Nov. 22). Hype around cure for MS proves deadly. Toronto Star. p, A13.

20. Zamboni explains CCSVI and MS. [YouTube video]. Retrieved from: http://www.youtube.com/watch? $\mathrm{V}=\mathrm{C}$ RXs5dPh6E\&feature=grec index

21. Laupacis, A. Personal interview. June 29, 2011.

22. Hill, M. Personal interview. February 13, 2011.

23. Multiple Sclerosis Society of Canada. [Facebook group]. Retrieved from: http://www.facebook.com/MSSocietyCanada

24. Multiple Sclerosis Society of Canada. [Twitter account]. Retrieved from: https://twitter.com/\#!/MSSocietyCanada

25. Multiple Sclerosis Society of Canada. [YouTube channel]. Retrieved from: http://www.youtube.com/user/MSSocietyCanada\#p/u/5/3Ji5nB8b-4U

26. Coulombe, D. Canadian Institutes of Health Research. Personal email. July 20, 2011.

27. Picard, A. Personal interview. June 20, 2011.

28. Owen, K. (2011, Feb. 8). The Liberation Treatment: How the audience is changing health reporting." $J$-Source. Retrieved from:

http://j-source.ca/article/liberation-treatment-how-audience-changing-health-reporting 


\section{Chapter 9: Conclusion}

It has been less than two years since a relatively unknown scientist in Italy made headlines, mostly in Canada, with a new hypothesis about the cause of multiple sclerosis, a disease with no apparent cure. The story about Dr. Paolo Zamboni became a Canadian sensation when a reporter and producer from CTV, the largest private television network in the country, travelled to an ancient Italian city to witness first-hand the apparent transformative impact of what was described as the "liberation procedure." Characterizing MS as a vascular disease, instead of an auto-immune disorder, Dr. Zamboni unblocked veins in the necks and chests of MS patients to reverse or halt the symptoms of disease.

The CTV story and a companion piece in Canada's national newspaper, The Globe and Mail, captured the attention of people across the country and led to more media coverage and a greater public response here than anywhere else. A year and a half after the initial news reports, more than half of Canadians were aware of the use of venoplasty to treat MS and more people had "googled" the topic in Canada than in Italy, the U.S. or the U.K. [1]

The purpose of this research has been to examine the influence of mainstream news media in the promotion of new and unproven medical therapies. The Zamboni story has provided a striking case study because Canadian news reporting clearly influenced decision-making by individuals, organizations, medical professionals, governments and funding agencies; confirmed media theory around agenda-setting, framing and priming; and raised questions for future research. "This controversy over access to novel treatment 
illustrates how quickly news of promising scientific discoveries can create unrealistic expectations," according to an editorial in the Canadian Medical Association Journal. [2]

As indicated throughout this study, the CCSVI story is still evolving. Over the past year, new developments, contradictory studies, political decisions and position papers have emerged almost weekly. In spring 2011 , for example, the journal that first published Dr. Zamboni's news-making research, the Journal of Neurology, Neurosurgery and Psychiatry (JNNP), questioned whether his work had been "science or science fiction...greatly facilitated by the media and Internet blogs" [3] and, while Dr. Zamboni had encouraged scientists to think outside the box, double- and triple-blinded follow-up studies failed to confirm his findings. In the same issue of JNNP, a group of German researchers referred to Dr. Zamboni's work as "the perfect crime." They said no one could find a link between blocked veins and MS except Dr. Zamboni and his supporters. [4] Yet, just two months later, Canada's federal health minister announced plans to fund the first clinical trials into the vein-widening therapy because expert advice and a metaanalysis of scientific literature suggested there was enough evidence to proceed. The contradictions continue.

As the scan of news coverage revealed, early reporting on the issue was unbalanced, failed to include the perspective of MS specialists, failed to communicate risks associated with a new treatment and did not place research in the context of other scientific advances in the field. The treatment was framed as a potential cure for the disease and news stories included language that hyped the research - words like breakthrough, hope and cure. Especially disconcerting was the news media's use of the term "liberation procedure", coined by the researcher, because it implied that individuals 
could be freed from their disease. There is no question people living with MS, including some of those interviewed for this study, were understandably energized by news coverage. "The media have great power to change or shape public opinion," says neurologist Dr. Paul O'Connor, scientific adviser to the MS Society of Canada. "I have definitely learned that first hand." [5]

The central character in this story, Dr. Paolo Zamboni, was portrayed as a herohelper, who developed a simple technique to treat a complex disease. These two elements (a hero and a non-technical solution) are particularly attractive to health reporters in story development, according to media literature. In this case, the audience was primed to believe the discovery would change people's lives and stories set the agenda for political and public discussion around the therapy. Analysis and discussion in mainstream media about the quality of Dr. Zamboni's research and the depth of health reporting was minimal and lacked journalistic backup.

Among those who publicly spoke out about the media's handling of the topic was Canadian historian and intellectual Michael Bliss. He weighed in on early news coverage when he congratulated the National Post in a January 2010 letter to the editor for exposing the "media's distorted and distorting enthusiasm for the Zamboni treatment." He argued that "other outlets' coverage of Dr. Paolo Zamboni's work seems to be yet another case of naive reportage doing cruel harm in raising false hope in sick people. Corrective work (by the National Post) ... reminds us why it's important for Canada to continue to have two national newspapers." [6] Another Canadian observer to speak out about media coverage was Dr. Michael Rasminsky, McGill University neurology professor, who wrote a September 2010 letter in The Globe and Mail: "The media have 
reported miraculous responses $\ldots$ but anecdotal reports are meaningless. Individuals who did not "respond" to the treatment are not news." [7]

While many patients reported remarkable improvements in their symptoms, it took almost a year before stories of complications began to surface. It is unknown how many people have travelled outside of Canada for treatment - with figures ranging from 1,000 to more than 12,000 individuals. The Canadian government announced the creation of a national registry early in 2011 in an effort to quantify the number of patients and to determine the outcomes from treatment. [8]

It is interesting to note that, although several of the reporters interviewed for this study indicated a scientific journal's influence and reputation are normally factors in story selection, Dr. Zamboni's work did not come from a high-impact journal. According to the reporter who broke the story, the story idea came from social media and not a news release or public relations person, a deviation from common practice but a new reality of modern newsgathering. Also worth noting is the quality of the research published by JNNP and highlighted by the media. Dr. Zamboni's study involved a small sample size and it was not double-blinded (the physician knew that his patients had MS and the patients knew they were receiving the treatment.) This confirms that material published and promoted by the scientific community can be weak and unworthy of attention, requiring reporters to be cautious or, as described in Chapter 1, to exercise the "prudent reader test." That is, health journalists should ask themselves what a prudent person would do or assume about a medical intervention based on their news report.

Reluctance by the MS Society and medical specialists to embrace the vascular hypothesis created tension among physicians, patients, research funding agencies and 
journalists. Tension among opposing forces heightened the story's appeal. Two MS experts interviewed in Chapter 4 indicated they had been contacted for input into the Zamboni research, but were never interviewed on camera or quoted in stories. However, reporters who covered the story said the medical community is partly responsible for the lack of balance in news stories because physicians failed to speak up early and forcefully about their concerns around the Zamboni research.

The literature on medical reporting indicates health reporters often fail to ask tough questions about commercial interests behind new medical therapies. The media scan and interviews with health reporters, medical specialists and people living with MS confirm this to be true. There was little reporting on how foreign clinics profited from performing vein-widening treatment, how Dr. Zamboni himself may have profited from patents or speaking engagements and how neurologists and pharmaceutical companies stood to gain or lose. Reporters admitted they should have asked more questions. There is also a need for the medical community to be more forthcoming about relationships with drug companies and commercial interests.

Journalists failed to put the discovery in the context of other scientific advances. For example, stem cell therapy - a risky procedure of possibly limited clinical benefit required years of rigorous review and complex approvals. The slow and measured response from funding agencies to the Zamboni findings was typical of the path of scientific research but never described that way in media reports.

Reporters, scientists and people living with MS agreed that social media played a huge role in the evolution of news coverage and provided the strongest example to date of the magnifying effect on health news. Social media were used to disseminate 
mainstream news, organize rallies and share personal stories without the filter of professional journalism. Reporters used social media to find sources and monitor conversations. While journalists saw the impact of social media on health news like never before, they indicated that they would like to learn how to deal with this relatively new phenomenon. The role of social media in helping patients organize, educate themselves and to push mainstream news coverage warrants further study. Also worthy of further study is the process of borrowed legitimacy between social media and traditional media.

Media coverage set the agenda for discussions by health-research funding agencies and provincial governments. The Canadian Institutes of Health Research devoted considerable time and effort to studying the issue and pulling together research expertise. Meeting notes obtained through Access to Information reveal the research community believed the news media were to blame for hyping the issue, but this viewpoint was not reflected by CIHR in its online summary of discussions or in any public statements. Fear of alienating members of the news media is very real in communication circles, further illustrating the power of the press.

The time and money required to respond to public interest in the MS story was significant, but has not been quantified in this study due to lack of information from the agencies involved. The MS Society of Canada devoted considerable resources to the creation of an elaborate website dedicated to the Zamboni research, to the organization of public information sessions as well as media and public outreach. Many professional societies and health funding organizations were also required to develop a public response. 
For his part, health researcher and physician Dr. Andreas Laupacis said it could take years to know the true impact of media reporting into Dr. Zamboni's MS research.

"If I was able to talk to (the reporter who broke the story) and say 'look, now, there is an unbelievable flurry about this treatment and this disease. And has that done more harm than good?' My sense is, actually, we can't answer that until we find out what the final story is, right? Five years from now if all the studies have been done and it turns out that doing endovascular therapy is found to be useless, then I would argue that initial story did a huge amount of harm. It probably bankrupted a bunch of people. It probably killed a few people who had the treatment and died from the complications. It probably gave a whole bunch of people inappropriate hope and it lined the pockets of a whack-load of doctors who are doing this procedure. If it turns out that doing endovascular therapy has a modest amount of benefit, then you could argue that maybe had that article not come out and had it not led to all the media attention the trials wouldn't have been done. So, it's hard to know." [9]

In the end, this study indicates that journalists have an ethical responsibility to stick with their stories, to stay on top of new developments and to dig deeper. They also need to admit their mistakes and to correct those mistakes as required. Precedent for this includes the 2009 New York Times apology for reporting by journalist Judith Miller on the presence of weapons of mass destruction in Iraq. Erroneous reports, based on "dramatic but unverified claims and unreliable sources" helped justify a costly and deadly war and occupation, the newspaper said. In the case of "liberation therapy", if subsequent research disproves the Zamboni hypothesis and it is determined that a number of people suffered as a result of media coverage, news organizations should revisit their early coverage, correct misinformation and apologize for inaccuracies.

As medical specialists and media observers monitor the continuing evolution of the story, some important questions have been raised from this research that require further investigation. 


\section{Recommendations for further research:}

1. Social media play a huge role in modern-day newsgathering and news dissemination, but many reporters have indicated they don't know how to handle this new world order. Social media magnified mainstream news and promoted selective parts of news stories. Journalists need tools and training to respond to social media and to interact with citizen journalists. There also needs to be greater understanding of how mainstream media legitimize reports circulating in the blogosphere and how social media then use traditional media to justify their claims. How does this borrowed legitimacy affect the credibility of both new and traditional media? Should mainstream media push back against the magnifying effect of social media, especially when elements of news stories are taken out of context? And, if so, how might reporters do so? Should reporters try to correct misinformation put out in social media circles?

2. Three of the five reporters interviewed for this study had received specialized training in health and science journalism, however, news editors and producers also need to better understand the unique challenges of covering health news. Headlines, placement and play of stories as well as the on-air banter between reporters and anchors prime the audience, frame the story and set the agenda for discussion - probably as much as the content of the news stories. Should "debriefs" - the casual chatter between a television reporter and anchor about a news story - be allowed to accompany health stories as this is where mistakes can be made? One of the reporters involved in breaking the MS story indicated that if 
he could change anything, it would be the headline. What can be done to tame health headlines in an era of headline news?

3. How can news media right the wrongs of health misinformation? Certainly some MS medical specialists feel that apologies - and, potentially, restitution - are required if the Zamboni therapy results in harm to patients and their families. From a journalism-research perspective, it would be worthwhile to track this story for the next several years as research studies and clinical trials either validate or disprove Dr. Zamboni's hypothesis. How was news coverage rebalanced over time? Will members of the health news media eventually apologize if research confirms that early news reports were erroneous?

4. In the case of the MS "liberation therapy" story, reporters felt that medical experts were reluctant to express their views or they were slow off the mark in providing scientific background. Members of the public do not understand the complicated approval processes and timelines for clinical trials and this kind of perspective is important to provide context for stories. Why are scientists reluctant to insert themselves into the conversation? How can they be encouraged to speak with reporters and to right what they perceive as wrongs spread by social media?

5. Journalists admit they rely heavily on scientific publications to develop health stories. Can medical and scientific journals do anything to better equip general assignment and health reporters to evaluate and contextualize the significance of a 
given journal article? Can more be done to highlight the size of studies, the breadth of research efforts and the rigour of the peer-review process? Science media centres and groups like the Cochrane Collaboration are working to improve training and education but are they reaching general-assignment reporters who often cover health news?

Our society assigns tremendous value to health and medical news. Reporters, news editors, public-relations people, medical specialists and funding agencies play important roles in ensuring the clear communication of solid and verifiable research evidence. Because social media rapidly disseminates and magnifies news, extra care is required to ensure that stories are framed without hype and placed in the context of other developments. As has been stated, it will take years to determine the full impact of Canadian news coverage of MS "liberation therapy," but it is evident that the media's handling of this story provides a powerful illustration of the pitfalls and challenges of medical reporting on new and unproven therapies.

\section{References:}

1. Chafe, R.; Born, Karen, B.; Slutsky, Arthur, S.; Laupaucis, A. (2011). The rise of people power. Nature, 472, 410-411.

2. Stanbrook, M. B., Hebert, P. C. (2010) Access to treatment for multiple sclerosis must be based on science, not hope. Canadian Medical Association Journal, 182(11), p. 1151

3. Khan, O; Tselis, A. (2011) Chronic cerebrospinal venous insufficiency and multiple sclerosis: science or science fiction? Journal of Neurology Neurosurgery and Psychiatry, 82(4), p. 355. 
4. Mayer, C.A.; Pfeilschifter, W.; Lorenz, M.W.; Nedelmann, M.; Bechmann, I.; Steinmetz, H.; Ziemann., U (2011) Journal of Neurology Neurosurgery and Psychiatry, 82(4): 436-40.

5. O’Connor, P. Personal interview. February 11, 2011.

6. Bliss, M. Letter. (2010, January 26). Exposure of cruel MS hype is appreciated. National Post, p. A13.

7. Rasminsky, M. [Letter] (2010, September 4). In the end. The Globe and Mail, p. A16.

8. Public Health Agency of Canada. (2011, March 23). News release. Government of Canada announces new monitoring system for multiple sclerosis. Retrieved from: http://www.phac-aspc.gc.ca/media/nr-rp/2011/2011 0323-eng.php

9. Laupacis, A. Personal interview. June 29, 2011.

10. NYT Editorial. (2009, July 4) We apologize. New York Times. Retrieved from: http://www.nytimes-se.com/2009/07/04/we-apologize/ 


\section{REFERENCES:}

\section{Primary sources:}

Personal interviews:

\section{People living with MS:}

R. Cooney, personal interview, April 8, 2011.
A. Katz, personal interview, March 25, 2011.
E. Thornton, personal interview, February 21, 2011.
J. Molson, personal interview, March 10, 2011.
M. Murchison, personal interview, March 23, 2011.

\section{Physicians:}

Dr. B. Amason, email communication, June 27, 2011.

Dr. H. Atkins, personal interview, March 2, 2011.

Dr. M. Freedman, personal interview, January, 31, 2011.

Dr. M. Hill, personal interview, February 13, 2011.

Dr. A. Laupacis, personal interview, June 29, 2011.

Dr. P. O'Connor, personal interview, February 11, 2011.

\section{Journalists:}

T. Blackwell, National Post, personal interview, June 20, 2011.

K. Crowe, CBC News, personal interview, June 21, 2011. 
C. Goomansingh, Global News, personal interview, June 22, 2011.

A. Picard, The Globe and Mail, personal interview, June 20, 2011.

J. Smith, Toronto Star, personal interview, June 22, 2011.

\section{Communication officers:}

C. Cockburn, Media Relations Office, Canadian Institutes of Health Research, personal communication, August 9, 2011.

D. Coulombe, Media Relations Office, Canadian Institutes of Health Research. Personal communication. July 20, 2011.

S. Wong, MS Society of Canada, personal communication. June 16, 2010.

Reports, news releases and websites:

Alberta Health Services. (2010, February 16). Alberta Health Services statement on venous imaging and venous angioplasty in Multiple Sclerosis (MS). [Position statement.] Retrieved from: http://www.albertahealthservices.ca/feat/ne-feat-position-statementccsvi-ms.pdf

Alberta Health Services. (2010, August 6). Multiple Sclerosis (MS) and Chronic Cerebrospinal Venous Insufficiency (CCSVI). [Information Sheet.] Retrieved from: http://www.albertahealthservices.ca/feat/ne-feat-ccsvi-ms-info-sheet.pdf

Association des neurologues du Quebec. (2010, March 22). The Quebec Neurologists Association calls for calm. [News release.] Retrieved from:

http://mssociety.ca/ccsvi/resources/20100322_qcneurologists_release.pdf

Bennett, C.; Duncan, K. (2010, May 6). Letter to Minister of Health Leona Aglukkaq, Retrieved from: http://carolynbennett.liberal.ca/blog/letter-to-the-minister-of-healthregarding-ms-and-cesvi/

Canadian Institutes of Health Research and MS Society of Canada. (2010, August 26). Joint Invitational Meeting on Multiple Sclerosis Research: Participants list. Retrieved from: http://www.cihr-irsc.gc.ca/e/42381.html\#s6a

Canadian Institutes of Health Research and MS Society of Canada. (2010, August 26). Joint Invitational Meeting on Multiple Sclerosis Research: Summary Report. Retrieved from: http://www.cihr-irsc.gc.ca/e/documents/MSSummaryreport_e.pdf 
Canadian Institutes of Health Research and MS Society of Canada. (2010, August 26) Joint Invitational Meeting on Multiple Sclerosis Research. Executive Summary. (Obtained through Access to Information Request.)

Canadian Institutes of Health Research and MS Society of Canada. (2010, August 26) Joint Invitational Meeting on Multiple Sclerosis Research. Open Discussion. (Obtained through Access to Information Request.)

Canadian Institutes of Health Research and MS Society of Canada. (2010, August 26) Joint Invitational Meeting on Multiple Sclerosis Research: Research Priorities. (Obtained through Access to Information Request.)

Canadian Institutes of Health Research. (2010, August 31). CIHR makes recommendations on Canadian MS research priorities. [News release.] Retrieved from: http://www.cihr-irsc.gc.ca/e/42382.html

Canadian Network of MS Clinics. (2010, July). CCSVI and its possible relationship to Multiple Sclerosis. [Web content.] Retrieved from: http://www.cnmsc.org/CCSVImultiple-sclerosis-patient.aspx

Collège des médecins du Québec. (2010, November 9). Multiple Sclerosis and Chronic Cerebrospinal Venous Insufficiency. [News release.] Retrieved from:

http://www.cmq.org/en/Medias/Profil/Commun/Nouvelles/2010/2010-1109/communique.aspx

Government of Alberta. (2010, December 16). Alberta commits to study MS treatment. [News release.] Retrieved from: http://alberta.ca/acn/201012/29688F01DDE29-0DD71BF7-C08FCC884BD11EA0.html

Government of Manitoba. (2010, October 15) Manitoba invests in multiple sclerosis support and research. [News release.] Retrieved from:

http://news.gov.mb.ca/news/index.html?archive $=$ \&item $=9963$

Government of Newfoundland and Labrador. (2010, September 13). Province to fund observational study of MS patients. [News release.] Retrieved from:

http://www.releases.gov.nl.ca/releases/2010/health/0913n07.htm

Health Canada. (2010, September 1). Government of Canada accepts recommendations on MS research. [News release.] Retrieved from: http://www.hc-sc.gc.ca/ahcasc/media/nr-cp/2010/2010 148-eng.php

McDonald, S. (2010, May 11) Address to the Subcommittee on Neurological Disease of the Standing Committee on Health. Retrieved from:

http://www.parl.gc.ca/HousePublications/Publication.aspx?Docld $=4519570 \&$ Language= E\&Mode $=1 \&$ Parl $=40 \&$ Ses $=3$ 
Multiple Sclerosis Society of Canada. (2009, November 23). MS Society of Canada announces request for research operating grants related to CCSVI and MS. Retrieved from: http://mssociety.ca/en/releases/nr_20091123.htm

Multiple Sclerosis Society of Canada (2010, May 5). MS Society lobbies government for $\$ 10$ million for funding into CCSVI and MS research. Retrieved from: http://mssociety.ca/en/releases/nr 20100505.htm

Multiple Sclerosis Society of Canada (2010, June 11). Over \$2.4 Million Committed to Support Seven Operating Grants to Explore the Relationship of CCSVI to Multiple Sclerosis. Retrieved from: http://mssociety.ca/en/releases/nr_20100611.htm

Multiple Sclerosis Society of Canada (2010, September 16). MS Society of Canada commits \$1 million for CCSVI clinical trial. Retrieved from: http://mssociety.ca/en/releases/nr_20100916.htm

Ontario Health Technology Advisory Committee. (2010, May). OHTAC Recommendation. "Multiple Sclerosis and Chronic Cerebrospinal Venous Insufficiency" Retrieved from:

http://www.health.gov.on.ca/english/providers/program/ohtac/tech/recommend/rec_ccsvi 20100611.pdf

Society of Interventional Radiology. (2010, August 26). Society of Interventional Radiology supports research for new M.S. treatments. [News release.] Retrieved from: http://www.sirweb.org/news/newsPDF/Release_JVIR_MS final.pdf

The Association of Faculties of Medicine of Canada. (2010, September 21). AFMC supports CIHR recommendation regarding clinical trials on liberation procedure for MS. [News release.] Retrieved from: http://www.afmc.ca/news-press-releases-detailse.php?pid $=63$

\section{Blogs and websites:}

Appolo Hospital India. Retrieved from: http:/liberation-treatment.com/letter-appolohospital-india

Arterial excursions. Retrieved from: http://evanthornton.wordpress.com/

CCSVI Alliance [website] Retrieved from: http://ccsvi.org/index.php/the-basics/intro-to$\underline{\text { ccsvi }}$

CCSVI Alliance. Roundtable discussion. [YouTube video]. Retrieved from: http://www.youtube.com/watch?v=JZVmOw1 rL6o\&feature=youtu.be 
Can CCSVI get more fans than Mark (pill pusher) Freedman? [Facebook site]. Retrieved from: http://www.facebook.com/group.php?gid=110929925605937\&v=wall

Liberation treatment. [website] Retrieved from: http://liberation-

treatment.com/liberation-treatment/doctors

Haacke, M. Google TechTalk. (2010, October 4) [YouTube video]. "Breakthroughs in imaging neurovascular diseases." Retrieved from:

http://www.youtube.com/watch?v=lqDrvNC7Oi8

MS, CCSVI, liberation surgery and me. [Personal blog.] Retrieved from:

http://iamsickofms.blogspot.com

MS after liberation. [YouTube video]. Retrieved from:

http://www.youtube.com/watch?NR=1\&v=R7G3vkwd3yl

MS Liberation. [website]. Retrieved from:

http://www.msliberation.ca/MS_Liberation_Group/Welcome.html

Multiple Sclerosis Society of Canada. [Facebook group]. Retrieved from: http://www. facebook.com/MSSocietyCanada

Multiple Sclerosis Society of Canada. [Twitter account]. Retrieved from: https://twitter.com/\#!/MSSocietyCanada

Multiple Sclerosis Society of Canada. [YouTube channel]. Retrieved from: http://www.youtube.com/user/MSSocietyCanada\#p/u/5/3Ji5nB8b-4U

My sister's experience with liberation therapy for multiple sclerosis. [YouTube video]. Retrieved from: http://www.youtube.com/watch? $=4$ Rt7rGHdsco

Rubin, B. University Health Network - Peter Munk Cardiac Centre, Public Lecture on CCSVI and MS. (2011, January 28) [YouTube video]. www.uhn.ca/Focus_of_Care/Munk_Cardiac/whats_new/PMCC_Conference/publiclectureMS/index.asp

Wheelchair Kamikaze. [blog]. The rants, ruminations and reflections of a mad MS patient. Retrieved from: http://www.wheelchairkamikaze.com/

Zamboni explains CCSVI and MS. [YouTube video]. Retrieved from: http://www. youtube.com/watch? $v=C$ RXs5dPh6E\&feature $=$ grec index 
Secondary sources:

\section{Book and Journal articles:}

Adam, M. \& Oransky, I. Retraction Watch: Tracking retractions as a window into the scientific process. Retrieved from: http://retractionwatch.wordpress.com/

Bell, A. (1998). The discourse structure of news stories. (Chapter 3) In Bell, A. and Garrett, P. (1998) (Eds.) Approaches to Media Discourse. Blackwell Publishers, UK.

Bubela, T.M. and Caulfield, T.A. (2004). Do print media 'hype' genetic research? A comparison of newspaper stories and peer-reviewed research papers. Canadian Medical Association Journal, 170(9), 1399-407

Brooks, M. The power of the placebo effect. New Scientist, 2670, 36-39.

Campion, E.D., (2004). Medical research and the news media. New England Journal of Medicine, 351(23), 2436-2437.

Cassels, A., Merrilee, A., Cole, C., Mintzes, B. Lexchin, J. and McCormack, J.P. (2003). Drugs in the news: an analysis of Canadian newspaper coverage of new prescription drugs. Canadian Medical Association Journal, 168(9), 1133-1137.

Cassels, A. (2007). The media-medicine mix: quality concerns in medical reporting. Open Medicine, 1(1). Retrieved from: http://www.openmedicine.ca/article/view/54/4

Castro HJ, Mendez-Inocencio JI, Omidvar B (2005) A phase I study of the safety of honeybee venom extract as a possible treatment for patients with progressive forms of multiple sclerosis. Allergy and Asthma Proceedings, 26(6), 470-476

Chafe, Roger; Born, Karen, B.; Slutsky, Arthur, S.; Laupaucis, Andreas. (2011). The rise of people power. Nature, $472,410-411$

Davies, N. (2008). Flat Earth News. London: Random House.

Dentzer, S. (2009). Communicating medical news - Pitfalls of health care journalism. New England Journal of Medicine, 360, 1-3

Deuze, M., Bruns, A. \& Neuberger, C. (2007). Preparing for an age of participatory news. Journalism Practice, 1(3), 322-335

Dorne, H., Zaidat, O.O, Fiorella, D., Hirsch, J., Prestigiacomo, C., Albuquerque, F., Tarr, R.W. (2010). Chronic cerebrospinal venous insufficiency and the doubtful promise of an endovascular treatment for multiple sclerosis. J Neurolntervent Surg, 2, 309-311 
Dyment, D. A.; Ebers, G. C; Sadovnick, A. D. (2004) Genetics of multiple sclerosis, Lancet Neurology, 3(2), 104-110.

Eggertson, L. Lancet retracts 12-year-old article linking autism to MMR vaccines. Canadian Medical Association Journal, 182(4), 199-200.

Einsiedel, E.F. (1992). Framing science and technology in the Canadian press. Public Understanding of Science, 1(89), 89-101.

Emke, I. (2000). "Agents and structures: journalists and constraints on AIDS coverage." Canadian Journal of Communication, 25(3).

Friedman, L.D. (2004). Through the looking glass: medical culture and the media. In Friedman, L.D. (Ed.) Cultural Sutures: Medicine and media. Duke University Press.

Gasher, M., Hayes, M., Hackett, R., Gutstein, D., Ross, I. \& Dunn, J. (2007). Spreading the news: social determinants of health reportage in Canadian daily newspapers. Canadian Journal of Communication, 32, 557-574.

Gillmor, D. (2006). We the media. Sebastopol, CA: O'Reilly Media Inc.

Goldacre, B. (2009). Bad Science. London: Random House.

Haacke E. M., Garbern J., Miao Y., Habib C., Liu M. (2010). Iron stores and cerebral veins in MS studied by susceptibility weighted imaging. International Angiology 29(2), 149-57.

Hinnant, A. \& Len-Rios, M.E. (2009). The tacit understandings of health literacy: interview and survey research with health journalists. Science Communication, 31(1), 84115.

Hivon, M., Lehoux, P., Denis, J.-L. \& Rock. M. (2010). Marginal voices in the media coverage of controversial health interventions: how do they contribute to the public understanding of science? Public Understanding of Science, 19(1), 34-51.

Hoag, Hannah. (2008) Membership survey, Canadian Science Writers Association. [using the online tool SurveyMonkey.com]

Kelly, B.J., Leader, A.E., Mittermaier, D.J., Hornik, R.C., Cappella, J.N. (2009). The HPV vaccine and the media: how has the topic been covered and what are the effects on knowledge about the virus and cervical cancer? Patient Education and Counselling, 77, 308-313. 
Laupacis, A., Slutsky, A. Endovascular treatment for multiple sclerosis: The intersection of science, policy and the public. Open Medicine, 4(4) Retrieved from:

http://www.openmedicine.ca/article/view/443/366

Manning, P. (2001). New media politics and the politically marginal. News and News Sources: A Critical Introduction. London: Sage.

Nelkin, D. (1987). Selling Science: How Press Covers Science and Technology. New York: W.H. Freeman and Company.

Noseworthy, J.H., Lucchinetti, C., Rodriguez, M., Weinshenker, B.G. (2000). New England Journal of Medicine, 343, 938-952

Orton, S.M, Ramagopalan, S.V., Brocklebank, D., Herrera, B.M., Dyment, D.A., Yee, I.M., Sadovnick, A.D., Ebers, G.C. (2010). Effect of immigration on multiple sclerosis sex ratio in Canada: the Canadian Collaborative Study. Journal of Neurology Neurosurgery \& Psychiatry, 81, 31-37.

Owen, K. (2011, Feb. 8). The Liberation Treatment: How the audience is changing health reporting." J-Source. Retrieved from:

http://j-source.ca/article/liberation-treatment-how-audience-changing-health-reporting

Picard, A. (2005). How can we improve medical reporting? Let me count the ways. International Journal of Health Services, 35(3).

Ramagopalan, S.,V. \& Sadovnick, A. D. (2011). Epidemiology of multiple sclerosis. Neurologic Clinics, 29(2), 207-217.

Roy, S.C, Faulkner, G., \& Finlay, S. (2007). Fit to print: A natural history of obesity research in the Canadian news media. Canadian Journal of Communication, 32, 575-594.

Rynor, B., (2010) Canadian trials to examine "liberation procedure" for multiple sclerosis. Canadian Medical Association Journal, 182(9), p. E403

Sawcer, S. (2008) The complex genetics of multiple sclerosis: pitfalls and prospects. Brain, 131(12), 3118-3131

Scheufele, D.A. \& Tewksbury, D. (2007). Framing, agenda-setting, and priming: The evolution of three media effects models. Journal of Communication, 57, 9-20.

Schwitzer, G. (1992). The magical medical tour. Journal of the American Medical Association, 267(14).

Schwitzer, G. (2000). Seven words you shouldn't use in medical news. (First published on MayoHealth.org on Feb. 1, 2000.) Retrieved from: 
http://www.healthnewsreview.org/article2 7 words not to use.php

Schwitzer G., Mudur G., Henry D., Wilson A., Goozner M., et al. (2005). What are the roles and responsibilities of the media in disseminating health information? PLoS Med $2(7), 576-582$.

Seale, C., Ed., (2004). Health and the Media. Oxford, U.K: Blackwell Publishing Seale, C. (2002). Media and Health, London: Sage Publications Ltd.

Sifry, M.L. (2009). A see-through society. Columbia Journalism Review. Retrieved from: www.cjr.org/feature/a_seethrough society.php

Smith, R. (2006). The trouble with medical journals. Journal of the Royal Society of Medicine, 99, 115-119.

Soroka, S. (2002). Issue attributes and agenda-setting by media, the public and policymakers in Canada. International Journal of Public Opinion Research. 14(3), 264518.

Stanbrook, M. B., Hebert, P. C. (2010). Access to treatment for multiple sclerosis must be based on science, not hope. Canadian Medical Association Journal, 182(11), 1151.

Waddell, C., Lomas, J., Lavis, J.N., Abelson, J., Shephard, C.A. and Bird-Gayson, T. (2005). Joining the conversation: newspaper journalists' view on working with researchers, Healthcare Policy, 1(1), 123-139.

Wakefield, A.J., Murch, S.H., Anthony, A., Linnell, J., Casson, D.M., Malik, M., Berelowitz, M., Dhillon, A.P., Thomson, M.A., Harvey, P., Valentine, A., Davies, S.E., Walker-Smith, J.A. Ileal-lymphoid-nodular hyperplasia, non-specific colitis, and pervasive developmental disorder in children. The Lancet, 351, 637-41.

Wattjes, M., van Oosten, BW, de Graaf, W. L, Seewan, A., Bot, JC, van den Berg, R., Uitdehaag, B.M., Polman, C.H., Barkhof, F. (2010). No association of abnormal cranial venous drainage with multiple sclerosis: a magnetic resonance venography and flowquantification study. Journal of Neurology Neurosurgery \& Psychiatry. Doi: 10.1136/jnnp.2010.223479

Wei, R.; Lo, V-W; Lu, H-Y. (2008). Third-person effects of health news; Exploring the relationships among media exposure, presumed media influence and behavioral intentions. American Behavioral Scientist. 55 (2) 261-277

Yamout, B., Herlopian, A., Issa, Z., Habib, R.H., Fawaz, A., Salame, J., Wadih, A., Awdeh. H., Muallem, N., Raad, R., Al-Kutoubi, A. (2010). Extracranial venous stenosis is an unlikely cause of multiple sclerosis. Multiple Sclerosis, 16(11, 1341-1348. 
Zamboni, P., Galeotti, R., Menegatti, E., Malagoni, AM, Tacconi, G., Dall'Ara, S., Bartolomei, I., Salvi, F. (2009) "Chronic cerebrospinal venous insufficiency in patients with multiple sclerosis." Journal of Neurology Neurosurgery \& Psychiatry, 80(4), 392399.

Zamboni, $P$. Iron-dependent inflammation in venous disease and proposed parallels in multiple sclerosis. (2006). Journal of the Royal Society of Medicine, 99, 589-93.

Zivadinov, R.; Lopez-Soriano, A.; Weinstock-Guttman, B.; Schirda, C.V; Magnano, C. R; Dolic, K.; Kennedy, C. L; Brooks, C. L; Reuther, J. A; Hunt, K.; Andrews, M.; Dwyer, M. G; Hojnacki, D. W. (2011) Use of MR venography for characterization of the extracranial venous system in patients with multiple sclerosis and health control subjects. Radiology, 258(2), 562-570.

\section{Newspaper articles:}

\section{National Post}

Barber, M., Canwest News Service. (2010, June 7) Treatment debate dividing MS Society; Advocates want 'liberation therapy' at top of agenda. National Post, p. A8

Blackwell, T. (2010, January 23). Cure vs. hype; Is new MS research the real thing, or a media-driven frenzy. National Post, p. Al

Blackwell, T. (2010, February 9). Test theory, but treat MS patients, doctor says; Canadian visit. National Post, p. Al

Blackwell, T. (2010, February 11). Research casts doubt on new MS theory. National Post, p. A1.

Blackwell, T. (2010, April 15). MDs warn against MS treatment; Blocked vein theory. National Post, p. A4.

Blackwell, T. (2010, September 1). Little proof to back MS procedure, agency says; Call for more study leaves critics 'dumbfounded', National Post, p. A4.

Blackwell, T. (2010, November 29). Unproven treatments get indirect subsidies; Tax credits given for foreign health procedures. National Post, p. A1

Blackwell, T. (2010, December 8). Science only one factor in MS trials: critics; Zamboni treatment; Federal body failed to consult public, they say. National Post, p. A6.

Bliss. M. [Letter]. (2010, Jan. 26). Exposure of cruel MS hype is appreciated. National Post, p. A13. 
Canwest News Service. (2010, May 1). Canadians to study possible link between MS and vein blockages. National Post, p. A5.

Carlson, K.B. (2010, June 30). Don't base MS Cure on hope: paper; 'Insist on evidence' says CMA Journal. National Post, p. A4.

Corcoran, T. [Column]. (2010, January 23). 'A cure in sight?' Not so fast; Media coverage reeks of typical hope-mongering. National Post, p. A7.

Corcoran, T. [Column]. (2010, June 15). Hope mongering. National Post, p. FP11.

Fitzpatrick, M.; Fowlie, J. Postmedia News. (2010, September 14). Ministers to develop limits on salt levels; Provinces to look into clinical trials for MS therapy. National Post, p. A4.

Fitzpatrick, M. Postmedia News. (2010, November 20). Don't fall for overseas MS cure: Minister; Linked to death. National Post, p. A11.

Francis, S. [Editorial]. (2010, September 28). The liberation of health care. National Post, p. A16.

Gunter, L. [Column]. (2010, June 11). They just want some relief. National Post, p. Al6.

Gunter, L. [Column]. (2010, September 17). Relief on their own dime. National Post, p. A 16.

Inwood, D. Canwest News Service. (2010, June 12) \$2.4M study for controversial MS treatment. National Post, p. A19.

Ivens, A. Postmedia News. (2010, July 30) B.C. urged to join MS trials. National Post, p. A6.

Iype, M. Postmedia News. (2010, September 2). No money for MS trials yet, Ottawa says; Awaiting test results. National Post, p. A5.

Kleiss, K. Postmedia News. (2010, December 17) Alberta to fund study on Zamboni MS treatment. National Post, p. A8.

Postmedia News. (2010, July 28). Saskatchewan willing to fund trials for MS; "Liberation" therapy; Controversial, unproven but promising. National Post, p. A6.

Postmedia News. (2010, August 19). Quebec may join MS liberation trials. National Post, p. A6.

Postmedia News. (2010, August 21). Nova Scotia backs disputed MS treatment. National Post, p. A4. 
Postmedia News. (2010, August 25). N.L. summit to shed light on MS treatment. National Post, p. A4.

Postmedia News. (2010, August 26). Clinical trial of new MS treatment years away, researcher cautions. National Post, p. A8.

Postmedia News. (2010, October 20). Saskatchewan takes lead in MS liberation treatment trials. National Post, p. A7.

Sinnema, J. Postmedia News. (2010, August 7). MS patients told to be cautious of hyped cure; Alberta Health. National Post, p. A7.

Stinson, S. [Column]. (2010, August 5). MS elixir tempts, but still untested. National Post, p. A1.

Winston, I. Postmedia News. (2010, December 14). New MS treatments call for more studies: MDs; 'Unblocking veins'; Early results need to be replicated and validated. National Post, p. AL4.

\section{The Globe and Mail}

Agrell, S. (2010, April 29). Legal fears thwart doctor's bid for 'liberation' from MS pain; Canadian seeks new treatment in U.S. but hospitals banning it until more research is done. The Globe and Mail, p. A1.

Agrell, S. (2010, November 24). Father of 'liberation' treatment calls on Ottawa to step in and help MS sufferers. The Globe and Mail, p. A1.

Agrell, S. (2010, November 25). Controversial MS treatment trials getting under way in Newfoundland; 'Liberation' therapy gets 320,000 in funding. The Globe and Mail, p. A 7.

Alphonso, C. (2010, February 9). Hamilton researchers to test Italian scientist's MS theory; Idea that MS is treatable vascular disease has been controversial. The Globe and Mail, p. A4.

Alphonso, C. (2010, February 11). Second MS study finds high rate of blocked veins; Buffalo scientists call work promising. The Globe and Mail, p. A6.

Alphonso, C. (2010, April 14). MS patient has 'energy to burn' after Zamboni treatment; Two Canadian research teams set to test Italian scientist's controversial blocked blockedvein theory. The Globe and Mail, p. A 10.

Alphonso, C. (2010, August 4). Studies cast doubt on hotly debated MS treatment; 
Researchers reject blocked-vein theory, but small samples leave room for error. The Globe and Mail, p. A1

Alphonso, C.; Galloway, G. (2010, September 2). Defiant Saskatchewan refuses to bend on clinical trials for MS treatment; MS Society joins Ottawa in criticizing decision to forge ahead.

Alphonso, C. (2010, November 20). Death of MS patient fuels debate over new treatment. The Globe and Mail, p. A4.

Alphonso, C.; Agrell, S. (2010, November 27). Folio: Liberation Therapy/CCSVI. The Globe and Mail, p. A16.

Armstrong, J. (2009, December 16). UBC targets new way of looking at MS; University plans patient trials in hopes of building on potentially groundbreaking studies of Italian research Paolo Zamboni. The Globe and Mail, p. A13.

Boesveld, S. (2010, June 5). Controversial theory creating bitter MS Society elections; Worries grow supporters of Italian doctor's 'liberation' theory could overwhelm board. The Globe and Mail, p. A8.

Editorial. (2010, August 19). A trial is worth a try. The Globe and Mail, p. A14

Editorial. (2010, September 3). Don't put this idea on ice. The Globe and Mail, p. A14.

Galloway, G. (2010, September 1). Health agency dampens hopes of MS patients by rejecting clinical trials; Decision divides Ottawa and provinces. The Globe and Mail, p. Al.

Galloway, G. (2010, September 14). Nfld to pay for study on disputed MS therapy; Province joins Sask in defying Ottawa's call for caution. The Globe and Mail, p. Al.

Galloway, G. (2010, September 15). MS Therapy. The Globe and Mail, p. A3.

Galloway, G. (2010, September 20). MS patients turn outrage into organized force; Frustrated by delayed trials of "liberation therapy," groups have started Facebook pages, signed petitions and now plan protest at Parliament. The Globe and Mail, p. A6.

Howlett, K. (2010, September 13). Don McMorris; The Saskatchewan health minister speaks with Karen Howlett about the province's controversial MS treatment plan. The Globe and Mail, p. A6.

Lambert, S. [Canadian Press]. (2010, August 17). Health; Manitoba proposes national MS trial. The Globe and Mail, p. A4. 
Morrow, A. (2010, October 16). 'Liberation therapy' doctor tells MS patients to wait; Controversial surgery not recommended until more clinical trials are done, Zamboni now says. The Globe and Mail, p. A6.

Peritz, 1. (2010, May 6). MS activists demand access to 'liberation' therapy; 'This illness won't wait,' says one patient at rally in support of controversial experimental treatment. The Globe and Mail, p. A9.

Perreaux, L. (2010, November 27). The search for MS miracles in Costa Rica; Canadians, undeterred by a recent death, measure progress in wiggled toes, warm hands and a surgeon's bedside manner. The Globe and Mail, p. A14.

Perreaux, L. (2010, December 11). Medical miracle or just common sense? Les Perreaux travels to Costa Rica in search of the real reason so many MS patients who leave home to undergo the controversial Zamboni treatment say they feel markedly better afterward: 'Care in a four-star resort'. The Globe and Mail, p. F5.

Picard, A.; Favaro, A. (2009, November 21). A cure in sight: Canada has the highest incidence of multiple sclerosis in the world. Half the population knows someone with the disease. And it affects more than three women for every man. Now one doctor in Italy has made an astounding discovery, one that suggests MS can be cured or even prevented. He did it out of love for his wife. And it has given people everywhere hope; Dr. Paolo Zamboni's work shows MS to be a vascular condition, contrary to common belief. André Picard and Avis Favaro report. The Globe and Mail, p. Al.

Picard, A. (2009, November 24). Medical breakthrough: Multiple Sclerosis. MS group to fund research into 'liberation procedure'; Society calls for probe after huge response to doctor's theory of treating MS with surgery. The Globe and Mail, p. Al.

Picard, A. [Column] (2010, September 16). Note to health ministers: Stop micromanaging. The Globe and Mail, p. L1.

Picard, A. [Column] (2010, November 20). Tragic case proves medical truth: There are no free passes. The Globe and Mail, p. A4.

Picard, A. [Column] (2010, December 2). Medical tourism: It's time for some tough debate. The Globe and Mail, p. L1.

Rasminsky, M. [Letter] (2010, September 4). In the end. The Globe and Mail, p. A16.

Taber, J. [Column] (2010, September 18). When public policy hits too close to private life. The Globe and Mail, p. Al4.

Taber, J. [Column] (2010, December 18). Family illnesses spur MPs into action; Backbenchers finish the year hopeful for success in their battles to change public attitudes and policy on debilitating diseases. The Globe and Mail, p. A13. 
Taylor, P. [Column] (2010, December 31). Tough on bisphenol A, dithering on cigarette packages; Ottawa's mixed signals at times seemed to suggest a half-hearted commitment to public health. The Globe and Mail, p. L6.

The Canadian Press. (2010, August 20). In brief; Nova Scotia wants in on MS treatment. The Globe and Mail, p. A5.

The Canadian Press. (2010, August 27). Health; Premier: Sask ready to move on MS trial. The Globe and Mail, p. A5.

Weeks, C. (2010, March 29). Study may have treatment implications. The Globe and Mail, p. Ll.

Weeks, C. (2010, April 15). Doctors behind new MS theory urge more testing; Demand by patients for Zamboni treatment prompts researchers to advise caution and safety, $p$. A7.

Weeks, C. (2010, November 10). Quebec MDs warn against disputed MS therapy; More voices caution patients not to go abroad for vein-widening procedure. The Globe and Mai, p. A9.

Wente, M. [Column] (2010, July 29). The explosive politics of MS. The Globe and Mail. p, A13.

Wente, M. [Column] (2010, September 30). A different message about MS. The Globe and Mail, p. A21.

White, P. [with a report from The Canadian Press] (2010, July 28). Saskatchewan moves to forefront on Canadian efforts to introduce experimental MS treatment; Premier vows to fund clinical trials for therapy in province with highest rate of disease. The Globe and Mail, p. Al.

White, P. (2010, July 29). Wall sticks by MS plan, but other premiers skeptical;

Saskatchewan aims to have clinical trials of liberation therapy as early as next year. The Globe and Mail, p. A1.

Wingrove, J.; Alphonso, C. (2010, December 17). Alberta backs a closer look at disputed MS treatment; Province to track results of liberation therapy. The Globe and Mail, p. A9

\section{Toronto Star}

Allen, K. (2010, November 19). MS patient dies in quest for 'magic cure'; Niagara Falls man had controversial vein surgery in Costa Rica. Toronto Star, p. Al. 
Allen, K. (2010, November 22). Hype around cure for MS proves deadly. Toronto Star. p, A13.

Aulakh, R. (2010, July 11). Desperate MS patients revolt, seek help abroad; Canadians opting for 'unproven' procedure over doctors' protests. Toronto Star, p. Al.

Branswell, H. [The Canadian Press]. (2010, April 27). Internet empowering patient activism; The networking power of the Web is shifting power balance between doctors and patients. Toronto Star, p. E7.

Coyle, J. [Column] (2010, August 7). Disappointment replaces bare knuckles. Toronto Star, p. A6.

Digest. [News brief] MS Society to fund \$1M if studies show promise. Toronto Star, p. A19.

Digest. [News brief] Quebec: MS patients warned about treatment. Toronto Star, p. A18.

Editorial. (2010, September 2). Prudent steps on MS surgery. Toronto Star, p. A22.

Hall, J.; Smith, J. (2010, September 1). Living life in a sleeper hold; Multiple sclerosis patient says life has never been better since he had experimental surgery. Toronto Star, $\mathrm{p}$. A1

Smith, J. (2010, September 2). Ottawa won't fund MS trials; But Saskatchewan can if strict reviews passed. Toronto Star, p. A10.

Smith, J. (2010, September 9). Saskatchewan MS trials could still go ahead; Doctor says decision will be based on data. Toronto Star, p. A14.

Smith, J. (2010, September 14). MS on the table. Toronto Star, p. A10.

Smith, J. (2010, September 15). Health ministers pin hopes on prevention; Averting illness answer to soaring health costs, Aglukkaq says, Toronto Star, p. A8.

Smith, J. (2010, September 21). MS patients take the fight to Ottawa; Parliament Hill protesters criticize government's decision to delay studying experimental treatment. Toronto Star, p. A4.

Smith, J.; Ogilvie, M. ( 2010, September 25). MS doctors attacked for their skepticism; Neurologists stunned by backlash from patients furious with them for advising caution on new therapy. Toronto Star, p. A1.

Smith, J. (2010, October 14). MS members pick surgery over waiting; Group on Facebook denounces what it calls hypocrisy of Multiple Sclerosis Society 'big shots'. Toronto Star, p. A18. 
Smith, J. (2010, November 20). Fate of MS patients abroad brings new dilemma for doctors; MDs not obliged to repeat or redo 'experimental' operation. Toronto Star, p. A16.

Smith, J. (2010, December 19). Hoping for a multiple sclerosis miracle; After waiting a year to have experimental 'Liberation' surgery at a clinic in New York state, Tonie Turner, who has suffered from MS since 1999, finally received her treatment. Toronto Star, p. Al0.

Steward, G. [Opinion] (2010, August 3). Wall steps up for MS patients. Toronto Star, p. A19

Steward, G. [Opinion] (2010, December 21). Premier Wall vindicated on MS trials? Toronto Star, p. A25.

Takacs, M. (2010, November 21). Man regrets having MS therapy: "I felt like I was dying, really"; Fresh concerns raised over the risks of the controversial procedure and lack of follow-up. Toronto Star, p. A8.

Talaga, T. (2010, July 29). Ontario holds off on funding MS therapy; Saskatchewan paying to test treatment some hail as a breakthrough. Toronto Star, p. A8.

Talaga, T. (2010, August 6). McGuinty urges partnership for approving drugs; Proposal comes as premiers remain divided over clinical trials for controversial treatment. Toronto Star, p. A6

The Canadian Press. (2010, October 20). Saskatchewan puts up \$5M for trials of MS treatemtn; Controversial therapy unblocks neck veins. Toronto Star, p. A10.

Steward, G. [Opinion] (2010, August 3). Wall steps up for MS patients. Toronto Star, p. A19

Van Rijn, N. (2009, November 21). Researcher says surgery has cured MS patients; His belief that twisted veins trigger the disease met with skepticism. Toronto Star, p. A26.

\section{New York Times:}

Grady, Denise. "From M.S. Patients, Outcry for Surgery." The New York Times. 29 June 2010. Page 1, Science Section. 


\section{Television Transcripts:}

\section{CBC}

Crowe, K.; Mansbridge, P. (2009, December 15). Reality check on MS hypothesis. [Broadcast transcript]. CBC NEWS - The National. Retrieved from: http://www.fpinfomart.cal.

Crowe, K.; Mansbridge, P. (2010, April 12). Ginger's last hope. [Broadcast transcript]. CBC NEWS - The National. Retrieved from: http://www.fpinfomart.cal.

Crowe, K.; Mansbridge, P. (2010, April 12). Pushing for treatment. [Broadcast transcript]. CBC NEWS - The National. Retrieved from: http://www.fpinfomart.ca/.

Crowe, K.; Mesley, W. (2010, May 5). Canadian patients rally for procedure. [Broadcast transcript]. CBC NEWS - The National. Retrieved from: http://www.fpinfomart.ca/. .

Crowe, K.; Mansbridge, P. (2010, July 28). Saskatchewan premier promises mass clinical trial for MS sufferers. [Broadcast transcript]. CBC NEWS - The National. Retrieved from: http://www.fpinfomart.ca/.

Crowe, K.; Mesley, W. (2010, August 31). Experts urge rejection of MS therapy trial. [Broadcast transcript]. CBC NEWS - The National. Retrieved from:

http://www.fpinfomart.ca/.

Crowe, K.; Mansbridge, P. (2010, September 13). MS blogger sees improvement after procedure. [Broadcast transcript]. CBC NEWS - The National. Retrieved from:

http://www.fpinfomart.cal.

Crowe, K.; Mansbridge, P. (2010, October 26). MS patients claim vein therapy on taxes. [Broadcast transcript]. CBC NEWS - The National. Retrieved from:

http://www.fpinfomart.ca/.

Crowe, K.; Mansbridge, P. (2010, November 15). MS patients lacking follow-up after experimental procedure. [Broadcast transcript]. CBC NEWS - The National. Retrieved from: http://www.fpinfomart.ca/.

Crowe, K.; Swain, D. (2010, November 18). Ontario man dies after MS vein opening procedure. [Broadcast transcript]. CBC NEWS - The National. Retrieved from: http://www.fpinfomart.ca/.

Crowe, K.; Lang, A. (2010, November 19). MS vein opening risks. [Broadcast transcript]. CBC NEWS - The National. Retrieved from: http://www.fpinfomart.ca/. 
Crowe, K.; Lang, A. (2010, December 29). Top health story of 2010: the controversial MS "liberation therapy". [Broadcast transcript]. CBC NEWS - The National. Retrieved from: http://www.fpinfomart.ca/.

Duncombe, L.; Lang, A. (2010, March 18). Two Canadian brothers travel to Poland for help. [Broadcast transcript]. CBC NEWS - The National. Retrieved from:

http://www.fpinfomart.cal.

Fung, M.; Mesley, W. (2010, September 1). Health minister rejects MS therapy trial. [Broadcast transcript]. CBC NEWS - The National. Retrieved from:

http://www.fpinfomart.cal.

Labby, B.; Brunhuber, K. (2010, August 15). Canadians travel abroad for medical treatment despite risk of superbug. [Broadcast transcript]. CBC NEWS - The National. Retrieved from: http://www.fpinfomart.ca/.

MacIntrye, D.; Swain, D. (2009, November 27). Patients anxious to give treatment a try. [Broadcast transcript]. CBC NEWS - The National. Retrieved from: http://www.fpinfomart.cal.

Mansbridge, P. (2010, April 14). Zamboni visits Canada. [Broadcast transcript]. CBC NEWS - The National. Retrieved from: http://www.fpinfomart.ca/.

Swain, D. (2009, November 21). Interview with Dr. Paul O'Connor. [Broadcast transcript]. CBC NEWS - The National. Retrieved from: http://www.fpinfomart.ca/.

\section{CTV}

Battis, T.; Laflamme, L. (2010, August 4). MS-patient reaction to European study. [Broadcast transcript]. CTV NEWS. Retrieved from: http://www.fpinfomart.ca/.

Ien, M.; Dworkin, B. (2009, December 29). 2009 Top five medical breakthroughs. [Broadcast transcript]. CANADA AM. Retrieved from: http://www.fpinfomart.cal.

Favaro, A.; Thomson, B. (2009, November 20). W5 to examine possible breakthrough [Broadcast transcript]. CANADA AM. Retrieved from: http://www.fpinfomart.ca/.

Favaro, A.; Laflamme, L. [FPInfomart Transcript] (2009, November 20). MS treatment. [Broadcast transcript]. CTV NEWS. Retrieved from: http://www.fpinfomart.cal.

Favaro, A.; Robertson, L. (2009, November 21). The liberation treatment. [Broadcast transcript]. CTV NEWS - W5. Retrieved from: http://www.fpinfomart.ca/.

Favaro, A.; Rinaldo, S. (2009, November 21). MS-major medical breakthrough. [Broadcast transcript]. CTV NEWS. Retrieved from: http://www.fpinfomart.ca/. 
Favaro, A.; Robertson, L. (2009, November 23). MS breakthrough. [Broadcast transcript]. CTV NEWS. Retrieved from: http://www.fpinfomart.ca/.

Favaro, A.; Clark, T. (2010, February 8). MS-Zamboni comes to Canada. [Broadcast transcript]. CTV NEWS. Retrieved from: http://www.fpinfomart.ca/.

Favaro, A.; Clark, T. (2010, February 10). MS- promising early results. [Broadcast transcript]. CTV NEWS. Retrieved from: http://www.fpinfomart.ca/.

Favaro, A.; Rinaldo, S. (2010, April 10] The liberation war. [Broadcast transcript]. CTV NEWS - W5. Retrieved from: http://www.fpinfomart.ca/.

Favaro, A.; Clark, T. (2010, April 14). International meeting on MS. [Broadcast transcript]. CTV NEWS. Retrieved from: http://www.fpinfomart.ca/.

Favaro, A.; Robertson, L. (2010, May 5). MS-patients rally. [Broadcast transcript]. CTV NEWS. Retrieved from: http://www.fpinfomart.ca/.

Favaro, A.,; Robertson, L. (2010, June 1). MS- patients plead for funding. [Broadcast transcript]. CTV NEWS. Retrieved from: http://www.fpinfomart.ca/.

Favaro, A.; Rinaldo, S. (2010, June 5). MS- friction between patients and society. [Broadcast transcript]. CTV NEWS. Retrieved from: http://www.fpinfomart.ca/.

Favaro, A.; Laflamme, L. (2010, September 13). MS trials. [Broadcast transcript]. CTV NEWS. Retrieved from: http://www.fpinfomart.ca/.

Favaro, A.; Laflamme, L. (2010, November 19). MS treatment. [Broadcast transcript]. CTV NEWS. Retrieved from: http://www.fpinfomart.ca/.

Favaro, A.; Rinaldo, S. (2010, April 10). The liberation war. [Broadcast transcript]. CTV NEWS - W5. Retrieved from: http://www.fpinfomart.ca/.

Favaro, A.; Rinaldo, S. (2010, November 13). Liberation treatment - complications reported. [Broadcast transcript]. CTV NEWS. Retrieved from: http://www.fpinfomart.ca/.

Laflamme, L. (2010, September 1). Negative reaction to funding decision. [Broadcast transcript]. CTV NEWS. Retrieved from: http:/www.fpinfomart.ca/.

Laflamme, L. (2010, September 2). MS-Wall's response. [Broadcast transcript]. CTV NEWS. Retrieved from: http://www.fpinfomart.ca/.

Thomson, B. (2009, November 23). MS patient hopes new treatment is "answer to everything". [Broadcast transcript]. CANADA AM. Retrieved from:

http://www.fpinfomart.cal. 
Thomson, B. (2009, December 16). The Multiple Sclerosis theory. [Broadcast transcript]. CANADA AM. Retrieved from: http://www.fpinfomart.ca/.

Thomson, B. (2010, May 5). MS patients rally nationwide for liberation treatment. [Broadcast transcript]. CANADA AM. Retrieved from: http://www.fpinfomart.ca/.

Thomson, B. (2010, September 1). Federal agency won't fund promising MS treatment. Interview with Dr. Sandy McDonald. [Broadcast transcript]. CANADA AM. Retrieved from: http://www.fpinfomart.ca/.

Thomson, B. (2010, November 19). Canadian man dies following Costa Rican MS treatment. Interview with Dr. Sandy McDonald. [Broadcast transcript]. CANADA AM. Retrieved from: http://www.fpinfomart.ca/.

O'Regan, S. (2010, April 15). MS patients debate merits of angioplasty treatment interview with Rebecca Cooney. [Broadcast transcript]. CANADA AM. Retrieved from: http://www.fpinfomart.ca/.

O'Regan, S. (2010, August 4). MS treatment- interview with Dr. Lindsay Machan of UBC. [Broadcast transcript]. CANADA AM. Retrieved from: http://www.fpinfomart.ca/.

O'Regan, S. (2010, February 8). Scientists meet to discuss Italian's MS treatment theory - interview with Dr. Paolo Zamboni. [Broadcast transcript]. CANADA AM. Retrieved from: http://www.fpinfomart.ca/.

O'Regan, S. (2010, February 11). Second MS study shows high rate of blocked veins. [Broadcast transcript]. CANADA AM. Retrieved from: http://www.fpinfomart.ca).

O'Regan, S. (2010, September 14). Newfoundland and Labrador to research liberation therapy. Interview with Dr. Paul Hebert. [Broadcast transcript]. CANADA AM. Retrieved from: http://www.fpinfomart.ca/.

Rinaldo, S. (2010, September 12). Health ministers to discuss issue. [Broadcast transcript]. CTV NEWS. Retrieved from: http://www.fpinfomart.ca/.

\section{Global}

Gill, R. (2010, September 13). MS treatment. [Broadcast transcript]. GLOBAL NEWS. Retrieved from: http://www.fpinfomart.ca/.

Goomansingh, C.; Sorensen, E. (2010, July 28). The liberation treatment. [Broadcast transcript]. GLOBAL NEWS. Retrieved from: http://www.fpinfomart.cal. 
Goomansingh, C.; Steinke, G. (2010, August 31). The liberation treatment. [Broadcast transcript]. GLOBAL NEWS. Retrieved from: http://www.fpinfomart.ca/.

Goomansingh, C; Jarvis, C. (2010, November 19). Controversial treatment. [Broadcast transcript]. GLOBAL NEWS. Retrieved from: http://www.fpinfomart.cal.

Goomansingh, C.; Jarvis, C. (2010, December 31). Top ten health stories. [Broadcast transcript]. GLOBAL NEWS. Retrieved from: http://www.fpinfomart.cal.

Lord, R.; Gill, R. (2010, May 5). Surgical roadblock. [Broadcast transcript]. GLOBAL NEWS. Retrieved from: http://www.fpinfomart.ca/.

McNabb, L.; Friesen, D. (2010, September 20). The liberation treatment. [Broadcast transcript]. GLOBAL NEWS. Retrieved from: http://www.fpinfomart.ca/.

Steinke, G. (2010, September 1). Liberation therapy. [Broadcast transcript]. GLOBAL NEWS. Retrieved from: http://www.fpinfomart.ca/. 